VELÁSQUEZ, Javier. "El origen del paradigma de riesgo".

Polít. crim. Vol. 9, № 17 (Julio 2014), Art. 3, pp. 58-117.

[http://www.politicacriminal.cl/Vol_09/n_17/Vol9N17A3.pdf]

\title{
El Origen del Paradigma de Riesgo
}

\author{
Javier E. Velásquez Valenzuela \\ Licenciado en Ciencias Jurídicas y Sociales, Pontificia Universidad Católica de Chile \\ Magíster en Derecho Penal, Universidad de Talca y Universidad Pompeu Fabra. \\ Ayudante del Depto. de Derecho Penal de la Universidad Alberto Hurtado \\ jevelasq@uc.cl
}

\section{Resumen}

La reciente modificación a la ley 18.216 finaliza un proceso silencioso de introducción de tecnologías actuariales de predicción del riesgo de reincidencia de los infractores de ley. Estas tecnologías se encuentran estrechamente vinculadas a los cambios que han experimentado los sistemas penales anglosajones en los últimos 30 años. El presente trabajo pretende explicar los orígenes de estas tecnologías, su contenido y cuales son los principales problemas y desafíos que plantea su introducción al interior de los sistemas penales. En este trabajo se van a contrastar dos tipos de discursos explicativos del paradigma de riesgo que, siendo epistemológicamente diferentes, nos permiten tener un panorama más completo del escenario que se analiza.

Palabras Clave: Riesgo, peligrosidad, reincidencia.

\begin{abstract}
The recent amendment to Law 18.216 completes a silent process of insertion of actuarial technologies of risk prediction of recidivism among offenders. These technologies are closely linked to changes that Anglo-Saxon penal systems have experienced in the past 30 years. This paper aims to explain the origins of these technologies, their content and what are the main problems and challenges that their introduction poses to the penal system. This paper will contrast two types of explanatory speeches of risk paradigm that, while epistemologically different, allow us to have a more complete picture of the analyzed scenario.
\end{abstract}

Key words: Risk, dangerousness, recidivism.

\section{Introducción.}

Durante la década de 1980 el sistema penal anglosajón pudo atestiguar la aparición de una nueva tecnología en materia de predicción y tratamiento de infractores de ley: El Paradigma de Riesgo. Poco a poco las legislaciones de países como Canadá o Inglaterra la fueron integrando a sus sistemas penales, transformando radicalmente tanto el manejo como la gestión de los infractores de ley. Sin embargo, quienes han liderado esta pequeña "revolución" no han sido juristas ni sociólogos, sino profesionales vinculados con la reinserción de los condenados: psicólogos, psiquiatras y trabajadores sociales. Por otro 
VELÁSQUEZ, Javier. "El origen del paradigma de riesgo".

lado, el "éxito" de esta tecnología ha llegado a tal punto que ha comenzado a influenciar el manejo y tratamiento de infractores de ley fuera de las jurisdicciones anglosajonas.

En efecto, la reciente reforma a la ley 18.216 -efectuada por la ley 20.603-, que ha eliminado las viejas "medidas alternativas" reemplazándolas por un nuevo sistema de "penas sustitutivas", ha generado un nuevo paradigma dentro de nuestro sistema penitenciario. Este cambio ha repercutido especialmente en lo que respecta a la evaluación de aquellos sujetos (infractores de ley) para efecto de ver si son aptos para cumplir su pena en el medio libre. En concreto, el artículo 33 de la nueva ley se pronuncia explícitamente sobre la evaluación de los "factores de riesgo de reincidencia". Esta reforma viene a culminar un proceso silencioso que ha permitido al Ministerio de Justicia introducir instrumentos actuariales para evaluar el riesgo de reincidencia de los infractores de ley en el sistema penal chileno. ${ }^{1}$

Desde hace un par de años tanto el Ministerio de Justicia como el Ministerio de Interior han desarrollado proyectos relacionados con la introducción de instrumentos de predicción de riesgo de reincidencia en materia penitenciaria. ${ }^{2}$ El nuevo escenario viene a consolidar la incorporación paulatina de estos instrumentos, iniciando una nueva etapa en la que se deberá evaluar los resultados de su aplicación, pero que también tendrá que hacerse cargo de la forma en que esta tecnología será incorporada a nuestro sistema procesal penal.

El presente trabajo tiene como objeto clarificar el origen y la función que el paradigma de riesgo tiene en los sistemas penales anglosajones $\mathrm{y}$, muy especialmente, tratar de esclarecer la relación de éste con la idea de "delincuentes imputables peligrosos".

Como se podrá apreciar más adelante, definir lo que debe entenderse por "paradigma de riesgo" no es un tema sencillo, debido a que el fenómeno de la predicción de riesgo ha sido abordado por diferentes disciplinas y de diferentes formas. ${ }^{3}$ En otras palabras existe una suerte de Torre de Babel cognoscitiva, un laberinto de aproximaciones que hace que se utilicen las mismas palabras para discutir fenómenos disímiles, generando por tanto un entramado complejo y que puede fácilmente confundir. ${ }^{4}$

Este trabajo, por tanto, se va a dividir en 3 partes: En un primer momento vamos a tratar de explicar ¿Qué significa esto de "paradigma de riesgo" en materia penal? Este análisis

\footnotetext{
${ }^{1}$ Sin ir más lejos se puede citar SAAVEDRA, Oscar, "Justicia implanta nuevo modelo para pronosticar la reincidencia de presos" en: El Mercurio, Año CXIV, n 40.927, Santiago: jueves 8 de agosto de 2013.

${ }^{2}$ La información fue obtenida a través de consultas realizadas amparado en la Ley de Transparencia, ley 20.285. En el caso del Ministerio de Interior la respuesta fue obtenida mediante el Oficio $\mathrm{N}^{\circ} 78$ de fecha 06 de Enero del 2012. Asimismo el Ministerio de Justicia dio respuesta a la consulta formulada, mediante correo electrónico el día 16 de Enero del mismo año.

${ }^{3}$ GARLAND, David, "The Rise of Risk", en: ERICSON, Richard V. y DOYLE, Aaron, Risk and Morality, Toronto: University of Toronto Press, 2003, pp. 48-50.

${ }^{4}$ En este sentido ver LUPTON, Deborah, Risk, $2^{\mathrm{a}}$ Ed., Londres: Routledge, 2013, passim; También O'MALLEY, Pat, Crime and Risk, Londres: Sage, 2010, pp. 11 y ss.; McSHERRY, Bernadette, Managing Fear: The Law and ethics of preventive detention and risk assessment, Nueva York: Routledge, 2013, pp. 12 y ss.; KEMSHALL, Hazel, Understanding risk in criminal justice, Maidenhead: Open University Press, 2003, pp. 48 y ss. GARLAND, “The Rise", cit. nota n 3 , p. 48.
} 
Polít. crim. Vol. 9, No 17 (Julio 2014), Art. 3, pp. 58-117.

[http://www.politicacriminal.cl/Vol_09/n_17/Vol9N17A3.pdf]

introductorio nos permitirá conocer que existen diferentes aproximaciones al fenómeno del riesgo que es necesario tener en cuenta para no confundir los alcances y sentidos del debate. Hecho esto, nos vamos a abocar a explicar dos de estas posturas, por un lado abordaremos la historia y el desarrollo de la tecnología predictiva de riesgo de reincidencia desde la perspectiva de la psicología, puesto que ha sido esta disciplina la que ha creado los instrumentos de riesgo. Nos basaremos fundamentalmente en la obra de Francis Cullen, quien pese a ser sociólogo, ha sido uno de los principales autores que se ha dedicado a explicar y difundir los éxitos de éste paradigma. La tercera parte de este trabajo, consiste en el desarrollo de una línea de discurso crítico proveniente de la sociología y derivada del trabajo de Michel Foucault. Este contraste nos permitirá arrojar nuevas luces sobre el real contexto en el que surgen los instrumentos de riesgo al interior del sistema penal.

\section{1. ¿Qué significa hablar de "paradigma de riesgo" en materia penal?}

El riesgo se ha convertido en un lugar común no sólo en nuestras vidas diarias, sino también en la forma en que las empresas, e incluso los Estados, rigen sus decisiones. ${ }^{5}$ Por lo pronto, uno puede encontrar predicciones de riesgo de accidentes vasculares, de desastres ecológicos, de accidentes vehiculares, etc. El combatir la incertidumbre se ha vuelto un ejercicio habitual en nuestra existencia, por lo que las tecnologías predictivas parecen darse por sentado, como si siempre hubieren existido. No es de extrañar, por tanto, que autores como Ulrich Beck y Anthony Giddens, ${ }^{6}$ hablen de que vivimos en una "sociedad de riesgo".

Sin embargo, esta misma facilidad a la que nos hemos referido tiene como consecuencia que, al intentar estudiar el fenómeno del riesgo, nos encontremos con una inmensa cantidad de conocimiento proveniente de variadas disciplinas, que no siempre son coherentes ni congruentes entre sí, ni en sus estudios ni en las explicaciones del fenómeno. Se trata de un mismo concepto que, abordado desde saberes y técnicas radicalmente diferentes, tiene diversos significados.

Dicho lo anterior, lo primero que debemos preguntarnos es: ¿Qué es el riesgo? Siguiendo a David Garland, podemos señalar que el riesgo “... es una medida de exposición al peligro, de la probabilidad y la extensión de un daño..." o, en palabras más sencillas, "los riesgos son estimaciones de la posibilidad de impacto de los peligros". ${ }^{\prime}$ Se trata de una forma que tienen los individuos para hacer frente a las incertidumbres y las posibilidades que estas contienen. No se trata de una predicción del futuro, sino más bien de la toma de decisiones contingentes basadas en la probabilidad de ocurrencia de determinados sucesos,

\footnotetext{
${ }^{5}$ GARLAND, "The Rise", cit. nota n' 3, p. 48.

${ }^{6}$ BECK, Ulrich, La Sociedad del Riesgo: Hacia una nueva modernidad, trad. NAVARRO, Jorge, JIMENEZ, Daniel y BORRAS, María Rosa, Buenos Aires: Editorial Paidos, 1986/1998, passim y GIDDENS, Anthony, Consecuencias de la modernidad, trad. LIZÓN, Ana, Madrid: Alianza Editorial,1990/1993, pp.119 y ss.; Ver también GIDDENS, Anthony, "La sociedad del riesgo: El contexto de la política británica", trad. ORENSANZ, Lucrecia, Estudios Demográficos y Urbanos, vol. 13, no 3 (1998), pp. 517-528. Ver LUPTON, Risk, cit. nota no 4, pp.77 y ss., así como también GARLAND, “The Rise”, cit. nota no 3, pp. 74 y ss.

${ }^{7}$ GARLAND, "The Rise", cit. nota $\mathrm{n}^{\circ} 3$, passim.

${ }^{8}$ GARLAND, "The Rise", cit. nota n' 3, p. 50.
} 
VELÁSQUEZ, Javier. "El origen del paradigma de riesgo".

normalmente negativos. ${ }^{9}$ Precisamente por ello uno puede hablar de que los riesgos son siempre reactivos, continuamente calculados y, en consecuencia, compensados. ${ }^{10}$

Esta definición nos lleva entonces al objeto del presente artículo. El riesgo siempre es "riesgo de algo", y en este trabajo, al hablar de riesgo, tenemos que buscar qué es lo específico del paradigma de riesgo en el campo penal, ¿Qué es lo que se predice?, ¿Cómo se predice? y ¿Cuáles son los motivos de la predicción?

De manera provisoria podemos señalar que cuando se habla de paradigma de riesgo, ${ }^{11}$ al interior de las instituciones que alojan al sistema penal, se hace refiriéndose a la introducción de una tecnología actuarial que la psicología (y en algunos casos la psiquiatría) ha desarrollado en las ultimas tres décadas. El corazón de esta tecnología se encuentra en la evaluación del nivel de riesgo de reincidencia de sujetos imputables. En efecto, a través de la evaluación que los psiquiatras hacen del individuo, se obtiene una serie de datos que permiten clasificar la probabilidad que éste sujeto tiene de reincidir. De este modo la medición permite adecuar el tipo de sanción, su duración y las estrategias de intervención a las necesidades específicas del condenado. De esta manera el sujeto no sólo cumple una sanción, sino que se pretende que el mecanismo punitivo además cumpla la función de intervenir los factores de riesgo del sujeto, de manera que cuando cumpla su condena, al momento de quedar en libertad, ya no represente un riesgo para la sociedad. Es por esto el paradigma de riesgo se suele dividir en dos etapas: Un primer momento destinado a la evaluación del riesgo (Assessment) y una segunda etapa orientada a la gestión (Management) del riesgo.

Sin embargo, como ya hemos planteado, no existe una sola gran forma de estudiar y analizar el fenómeno del riesgo. En este sentido la explicación precedente es la principal, pero no la única forma de comprender el paradigma de riesgo al interior del sistema penal. De este modo, de manera de establecer bien los contornos de nuestro estudio, por motivos metodológicos vamos a seguir la clasificación propuesta por la socióloga Deborah Lupton en su libro Risk. La autora destaca, de forma pedagógica, dos grandes grupos de aproximaciones: ${ }^{12}$

(1) Aquellos cuya postura epistemológica frente al riesgo es realista, vale decir, entienden que el riesgo es un fenómeno que existe en la realidad y que puede ser cuantificado con independencia de los procesos culturales, tal y como ocurre con los estudios técnicocientíficos. Lupton da como ejemplo a los estudios relacionados de la psicología cognitiva. ${ }^{13}$

(2) Aquellos trabajos que han estudiado los aspectos sociales y culturales del riesgo. En otras palabras, lo relevante no es la "realidad" del riesgo sino su valoración y comprensión por la sociedad. Por lo mismo, estas aproximaciones estudian cómo la

\footnotetext{
${ }^{9}$ GARLAND, "The Rise", cit. nota $\mathrm{n}^{\circ}$ 3, p. 52.

${ }^{10}$ GARLAND, "The Rise", cit. nota n ${ }^{\mathrm{o}} 3$, pp. 53-56.

${ }^{11}$ WARD, Tony y MARUNA, Shadd, Rehabilitation, London: Routledge, 2007, pp. 20 y ss.

${ }^{12}$ LUPTON, Risk, cit. nota $\mathrm{n}^{\circ} 4$, pp. 26 y ss.

${ }^{13}$ LUPTON, Risk, cit. nota no 4 , pp. 26 -35 y pp. 49-50.
} 
Polít. crim. Vol. 9, No 17 (Julio 2014), Art. 3, pp. 58-117.

[http://www.politicacriminal.cl/Vol_09/n_17/Vol9N17A3.pdf]

sociedad reacciona ante estas nuevas formas de conocimiento. Así se ha llegado a hablar de que el riesgo no es una realidad dada, sino un constructo social. ${ }^{14}$ Esta posición ha sido adoptada por la sociología y la antropología. ${ }^{15}$

De esta forma, y como ya habíamos adelantado, en la primera parte de nuestro trabajo nos vamos a centrar en lo que Hazel Kemshall denomina "Riesgo-Artefacto", 16 vale decir, el surgimiento de tecnologías de predicción de riesgo de reincidencia provenientes de la psicología y la psiquiatría. La narración de sus orígenes nos ha llegado principalmente a través de los trabajos del sociólogo norteamericano Francis Cullen, quien será nuestro principal referente a la hora de ir delineando el discurso histórico que explica el surgimiento de los instrumentos de riesgo. En efecto, pese a que Cullen no es psicólogo su relación con el movimiento de psicólogos canadienses detrás del origen del paradigma de riesgo y su constante lucha por reposicionar la rehabilitación como una política criminal valida, lo ha convertido en uno de los principales proponentes de esta perspectiva fuera de la psicología.

Como veremos más adelante, este primer discurso explicativo del paradigma de riesgo, adopta una postura realista frente al riesgo. En concreto, el relato narra la los orígenes y la evolución de una investigación científica y como los investigadores han luchado por posicionar el resultado de sus descubrimientos ante un status quo político criminal poco favorable: El debate de lo técnico/científico contra lo político/irracional. Sin embargo, como quedará pronto en evidencia, el relato técnico se queda corto en darnos luces sobre el verdadero impacto del paradigma de riesgo en materia penal, esto quedará en evidencia al contrastar el relato con una explicación proveniente del segundo grupo señalado por Lupton.

En efecto, en la segunda parte del trabajo, nos haremos cargo de una de las tres aproximaciones socio-culturales del riesgo que menciona Lupton. Esta autora agrupa a las distintas posturas constructivistas sobre el riesgo en tres constelaciones de autores: la línea iniciada por Ulrich Beck y su concepto de la "sociedad de riesgo" (a la que también incorpora a Anthony Giddens), el trabajo desarrollado por la antropóloga Mary Douglas y su teoría cultural del riesgo, y finalmente se encuentra una tercera corriente de autores que, en base a las ideas Michel Foucault sobre gubernamentalidad, han desarrollado un análisis sobre el uso de los instrumentos de riesgo como formas de estrategias control. ${ }^{17}$

\footnotetext{
${ }^{14}$ Lupton utiliza como ejemplo de esta postura a François Ewald, específicamente por su artículo "Seguros y Riesgo" en el cual sostuvo que "Nada es un riesgo en sí mismo; no existen los riesgos en la realidad. Pero, por otro lado, cualquier cosa puede ser un riesgo todo depende de cómo uno analice el peligro y considere el evento" ver EWALD, François, "Insurance and Risk", en: BURCHELL, Graham, GORDON, Colin y MILLER, Peter (Eds.), The Foucault Effect: Studies in Governamentality, Chicago: The University of Chicago Press, 1991, pp. 197-210, p. 199. Esta postura, por lo demás, parecer ser compartida por Garland, ver GARLAND, "The Rise", cit. nota $\mathrm{n}^{\circ}$ 3, p. 53.

${ }^{15}$ LUPTON, Risk, cit. nota $\mathrm{n}^{\mathrm{o}} 4$, pp. 36 y ss.

${ }^{16}$ Kemshall adopta la clasificación de Lupton para su trabajo. Ver KEMSHALL, Understanding risk, cit. nota $\mathrm{n}^{\circ} 4$, p. 49.

${ }^{17}$ LUPTON, Risk, cit. nota $\mathrm{n}^{\mathrm{o}} 4$, pp. 36 y ss.
} 
VELÁSQUEZ, Javier. "El origen del paradigma de riesgo".

Cabe preguntarse, como ya dijimos, cuáles de estas aproximaciones resultan útiles para comprender el fenómeno del paradigma de riesgo en el sistema penal. Uno tendería a pensar que el trabajo de Beck y el desarrollo de su teoría de la "sociedad de riesgo", ${ }^{18}$ es uno de los elementos centrales en esta discusión, pero aquello no es efectivo. La verdad de las cosas es que el trabajo de Beck se encuentra ligado a los efectos y consecuencias sociales de los riesgos creados por las sociedades post-industriales, tal como ocurre con la creación y manejo de los desechos tóxicos o el calentamiento global, ${ }^{19}$ pero, no obstante la popularidad de esta teoría, ${ }^{20}$ lo cierto es que ni Beck ni Giddens han analizado las particularidades del paradigma de riesgo al interior del sistema penal. ${ }^{21}$ Lo anterior no quiere decir que la teoría no pueda ser utilizada como un marco teórico para estudiar el fenómeno del riesgo en nuestro campo (de hecho Richard Ericson y Kevin Haggerty lo hicieron $^{22}$ ). Sin embargo, como sostiene críticamente Pat O'Malley:

"Aun cuando (la teoría de la sociedad de riesgo) esté en lo correcto ¿Nos ofrece formas útiles para pensar el delito y el control del mismo en el siglo XXI? ¿O es una explicación demasiado abstracta, demasiado vaga y general para lo que está ocurriendo en esta área?"23

Algo similar ocurre con el trabajo de la antropóloga Mary Douglas, ${ }^{24}$ ya que su aproximación, si bien diferente a la de Beck, guarda ciertas similitudes en cuanto a los aspectos socio-culturales en los que centra su estudio del riesgo. En efecto, en su libro Risk and Culture, escrito en conjunto con Aaron Wildavsky, su reflexión sobre el impacto de los riesgos y la selección de los mismos se basa en gran medida en los peligros para el medioambiente generados por la post-industrialización. ${ }^{25}$ Por tanto, al igual que con la teoría de Beck, la crítica de O’Malley es también aplicable al trabajo de Douglas, en cuanto a que ambos grupos de estudios demasiado generales y que, si bien pueden ser utilizados como marcos para estudiar aspectos y problemas en nuestro campo, no fueron desarrollados considerando las particularidades del mismo. ${ }^{26}$ No obstante, existe un aspecto particular del

${ }^{18}$ BECK, La Sociedad del Riesgo, cit. nota $\mathrm{n}^{\circ}$ 6, passim. También ver LUPTON, Risk, cit. nota ${ }^{\circ} 4$, pp. 77 y ss., así como también GARLAND, "The Rise", cit. nota n 3, pp. 74 y ss., o McSHERRY, Managing Fear, cit. nota $\mathrm{n}^{\mathrm{o}} 4$, pp. 17 y ss.

${ }^{19}$ En este mismo sentido O'MALLEY, Crime and Risk, cit. nota n ${ }^{\circ}$ 4, pp. 11-12.

${ }^{20}$ Entre otros GARLAND, “The Rise”, cit. nota n 3 , pp. 74 y ss., O’MALLEY, Crime, cit. nota no 4, pp. 1112, McSHERRY, Managing Fear, cit. nota ${ }^{\circ}$ 4, p.18, KEMSHALL, Understanding risk, cit. nota $\mathrm{n}^{\circ}$ 4, pp. 8 y ss.

${ }^{21}$ También lo hace presente McSHERRY, Managing Fear, cit. nota ${ }^{\circ}$ 4, p. 18.

${ }^{22}$ ERICSON, Richard y HAGGERTY, Kevin, Policing the risk society, Toronto: University of Toronto Press, 1998, passim, especialmente pp. 83 y ss.

${ }^{23}$ O'MALLEY, Crime and Risk, cit. nota n ${ }^{\circ}$ 4, p. 12.

${ }^{24}$ Ver DOUGLAS, Mary, Risk and Blame: Essays in cultural theory, Londres: Routledge, 1992, pp. 6 y ss. También DOUGLAS, Mary, Risk acceptability according to the social sciences, Nueva York: Russel Sage Foundation, 1985, pp. 2 y ss. Una explicación de la teoría de Douglas puede verse en LUPTON, Risk, cit. nota 4, pp. 68 y ss. Otro tanto en HACKING, Ian, "Risk and Dirt", en: ERICSON, Richard V. y DOYLE, Aaron, Risk and Morality, Toronto: University of Toronto Press, 2003, pp. 22-47.

${ }^{25}$ DOUGLAS, Mary y WILDAVSKY, Aaron, Risk and Culture: An essay on the selection of technological and environmental dangers, Londres: University of California Press, 1982, passim

${ }^{26}$ En este sentido, resulta pertinente agregar que Douglas, junto a Michel Lianos, abordó el problema del riesgo en el sistema penal, por lo menos en un artículo, aun cuando el resto de su trabajo es muchísimo más amplio. Ver LIANOS, Michalis, y DOUGLAS, Mary, "Dangerization and the end of deviance: the institutional environment", en: GARLAND, David y SPARKS, Richard (eds.) Criminology and social theory, 
Polít. crim. Vol. 9, № 17 (Julio 2014), Art. 3, pp. 58-117. [http://www.politicacriminal.cl/Vol_09/n_17/Vol9N17A3.pdf]

trabajo de Douglas que coincide y complementa parte de la lectura que asumiremos en este trabajo, por lo que nos referiremos a ella en su momento.

Esto nos lleva al tercer grupo mencionado por Lupton: autores que han desarrollado las ideas de gubernamentalidad de Michel Foucault, ${ }^{27}$ así como los comentarios que sobre este tema han hecho colegas y discípulos de Foucault como Jacques Donzelot, ${ }^{28}$ Robert Castel $^{29}$ y François Ewald. ${ }^{30}$ A diferencia de lo que ocurre con las otras teorías, el trabajo de autores como Malcom Feeley y Jonathan Simon, ${ }^{31}$ John Pratt, ${ }^{32}$ o Pat O'Malley, ${ }^{33}$ ha abordado

Londres: Oxford University Press, 2000, pp. 103-126. Por otro lado, como ocurre con el trabajo de Beck, también autores como Richard Sparks se han basado en este cuerpo de trabajo para comentar ciertos aspectos del paradigma de riesgo. Ver SPARKS, Richard, "Degrees of estrangement: The cultural theory of risk and comparative penology", Theoretical Criminology, vol. 5 n 2 (2001), pp. 159-176.

${ }^{27}$ Sobre la "Gubernamentalidad" ver especialmente FOUCAULT, Michel, Seguridad, Territorio, Población: Curso en el Collège de France (1977-1978), Trad. PONS, Horacio, Buenos Aires: Fondo de Cultura Económica, 2004/2006, passim; FOUCAULT, Michel, Nacimiento de la Biopolítica: Curso en el Collège de France (1978-1979), trad. PONS, Horacio, Buenos Aires: Fondo de Cultura Económica, 2004/2007, passim. También FOUCAULT, Michel, "Omnes et Singulatim: Towards a Criticism of "Political Reason" en Biblioteca digital de "Tanner Lectures" de la Universidad de Utah: http://tannerlectures.utah.edu/documents/a-to-z/f/foucault81.pdf [Visitado el 12.10.2013] Si bien existe una versión de este texto traducida al francés y publicada en FOUCAULT, Michel, "Omnes et Singulatim: vers une critique de la raison politique", trad.: DAUZAT, Pierre-Emmanuel, en: FOUCAULT, Michel, Dits et écrits II. 1976-1988, Paris: Quarto Gallimard, 1994/2001, pp. 953-980, para este trabajo se utilizó la versión en inglés que, entendemos, es la original. Adicionalmente puede resultar esclarecedor las primeras clases que realizó Foucault el año 1973. Ver FOUCAULT, Michel, El poder psiquiátrico: Curso en el Collège de France (1973-1974), Trad. PONS, Horacio, Buenos Aires: Fondo de Cultura Económica, 2003/2005, ver pp. 57 y ss.

28 DONZELOT, Jacques, "Misère de la culture politique", Critique, vol. 34 (1978), pp. 572- 586; DONZELOT, Jacques, "Pleasure in work", en: BURCHELL, Graham, GORDON, Colin y MILLER, Peter (Eds.), The Foucault Effect: Studies in Governamentality, Chicago: The University of Chicago Press, 1991, pp. 251-280.

${ }^{29}$ CASTEL, Robert, "De la dangerosité au risque", Actes de la recherche en sciences sociales, vol. 47-48 (1983), pp. 119-127, trabajo que fue posteriormente ampliado y traducido al inglés. Ver CASTEL, Robert, "From dangerousness to risk", en: BURCHELL, Graham, GORDON, Colin y MILLER, Peter (Eds.), The Foucault Effect: Studies in Governamentality, Chicago: The University of Chicago Press, 1991, pp. 281-298.

${ }^{30}$ EWALD, François, "Responsabilité et dangerosité: Extrait de l' ouvrage de F. Ewald, L' Etat Providence, Paris, Grasset, 1986, p. 409-416”, en: TULKENS, Françoise, Généalogie de la défense sociale en Belgique (1880-1914): Travaux du séminaire qui s' est tenu à L' Université Catholique de Louvain sous la direction de Michel Foucault, Bruselas: Editions Story-Scientia, 1988; EWALD, "Insurance" cit. nota $\mathrm{n}^{\mathrm{o}} 14$, passim; EWALD, François, "The Return of Descartes's Malicious Demon: An Outline of a Philosophy of Precaution", Trad. UTZ, Stephen, en: BAKER, Tom y SIMON, Jonathan (Eds.), Embracing Risk: The changing culture of insurance and responsibility, Chicago: The University of Chicago Press, 2002, pp. 273301.

${ }^{31}$ SIMON, Jonathan, "The Ideological Effects of Actuarial Practices", Law \& Society Review, Vol. 22, No 4 (1988), pp. 771-800; FEELEY, Malcom y SIMON, Jonathan, "The New Penology: Notes on the emerging strategy of corrections and it's implications", Criminology, vol. 4 (1992) pp. 449-479, FEELEY, Malcom y SIMON, Jonathan, "Actuarial Justice: the emerging new criminal law", en: NELKEN, David (ed.), The Futures of Criminology, Londres: Sage, 1994, pp. 173-201; SIMON, Jonathan, "Managing the Monstrous: Sex offenders and the new penology", Psychology, Public Policy, and Law, vol. 4, No. 1/2 (1998), pp. 452467; SIMON, Jonathan y FEELEY, Malcom, "The form and limits of the new penology", en: BLOOMBERG, Thomas y COHEN, Stanley, Punishment and social control: Enlarged second edition, New Jersey: Transaction Publishers, 2003, pp. 75-116; FEELEY, Malcom, "Origins of Actuarial Justice", en: ARMSTRONG, Sarah y MCARA, Lesley (eds.), Perspectives on punishment: The contours of control, Nueva York: The Oxford University Press, 2006, pp. 217-232; SIMON, Jonathan, "Punishment and the Political 
VELÁSQUEZ, Javier. "El origen del paradigma de riesgo".

específicamente la introducción del paradigma de riesgo en los sistemas penales anglosajones de la modernidad tardía. Por este motivo, en el presente trabajo nos centraremos en esta línea teórica. Más que desarrollar las posturas de cada uno de los autores nos vamos a enfocar en plantear los principales elementos que permiten comprender y complementar el surgimiento del paradigma de riesgo en los sistemas penales. Ahora bien la nota distintiva se encuentra en que esta aproximación nos da mayores luces sobre la forma de operar de estos sistemas penales antes y después de la aparición de los instrumentos de riesgo, por lo que, desde esta vereda arroja luces sobre como se explica o se inserta esta nueva tecnología en su interior.

Finalmente cabe aclarar que más que una particular toma de posición por uno de los tres marcos teóricos ya mencionados, reconocemos que la aproximación foucualtiana es simplemente una de las posibles formas de acercarse al estudio del fenómeno del riesgo al interior del sistema penal. Hemos optado por ella por cuanto su estudio genealógico del riesgo, y la vinculación que hacen con el concepto de peligrosidad, nos permiten establecer un contrapunto con la narración realista-técnica del riesgo que Cullen ofrece. En otras palabras, como ambos relatos se centran en describir los mismos sucesos desde posturas epistemológicas diferentes, se produce una suerte de complementación entre ambas, ampliándose el panorama y complejidad del problema del paradigma de riesgo en los sistemas penales anglosajones actuales. ${ }^{34}$

\section{El riesgo-artefacto: La aproximación "realista" al riesgo.}

Como ya habíamos mencionado, Lupton clasifica un grupo de aproximaciones como epistemológicamente realistas; de hecho ella habla de un "realismo ingenuo" (nä̈ve realism). Lo central es que parten de la base de que los riesgos existen, por lo que no existe realmente un cuestionamiento sobre ello, al contrario, para estas posturas el problema recae en la identificación de las que conductas o factores inciden en la producción del resultado que se desea evitar. Así Lupton nos dice que para esta aproximación el riesgo es un peligro

Technologies of the Body", en: SIMON, Jonathan y SPARKS, Richard, The Sage Handbook of Punishment and Society, Londres: Sage, 2013, pp. 60-89.

${ }^{32}$ PRATT, John, Governing the Dangerous: dangerousness, law and social change, Sidney: The Federation Press, 1997. También PRATT, John, "Dangerousness, Risk and Technologies of Power", Australian \& New Zealand Journal of Criminology, vol. $28 \mathrm{n}^{\circ} 3$ (1995), pp. 3- 31, PRATT, John, "Governing the Dangerous: An Historical Overview of Dangerous Offender Legislation", Social \& Legal Studies, vol. 5 (1996) pp. 21-36, PRATT, John, "Criminology and History: Understanding the Present", Current Issues in Criminal Justice, vol. 60 (1996-1997), pp. 60 - 76, PRATT, John y DICKSON, Marny, "Dangerous, inadequate, invisible, out: Episodes in the criminological career of habitual criminals", Theoretical Criminology, vol. 1 (1997) pp. 363384 y PRATT, John, "Dangerousness and modern society", en: BROWN, Mark y PRATT, John (eds.), Dangerous Offenders: Punishment and Social Order, Londres: Routledge, (2000), pp. 35-48.

${ }^{33}$ O'MALLEY, Pat, Riesgo, Neoliberalismo y Justicia Penal, trad. MONTERO, Augusto, Buenos Aires: Editorial Ad-hoc, 2006 y O’MALLEY, Crime, cit. nota n ${ }^{\circ}$, passim.

${ }_{34}$ Así, sobre la posibilidad de integración de las diferentes líneas teóricas basadas en el riesgo ver McSHERRY, Managing, cit nota $\mathrm{n}^{\mathrm{o}} 4$, p. 19. Otro tanto puede verse en la propuesta de integración de las teorías de Beck con la de Foucault que plantea Aaron Doyle. Ver DOYLE, Aaron, "Trust, Citizenship and Exclusion in the Risk Society", en: LAW COMMISSION OF CANADA, Risk and Trust: Including or Excluding Citizens?, Halifax: Fernwood Publishing, 2007, pp. 7-22. A su vez O'Malley plantea la complementariedad de su análisis, basado en la gubernamentalidad, con la teoría cultural de Douglas. Ver O’MALLEY, Crime and Risk, cit. nota n ${ }^{\circ}$ 4, pp. 17-18. 
Polít. crim. Vol. 9, № 17 (Julio 2014), Art. 3, pp. 58-117.

[http://www.politicacriminal.cl/Vol_09/n_17/Vol9N17A3.pdf]

o una amenaza objetiva "que existe y puede ser medida independientemente de los procesos socio-culturales." 35

Tal y como plantea Kemshall, esta aproximación en el sistema penal se ha traducido en tratar de construir instrumentos que puedan predecir el riesgo de reincidencia de los infractores de ley. ${ }^{36}$ Desde un punto de vista histórico, por lo menos dentro del sistema norteamericano, uno puede encontrar estudios sobre identificación de factores de riesgo y primitivos instrumentos de predicción de reincidencia ya en los años $30 .{ }^{37}$ No obstante, su uso sería relativamente restringido dentro del sistema, y no sería hasta los años 80 que se comenzaría a desarrollar toda una nueva tecnología de predicción de riesgo, la cual no sólo consideraría la creación de instrumentos predictivos, sino el desarrollo de todo un modelo vinculado con la predicción e intervención del riesgo.

En definitiva, en este primer apartado buscaremos tratar de esclarecer qué es y qué implica la tecnología de predicción de riesgo de reincidencia actualmente en el sistema anglosajón. Seguiremos surgimiento y desarrollo de los instrumentos de riesgo por parte de la psicología y nos centraremos en tres niveles. A saber:

1. Dar cuenta brevemente de la historia de la tecnología.

2. Explicar los aspectos centrales de ésta y,

3. Tratar de delinear los problemas y desafíos actuales del paradigma.

\subsection{La tecnología de predicción de riesgo de reincidencia como rescate de la rehabilitación.}

Como ya habíamos mencionado, la historia del surgimiento del modelo de predicción de riesgo de reincidencia e intervención nos ha llegado, en varias ocasiones, ${ }^{38}$ por parte del

\footnotetext{
${ }^{35}$ LUPTON, Risk, cit. nota no 4, p. 49.

${ }^{36}$ KEMSHALL, Understanding risk, cit. nota $\mathrm{n}^{\circ} 4$, pp. 50 y ss.

37 Volveremos sobre este punto durante la segunda parte de este trabajo, sin embargo desde ya puede mencionarse los trabajos de HART, Hornell, "Predicting Parole Success", Journal of Criminal Law and Criminology, vol. 14 (1924), pp. 405-413 y las investigaciones del prominente criminólogo de la escuela de Chicago, Ernest Burguess, quien también desarrolló esta línea. Ver BRUCE, Andrew A., BURGESS, Ernest W. y HARNO, Albert J., "The Probation and parole system”, en: WIGMORE, John H., (Ed.), Illinois Crime Survey, Chicago: Illinois Association for Criminal Justice, 1929, pp. 422-574, pp. 516 y ss. También BURGESS, Ernest W, "Is Prediction Feasible in Social Work? An Inquiry Based upon a Sociological Study of Parole Records", Social Forces, Vol. 7, No. 4 (1929), pp. 533-545 y BURGESS, Ernest W, "Protecting the Public by Parole and by Parole Prediction", The Journal of Criminal Law \& Criminology, vol. 27, n 4 (1936), pp. 491-502. Otras investigaciones derivadas del trabajo de Burgess pueden verse en SCHUESSLER, Karl F., "Parole Prediction; Its History and Status", Journal of Criminal Law, Criminology and police science, Vol. 45, no 4 (1954), pp. 425-431.

${ }^{38}$ Ver CULLEN, Francis T.; GENDREAU, Paul, "Assessing Correctional Rehabilitation: Policy, Practice, and Prospects", en: HORNEY, J. (Ed.), NIJ Criminal Justice 2000: Changes in decision making and discretion in the criminal justice system, Washington, DC: U.S. Department of Justice, National Institute of Justice (2000); CULLEN, Francis T., "The twelve people who saved rehabilitation: How the science of criminology made a difference", Criminology, vol. 48, no 1 (2004), pp. 1-42; CULLEN, Francis T., "It's time to reaffirm rehabilitation", Criminology \& Public Policy, vol. 5, No 4 (2006), pp. 665-672; CULLEN, Francis T.; SMITH, Paula; LOWENKAMP, Christopher T. \& LATESSA, Edward J., "Nothing works revisited: deconstructing Farabee's rethinking rehabilitation", Victims and Offenders, vol. 4 (2009), pp. 101-123; CULLEN, Francis T. y JONSON, Cheryl L., "Rehabilitation and Treatment Programs", en: WILSON, James Q y PETERSILIA, Joan (Eds.), Crime and Public Policy, Nueva York: Oxford University Press, 2011, pp.
} 
VELÁSQUEZ, Javier. "El origen del paradigma de riesgo".

criminólogo norteamericano Francis T. Cullen, quien ha dedicado gran parte de su carrera académica a defender la idea de la rehabilitación y difundir los logros del paradigma de riesgo en esta área. ${ }^{39}$ En este sentido, ha sido él quien, convertido en una suerte de historiador, mejor ha difundido los entretelones de esta historia. Este relato, como veremos, se basa en aquellos hitos específicos que marcaron el inicio del desarrollo de esta línea de investigaciones y como, a la postre, se ha ido consolidando y desarrollando el modelo al interior de los sistemas penales anglosajones.

\subsubsection{Martinson y la crisis de la rehabilitación.}

En el mundo anglosajón, por lo menos desde fines de siglo XIX, se fue desarrollando y consolidando un modelo de "Estado de Bienestar" (Welfare State). En este contexto se produjo lo que el sociólogo escocés David Garland denomina "Estado de Bienestar Penal" (Penal-Welfare State), lo que implicó que el sistema penal se orientase hacia una línea asistencialista afín con los principios de dicho modelo. Por esto, penológicamente hablando, el sistema asumía fines preventivos especiales; vale decir, la finalidad de la pena era la rehabilitación. ${ }^{40}$ No obstante, para los años 70 este modelo comenzó a sufrir una crisis de credibilidad. Dichos cuestionamientos llegaron a tal nivel que tanto liberales como conservadores se unieron en contra de la rehabilitación, claro que cada grupo por sus propias razones. $^{41}$

En este sentido, el Partido Republicano formulaba sus ataques sosteniendo que los programas de rehabilitación no eran otra cosa que paternalismo estatal, y culpaba a los jueces por considerar que estos utilizaban sus facultades discrecionales para otorgar penas en el medio libre a criminales que, apenas volvían a la comunidad, comenzaban a reincidir. ${ }^{42}$ Aún peor, para ellos la rehabilitación se encontraba infectada de los peores aspectos del "Estado de Bienestar": el deseo de dar un trato humanitario y digno a una

293-367; CULLEN, Francis T., "Taking rehabilitation seriously: Creativity, science, and the challenge of offender change", Punishment \& Society, vol. 14 (2012) pp. 94 - 113, y CULLEN, Francis T. y JONSON, Cheryl Lero, Correctional Theory: Context and Consequences, California: SAGE, 2012, pp. 147 y ss.

39 Así, además de la bibliografía citada en la nota anterior, puede verse su siguientes artículos y trabajos CULLEN, Francis T. y GILBERT, Karen, Reaffirming Rehabilitation, Cincinnati: Anderson Publishing, 1982; CULLEN, Francis T., "Assessing the penal harm movement", Journal of research in crime and delinquency, Vol. 32, No 3, (1995), pp. 338 - 358; CULLEN, Francis T.; GENDREAU, Paul, "From nothing works to what works: Changing professional ideology in the 21st century", The Prison Journal, Vol. 81, No. 3 (2001) pp. 313-338, LATESSA, Edward J., CULLEN, Francis T. y GENDREAU, Paul, "Beyond correctional quackery - Professionalism and the possibility of effective treatment", Federal Probation, Vol. 66, $\mathrm{N}^{\circ} 2$ (2002) p. 15-22, CULLEN, Francis T., "Make rehabilitation correction's guiding paradigm", Criminology \& Public Policy, Vol. 6, No 4 (2007) pp. 717-727, LISTWAN, Shelley J., JONSON Cheryl L., Cullen, Francis. T. y LATESSA, Edward. J., "Cracks in the penal harm movement: Evidence from the field", Criminology \& Public Policy, Vol. 7, No 3 (2008) pp. 423-465, CULLEN, Francis T., JONSON, Cheryl L., NAGIN, Daniel S., "Prisons do not reduce recidivism: The high cost of ignoring science", The Prison Journal, Vol. 91, № 3 (2011), pp. 48-65.

${ }^{40}$ Ver GARLAND, David, Punishment and Welfare, Aldershot: Gower, 1986, passim y GARLAND, David, La Cultura del Control: Crimen y Orden Social en la Sociedad Contemporánea, Trad. SOZZO, Máximo, Barcelona: Gedisa, 2001, pp. 71 y ss.

${ }^{41}$ CULLEN, "Taking", cit. nota $\mathrm{n}^{\circ} 38$, pp. 94-113.

${ }^{42}$ CULLEN, “Assessing the penal harm”, cit. nota no 38, pp. 114 y 122. 
Polít. crim. Vol. 9, No 17 (Julio 2014), Art. 3, pp. 58-117. [http://www.politicacriminal.cl/Vol_09/n_17/Vol9N17A3.pdf]

población que no lo merecía y que lo único que aprendía de esto era que la infracción de la norma era premiada. ${ }^{43}$

La sensibilidad afín al Partido Demócrata, en cambio, criticaba que los programas de rehabilitación, los reformatorios y los centros de salud mental, tenían como único objeto incapacitar a los infractores de ley. Afirmaban que en aquellos casos en los cuales realmente existían tratamientos éstos sólo tenían fines utilitaristas y represivos. ${ }^{44}$ Por otra parte, también se cuestionaba el alto grado de discrecionalidad con el que contaban los jueces a la hora de imponer una condena. La noción de que la sanción debía adecuarse al condenado se traducía, en la práctica, en una gran disparidad en la aplicación de las mismas. Lo anterior redundaba en discriminaciones por raza y clase social. Los afronorteamericanos y quienes pertenecían a clases sociales menos favorecidas obtenían condenas más duras que aquellos sujetos de rasgos caucásicos o mejor situados económicamente por el mismo tipo de delitos. ${ }^{45}$ Por estos motivos Norval Morris en su libro El Futuro de la prisión llegó a plantear que la rehabilitación no era otra cosa que una "mentira noble". 46

En síntesis, el sistema penal durante los años 70 estaba siendo cuestionado por toda la comunidad política. Las críticas, sin embargo como hemos visto, eran completamente contradictorias. Se acusaba al sistema de ser represivo, pero también se le acusaba de ser demasiado "blando", de ser inocuizador y a la vez permitir que los sujetos peligrosos volvieran a las calles. Tanto Cullen ${ }^{47}$ como otros autores ${ }^{48}$ plantean que el punto de quiebre

\footnotetext{
${ }^{43}$ CULLEN, "The twelve", cit. nota $\mathrm{n}^{\circ} 38$, pp. 6-7.
}

${ }^{44}$ En este contexto surgen críticas tan radicales como las de Thomas Szasz, quien atacó directamente la noción de "enfermedad mental" considerándola un mito y al tratamiento como un engaño en su clásico artículo SZASZ, Thomas, "The Myth of Mental Illness", American Psychologist, vol. 15 (1960), pp. 113-118, passim. También ver SZASZ, Thomas, The Second Sin, Nueva York: Anchor Books, (1972), pp. 89. En éste sentido CONROY, Mary Alice y MURRIE, Daniel C., Forensic Assessment of Violence Risk, New Jersey: John Wiley \& Sons, 2007, pp. 2 y ss.

${ }^{45}$ GARLAND, La Cultura del Control, cit. nota ${ }^{\circ} 40$, pp. 110 y ss. Sobre el sesgo racial ver en profundidad el sexto capitulo de WACQUANT, Loïc, Castigar a los pobres: El gobierno neoliberal de la inseguridad social, trad.: POLO, Margarita, Barcelona: Gedisa, 2009, pp. 281 y ss.

${ }^{46}$ Para ser exactos, si bien suele atribuirse el término Norval Morris, dicha idea no es suya, él lo tomó del trabajo de David J. Rothman "Decarcerating Prisoners and patients" publicado el primer número de el "Civil Liberties Review" de 1973, ver: MORRIS, Norval, The Future of imprisonment, Chicago: The University of Chicago Press (1974), pp. 20-22. En este sentido CULLEN, "Assessing the penal harm", cit. nota n $^{\circ} 38$, p. 114, y también LARRAURI, Elena, "Control de delito y castigo en Estados Unidos", Jueces para la democracia, $\mathrm{N}^{\circ} 32$ (1998), pp. 85-88, p. 85.

${ }^{47}$ Así en CULLEN, "Assessing the penal harm", cit. nota $\mathrm{n}^{\circ}$ 38, passim, CULLEN, "The twelve", cit. nota $\mathrm{n}^{\circ}$ 38, passim, y CULLEN, "Taking", cit. nota $\mathrm{n}^{\circ} 38$, passim; CULLEN/JONSON, "Rehabilitation", cit. nota $\mathrm{n}^{\circ}$ 38, pp. 293-367.

${ }^{48}$ WARD/MARUNA, Rehabilitation, cit nota $\mathrm{n}^{\circ} 11$, p. 8. También ver: RAYNOR, Peter y ROBINSON, Gwen, Rehabilitation, Crime And Justice: Revised and updated edition, Hampshire: Palgrave McMillan, 2009, pp. 65 y ss., ROBINSON, Gwen y CROW Ian, Offender Rehabilitation: Theory, Research and Practice, Londres: Sage, 2009, pp. 28 y ss., MAIR, George y BURKE, Lol, Redemption, Rehabilitation and Risk Management: A history of Probation, Londres: Routledge, 2012, pp. 106 y ss., RAYNOR, Peter, "Community penalties: Probation, "What Works" and Offender Management", en: MAGUIRE, Mike, MORGAN, Rod y REINER, Robert (Eds.), The Oxford Handbook of Criminology, Oxford: Oxford University Press, 2007, pp. 1069 y ss. Especialmente relevante es el texto de McGUIRE, James y PRIESTLEY, Philip, "Reviewing "What Works?": Past, Present and Future”, en: McGUIRE, James (ed.), 
VELÁSQUEZ, Javier. "El origen del paradigma de riesgo".

se produce en 1974, luego de que el sociólogo norteamericano Robert Martinson publicase un artículo titulado "¿Qué funciona? - Preguntas y respuestas sobre la reforma penitenciaria". ${ }^{49}$ En dicho trabajo, Martinson plantea que uno de los problemas fundamentales sobre el debate en torno a la reforma de la prisión era que no existía conocimiento empírico sobre el paradigma rehabilitador. En otras palabras, no se sabía si éste, valga la redundancia, rehabilitaba. ${ }^{50}$ Bajo esa premisa Martinson revisó 231 estudios sobre los efectos de los programas de rehabilitación, publicados entre los años 1945 y 1967. Las conclusiones a las que arribó fueron devastadoras, ${ }^{51}$ al punto de afirmar que: "Con algunas pocas y aisladas excepciones, los esfuerzos por rehabilitar (a los condenados) que han sido informados hasta ahora, no han tenido un efecto apreciable en el nivel de reincidencia". ${ }^{52} \mathrm{Si}$ bien Martinson no dijo expresamente en su artículo que nada funciona, su trabajo fue resumido con dicho slogan; este es el origen de la frase "Nada funciona" (Nothing Works). ${ }^{53}$

Es necesario recalcar que las conclusiones de la investigación de Martinson no eran novedosas dentro del ámbito académico. De hecho, desde los años 50 existía una larga lista de investigaciones similares, que llegaban a las mismas conclusiones. ${ }^{54}$ En este sentido, Michael Tonry diría que "el escepticismo en torno a la efectividad de los programas de

What works: Reducing Reoffending, West Sussex: John Wiley \& Sons, 1995, pp. 3-34, que daría origen al movimiento "What Works" en el Reino Unido. En contra de esta corriente y tratando de redimir la figura de Martinson, se encuentra el texto de FARABEE, David, Rethinking Rehabilitation: Why can't we reform our criminals?, Washington D.C.: American Enterprise Institute for Public Policy Research, 2005, passim. Texto, por lo demás que no estuvo exento de polémica, dado que luego de su publicación recibió una dura crítica de Cullen, ver CULLEN/SMITH/LOWENKAMP/LATESSA, "Nothing", cit. nota no 38, passim, y otra crítica particularmente ácida por parte del psicólogo Shadd Maruna, ver MARUNA, Shadd, "Book Review: Rethinking rehabilitation: Why can't we reform our criminals?" Punishment \& Society, vol. 9, no 3 (2005), pp. 333-337.

${ }^{49}$ MARTINSON, Robert, "What Works? - Questions and Answers About Prison Reform", The Public Interest (1974), pp. 22-54. Las implicancias de su trabajo llegaron al Reino Unido, lo que impactaría fuertemente en la libertad vigilada (Probation). Así, un par de años después en 1979 Anthony Bottoms escribiría su relevante artículo, BOTTOMS, Anthony E. y McWILLIAMS, William, "A Non-Treatment Paradigm for Probation Practice”, British Journal of Social Work, vol. 9, no 2 (1979), pp. 159-202. Sobre este proceso y la evolución posterior de la probation en el Reino Unido ver McNEILL, Fergus, "A desistance paradigm for offender Management”, Criminology \& Criminal Justice, vol. 6, nº 1 (2006), pp. 39-62, existe una traducción al español de este artículo, ver McNEILL, Fergus, "Paradigma del desistimiento para la gestión de delincuentes", trad.: OLIVERO, Carmen, en: Documento de Trabajo $n^{o}$ 27, Santiago: Defensoría Penal Pública, en: http://www.biblio.dpp.cl/biblio/DataBank/6190.pdf [visitado 12.03.2014].

${ }^{50}$ MARTINSON, "What Works?", cit. nota no 49, p. 22.

${ }^{51}$ GARLAND, La Cultura del Control, cit. nota no 40, p. 114.

${ }^{52}$ MARTINSON, “What Works?", cit. nota n ${ }^{\circ} 49$, p. 48.

${ }^{53}$ En estricto rigor, el término proviene de uno de los títulos utilizados por Martinson en su texto, específicamente del apartado donde analiza críticamente el resultado de los hallazgos. Este apartado se titulaba "Does nothing work?". Ver MARTINSON, "What Works?", cit. nota n 49, p. 25.

${ }^{54}$ CULLEN en su trabajo "The twelve", cit. nota $\mathrm{n}^{\circ} 38$, pp. 5-6 nombra una larga lista de estudios que remontan hacía comienzo de los años 50. Por lo demás, poco tiempo antes de su artículo, en 1971 se había publicado el estudio de ROBINSON, James y SMITH, Gerald, "The effectiveness of correctional programs", Crime And Delinquency n ${ }^{\circ} 17$ (1971), pp- 67-80 quienes, como haría Martinson, luego de revisar diversos estudios penitenciarios del Estado de California, concluían que los programas no estaban funcionando. Un breve resumen de los trabajos previos a Martison puede encontrarse en ANDREWS, Donald; BONTA, James, The Psychology of Criminal Conduct, $5^{\mathrm{a}}$ edición, New Jersey: Anderson Publishing, 2010, pp. 347 y ss. 
Polít. crim. Vol. 9, No 17 (Julio 2014), Art. 3, pp. 58-117.

[http://www.politicacriminal.cl/Vol_09/n_17/Vol9N17A3.pdf]

rehabilitación precedió significativamente al artículo de Martinson". 55 Entonces, ¿Por qué el trabajo de Martinson tuvo tanto impacto? Básicamente, por el momento y la forma en que éste dirigió su crítica en contra del sistema. Pese a decir nuevamente lo que en la academia ya se sabía, fue su artículo el que atrajo la atención de los políticos y la opinión publica, ${ }^{56}$ al punto de que:

"en poco tiempo las conclusiones de Martinson fueron vistas como la evidencia empírica concluyente del fracaso del sistema y se convirtieron en la base para la afirmación de que "nada funciona" (...) En pocos años se transformaría en el punto de vista convencional."

\subsubsection{La reacción al "Nothing Works": La refutación.}

La caída en desgracia de la rehabilitación, tanto como ideología como teoría de la pena, tuvo consecuencias importantes en los profesionales que se desempeñaban en el área del tratamiento penitenciario. El debate académico ya no trataba sobre cómo mejorar los programas de rehabilitación, sino en cómo defender a la rehabilitación de lo que parecía ser su inminente extinción.

Es en este sombrío escenario que se produjo una reacción de los psicólogos que trabajaban en el área penitenciaria (mayoritariamente canadienses), quienes iniciarían una lucha que se extendería desde los años 70, la que incluso se podría sostener continua hasta nuestros días. El objetivo era demostrar que la idea de que "nada funciona" estaba equivocada y proponer un modelo de rehabilitación que fuera funcional a las exigencias de resultados que tanto la opinión pública como los políticos buscaban.

Una de las primeras personas en hacer frente a las conclusiones de Martinson, fue el psicólogo norteamericano Ted Palmer. Palmer, durante los años 70, se encontraba a cargo de programas de intervención para adolescentes infractores. En 1975, tan sólo un año después de que el texto de Martinson viese la luz, Palmer publicó un artículo titulado "Martinson revisado". 58 En este artículo Palmer se dedicó a comprobar la metodología utilizada por Martinson; revisó los 82 estudios que éste había citado, y descubrió que 39 de estos estudios (el 48\% de la muestra) daban cuenta de efectos positivos en la disminución de reincidencia. ${ }^{59}$ La inconsistencia se explicaba, por cuanto la lapidaria crítica de Martinson era mucho más sutil y menos tajante que como se le había interpretado en un comienzo. Martinson criticó la inconsistencia en los resultados de los programas de tratamiento aplicados, vale decir, a la luz de los resultados existía un 50\% de probabilidad

\footnotetext{
55 TONRY, Michael, “Obsolescence and Immanence in Penal Theory and Policy”, Columbia Law Review, Vol. 105, $\mathrm{n}^{\circ} 4$ (2005), pp. 1233-1275, p. 1252.

${ }^{56}$ HOLLIN, Clive R. y PALMER, Emma J., "Offending behaviour programmes: history and development”, en: HOLLIN, Clive R.; PALMER, Emma J. (Eds.), Offending Behaviour Programmes: Development, application and controversies, West Sussex: John Wiley \& Sons, 2006, p. 6.

${ }^{57}$ GARLAND, La Cultura del Control, cit. nota $\mathrm{n}^{\circ}$ 40, p. 114.

58 PALMER, Ted, "Martinson Revisited", Journal of Research in Crime and Delinquency, vol. $12, \mathrm{n}^{\circ} 2$ (1975) pp. 133-152.

${ }^{59}$ PALMER, "Martinson Revisited", cit. nota n ${ }^{\circ} 58$, pp. 142 y ss.
} 
VELÁSQUEZ, Javier. "El origen del paradigma de riesgo".

de que un determinado tipo de programa funcionara o no. ${ }^{60}$ Pero de esta inconsistencia en los resultados de los programas, a la luz de los mismos estudios que Martinson revisó, no se sigue que nada funcione. Precisamente por ello, Palmer concluiría en su trabajo proponiendo un cambio de foco al momento de evaluar los programas, así planteó:

"En vez de preguntarnos, “¿Qué funciona para todos los infractores de ley por igual?; Debemos preguntar "¿Qué métodos funcionan mejor para que determinado tipo especifico de infractores de ley? y ¿Bajo qué condiciones o en qué tipo de entorno? ${ }^{61}$

Sin embargo el trabajo de Palmer no logró detener la corriente en contra de la rehabilitación. A nivel político, la tregua entre conservadores y liberales había cesado con la caída de la rehabilitación y ahora se debatía cómo reemplazarla. Por un momento pareció que los liberales, de la mano de Andrew von Hirsch, lograrían imponer un modelo basado en la retribución (just desert), sin embargo los conservadores extremaron los postulados de estas ideas y terminaron dando pie al surgimiento de un modelo basado en la incapacitación. ${ }^{62}$

Para finales de los años 70 el panorama era realmente oscuro para los partidarios de la rehabilitación. Pese a ello, en 1979 suceden dos hitos importante: por un lado Martinson publicó una retractación de su artículo de $1974,{ }^{63}$ y, por otro, los psicólogos canadienses Paul Gendreau y Robert Ross publicaron el artículo "Tratamiento correccional efectivo:

${ }^{60}$ CULLEN/JONSON, Correctional Theory, cit. nota $\mathrm{n}^{\mathrm{0}} 38$, pp. $155 \mathrm{y} \mathrm{ss.}$

${ }^{61}$ PALMER, "Martinson Revisited", cit. nota ${ }^{\circ}$ 58, p. 150.

${ }^{62}$ El modelo de "just desert" de Hirsch fue un claro retorno a un criterios basados en la retribución. Ver VON HIRSCH, Andrew, Doing Justice: The Choice of Punishments, Nueva York: Hill and Wang, 1977, passim. Este "neoclasicismo" tuvo un gran avance al ser incorporado en las "guías para dictar sentencia" de los estados de California y Minnesota. Ver GARLAND, La Cultura del Control, cit. nota no 40, p. 115, también ver VON HIRSCH, Andrew y GOTTFREDSON, Don M., "Selective Incapacitation: Some Queries About Research, Design, And Equity", New York University Review of Law and Social Change, vol. 12 (1983), pp. 38 y ss. Sin embargo el giro conservador que tanto Estados Unidos como el Reino Unido tomaron en los años 80 provocó una distorsión del modelo retribucionista, extremando varios de sus postulados y dando pie a un modelo derechamente incapacitador. En este sentido GARLAND, La Cultura del Control, cit. nota $\mathrm{n}^{\circ}$ 40, p. 253; en el mismo sentido CULLEN/JONSON, Correctional Theory, cit. nota $\mathrm{n}^{\mathrm{o}} 38$, pp. 60 y ss. Sobre el declive del control judicial y los cambios dentro del poder Estatal y Federal que incidieron en este cambio ver SIMON, Jonathan, Governing Through Crime: How the war on crime transformed American Democracy and Created a Culture of Fear, Nueva York: Oxford University Press, 2007, passim. También en CAPLOW, Theodore y SIMON Jonathan, "Understanding Prison Policy and Population Trends", en: TONRY, Michael y PETERSILIA, Joan (Eds.), Crime and Justice Vol. 26: Prisons, Chicago: The University of Chicago Press, 1999 , pp. 78 y ss. Sobre como fue introducida la incapacitación al debate político criminal durante los años 80, ver WILSON, James Q., Thinking about Crime, Nueva York,: Basic Books, 1975, pp. 198-209, también WILSON, James Q. y BOLAND, Barbara, "Incapacitation”, en: GORHAM, William y GLAZER, Nathan (eds.), The Urban Predicament, Washington, DC: The Urban Institute, 1976, pp. 179-230. Críticamente MATHIESEN, Thomas, "Selective Incapacitation Revisited", Law and Human Behaviour, vol. 22, n ${ }^{\circ}$ 4, (1998), p. 456, también en este sentido CULLEN/JONSON, Correctional Theory, cit. nota $\mathrm{n}^{\circ}$ 38, pp. 99-100 y 112-113 y VON HIRSCH, Andrew, "Selective Incapacitation Re-examined: The National Academy of Sciences "Report on Criminal careers and "Career Criminals", Criminal Justices Ethics, vol. 7, (1988), pp. 20.

${ }^{63}$ MARTINSON, Robert, "New Findings, New Views: A note caution regarding sentencing reform”, Hofstra Law Review, vol. 7, nº 2 (1979), pp. 243-258. 
Polít. crim. Vol. 9, No 17 (Julio 2014), Art. 3, pp. 58-117.

[http://www.politicacriminal.cl/Vol_09/n_17/Vol9N17A3.pdf]

Biblioterapia para cínicos". ${ }^{64}$ Se iniciaba la contraofensiva canadiense para rescatar la rehabilitación

El trabajo de Gendreau y Ross consistió en evaluar 95 estudios sobre la efectividad de programas de tratamiento publicados entre los años 1973 y 1978. (Posteriormente, en 1987, publicarían un segundo trabajo en el cual evaluaron 120 estudios publicados entre los años 1981 y 1987). ${ }^{65}$ Lo fundamental de estos trabajos no sólo está en que nuevamente se refutarían las conclusiones de Martinson, sino que presentarían tres descubrimientos que sentarían las bases del desarrollo de los programas de tratamiento durante los años 80 y que, en definitiva, tendría un impacto en el renacimiento de la rehabilitación durante los años 90 .

El aporte de Gendreau y Ross se puede sintetizar en tres puntos: (1) Descubrieron que gran parte de los fracasos de algunos programas se relacionaba con la falta de integridad terapéutica. En términos sencillos, algunos programas simplemente estaban mal diseñados o bien, estando adecuadamente diseñados de acuerdo a la literatura académica, en la práctica se alejaban de dichos estándares; (2) que los programas que más efectividad demostraron eran aquellos que estaban basados en la intervención de la conducta de los infractores de ley mediante intervenciones cognitiva-conductuales. Esto era especialmente llamativo, dado que este tipo de programas había quedado fuera del análisis de Martinson. Asimismo, observaron el éxito de aquellos programas que se enfocaron en las "necesidades criminógenas" de los sujetos y, finalmente, (3) recalcaron la importancia de reconocer las diferencias entre los distintos infractores de ley, sea por el tipo de delito cometido, como también por el nivel de riesgo de reincidencia. En otras palabras, hicieron ver que las intervenciones deberían ser considerando al infractor como individuo y no estandarizadas para todos los infractores de ley por igual. ${ }^{66}$

Mientras Gendreau y Ross demostraban que los programas de tratamiento funcionaban, los psicólogos Donald Andrews y James Bonta, también canadienses, comenzaron a desarrollar los que han sido llamados "principios de la intervención correccional efectiva", que sentarían las bases de su modelo de intervención llamado "Riesgo, Necesidad y Responsividad. ${ }^{, 67}$ En efecto, sabiendo que la rehabilitación arrojaba resultados positivos en

\footnotetext{
${ }^{64}$ GENDREAU, Paul y ROSS, Robert, "Effective Correctional Treatment: Bibliotherapy for Cynics", Crime \& Delinquency, vol. 25, nº (1979), pp. 463-489.

${ }^{65}$ GENDREAU, Paul y ROSS, Robert, "Revivification of rehabilitation: Evidence from the 1980s", Justice Quarterly, vol. 4 (1987), pp. 349-407.

${ }^{66}$ CULLEN/GENDREAU, “Assessing Correctional”, cit. nota $\mathrm{n}^{\mathrm{o}}$ 38, pp. 132-133, y CULLEN/JONSON, Correctional Theory, cit. nota $\mathrm{n}^{\mathrm{o}} 38$, pp. 157-158.

${ }^{67}$ El nombre original en inglés es "Risk, Need and Responsivity", hemos optado por traducirlo como "Riesgo, necesidad y responsividad". La palabra "responsivity", resulta de compleja traducción, su significado se refiere a la manera que responde algo frente a un estimulo. Una posibilidad de traducción podría ser "respuesta" o bien "receptividad". No obstante ello, en la literatura psicológica reciente se ha optado por utilizar el anglicismo "responsividad", por este motivo, y siendo que el término proviene de dicha disciplina hemos optado por dicha traducción. Nos excusamos de entregar una lata bibliografía sobre el uso del término dado que nos obligaría a acrecentar en demasía nuestra ya extensa bibliografía. Sin perjuicio de ello se puede señalar que esta traducción ha sido, incluso, utilizada por informes institucionales ver MINISTERIO DE JUSTICIA, Nueva Ley $N^{\circ}$ 18.216. Análisis de las modificaciones introducidas por la ley 20.603. Material para capacitación, Santiago: Ministerio de Justicia, 2012, pp. 46 y ss., asimismo cabe observar que la
} 
VELÁSQUEZ, Javier. "El origen del paradigma de riesgo".

algunos casos, ellos se enfocaron en responder una pregunta fundamental: ¿Qué era lo que estaba funcionando? Desarrollando sus investigaciones durante las décadas de los años $70 \mathrm{y}$ 80, apoyándose en el surgimiento de una nueva tecnología de evaluación de resultados llamada meta-análisis, ${ }^{68}$ presentaron los resultados de sus investigaciones en 1990 en un artículo titulado: “ ¿El tratamiento correccional funciona? Un meta-análisis clínicamente informado". ${ }^{69}$ Pronto comenzarían a surgir diversas investigaciones meta-analíticas que demostrarían resultados positivos en la forma y tipo de intervenciones propuestas por los canadienses. $^{70}$

Para mediados de los años 90, se había vuelto a producir un cambio en el debate político criminal anglosajón: la rehabilitación volvía de entre los muertos para demostrar que sí funcionaba. Ahora el desafío era demostrar a la opinión pública no sólo que existían resultados empíricamente validados, sino que también se debía determinar qué era exactamente lo que funcionaba.

vigésima tercera edición del diccionario de la RAE, ha modificado la definición de la palabra "responsivo" incorporando una tercera acepción "Perteneciente o relativo a la respuesta.". Ver Diccionario de la lengua española, "Responsivo", avance de la vigésima tercera edición, disponible en: http://lema.rae.es/drae/srv/search?id=h1H4hImVMDb2llFqVBkz [visitado 18.03.2014]. Sobre el contenido de estos principios se puede consultar ANDREWS/BONTA, The Psychology, cit. nota ${ }^{\circ}$ 54, passim, además ver infra apartado $2.2 \mathrm{y}$ ss.

${ }^{68}$ La idea del meta-análisis surge por primera vez en el trabajo GLASS, Gene, "Primary, Secondary, and Meta-Analysis of Research", Educational Researcher, vol. 5, no 10 (1976), pp. 3-8, y consiste en un método estadístico de análisis de una larga colección de resultados de investigaciones para el propósito de integrar el resultado de todos sus hallazgos. Representa una opción a los análisis narrativos de resultados, los que normalmente son sujeto de discusión por posibles sesgos de los investigadores que los realizan. De hecho, este fue la gran crítica formulada a la revisión narrativa que hizo Martinson. Este método comenzó a cobrar fuerza especialmente durante los años 80. A fondo sobre las ventajas del método ver WOLF, Fredric, MetaAnalysis: Quantitative Methods for Research Synthesis, California: Sage, 1986, pp.53 y ss.

${ }^{69}$ ANDREWS, Donald, ZINGER, Ivan, HOGE, Robert, BONTA, James, GENDREAU, Paul y CULLEN, Francis, "Does Correctional Treatment Work?: A clinically relevant and psychologically informed MetaAnalysis", Criminology, vol. 28 , n 3 3, (1990), p. 369-404 Dicho artículo suscitó la inmediata respuesta de dos académicos aludidos críticamente en éste ver LAB, Steven y WHITEHEAD, John, "From "Nothing Works" to "The aprópiate Works": The latest stop on the search for the secular grail", Criminology, vol. $28, \mathrm{n}^{\circ}$ 3, (1990), p. 405-417, la replica fue, a su vez, también inmediata ANDREWS, Donald, ZINGER, Ivan, HOGE, Robert, BONTA, James, GENDREAU, Paul y CULLEN, Francis, "A Human Sciencie approach or more punishment and pessimism: A rejoinder to Lab and Whitehead", Criminology, vol. 28, n 3, (1990), p. 419 429 , ver especialmente sus conclusiones en pagina 425-426.

${ }^{70}$ Sobre este punto ver CULLEN, "The twelve", cit. nota $\mathrm{n}^{\circ} 38$, pp. 17 y siguientes. También particularmente relevante ha sido en este aspecto el trabajo de Mark Lipsey, ver, entre otros, LIPSEY, Mark, "What do we learn from 400 research Studies on the effectiveness of treatment with juvenile delinquents?", en: MCGUIRE, James (ed.), What Works: Reducing Reoffending, West Sussex: John Wiley \& Sons, 1995, pp. 35-62, LIPSEY, Mark, "Can Intervention Rehabilitate Serious Delinquents?", Annals of the American Academy of Political and Social Science, vol. 564, (1999), pp. 142-166 y LIPSEY, Mark, CHAPMANN, Gabrielle y LANDENBERGER, Nana, "Cognitive-Behavioral Programs for Offenders" Annals of the American Academy of Political and Social Science, vol. 578, (2001), pp. 144-157. Asimismo el trabajo de Friedrich Lösel, en LÖSEL, Friedrich, "The efficacy of correctional treatment: A review and synthesis of Meta-evaluations", en: McGUIRE, James (ed.), What works: Reducing Reoffending, West Sussex: John Wiley \& Sons, 1995, pp. 79111; y ANDREWS, "The Psychology", cit. nota nº 54, p 356 y ss. 
Polít. crim. Vol. 9, No 17 (Julio 2014), Art. 3, pp. 58-117.

[http://www.politicacriminal.cl/Vol_09/n_17/Vol9N17A3.pdf]

\subsection{La psicología de la conducta criminal.}

Usualmente en la práctica penitenciaria cuando hablamos del surgimiento del paradigma de riesgo (o bien modelo de riesgo), en realidad nos estamos refiriendo a la aparición de una serie de intervenciones que se basan directa, o muchas veces muy indirectamente, en el modelo de intervención clínico creado y desarrollado por los psicólogos canadienses Don Andrews y James Bonta durante los años 80: El modelo de Riesgo, Necesidad y Responsividad (Risk-Need-Responsivity). ${ }^{71}$

Lo relevante del trabajo de Andrews y Bonta no es que ellos hayan creado el concepto de riesgo, los instrumentos actuariales, las revisiones meta-analíticas ni las terapias cognitivas conductuales. Al contrario, ellos se sirvieron de las herramientas, tecnologías y metodologías existentes y las utilizaron para armar un modelo de intervención para infractores de ley que ha demostrado su efectividad. ${ }^{72}$

El corazón del modelo se encuentra en lo que ellos han denominado "principios de intervención efectiva", ${ }^{73}$ los que no se restringen únicamente a los principios de Riesgo, Necesidad y Responsividad, que le dan su nombre. ${ }^{74}$ Con todo, desde un comienzo lo que estaba detrás del trabajo de Andrews y Bonta era la elaboración de un modelo que pudiera entregar al infractor de ley un servicio humano. Por lo mismo los autores siempre han sido muy críticos de las intervenciones criminológicas de paradigma sociológico. ${ }^{75}$ Inevitablemente, como se ha podido apreciar, la época en que estos autores canadienses deciden luchar por reposicionar la rehabilitación como una teoría de la pena estaba

\footnotetext{
${ }^{71}$ El desarrollo puede verse en ANDREWS/BONTA, The Psychology, cit. nota n ${ }^{\circ} 54$, passim Una evaluación crítica al modelo en WARD/MARUNA, Rehabilitation, cit. nota $\mathrm{n}^{\circ} 11$, passim, especialmente en pp. 75 y ss.. Tony Ward propone un modelo diferente denominado "Good Lives Model", el cual se ha logrado posicionar como una alternativa que plantea un retorno a un modelo más clínico. Por otro lado, también ha reforzado la sintonía de su modelo con la teoría sociológica del desistimiento, lo que le ha generado cierto apoyo. Sobre este punto ver LAWS, Richard y WARD, TONY, Desistance from sex offending: Alternatives to throwing away the keys, Nueva York: The Guilford Press, 2011, passim. Recientemente se generó un interesante debate donde Donald Andrews, James Bonta y Stephen Wormith se hacen cargo de las críticas de Ward. Ver ANDREWS, Donald; BONTA, James, WORMITH, Stephen, "The Risk-Need-Responsivity (RNR) Model: Does Adding the Good Lives Model?", Criminal Justice and Behavior, vol. 38, nº 7 (2011), pp.735-755. Este artículo inició un debate entre ambos "bandos" que se continuó en el primer número del año 2012 de la revista "Criminal Justice and Behavior", ver WARD, Tony, YATES, Pamela M. y WILLIS, Gwenda M., "The Good Lives Model and the Risk Need Responsivity Model: A Critical Response to Andrews, Bonta, and Wormith (2011)", Criminal Justice and Behavior, vol. 39, $\mathrm{n}^{\circ} 1$ (2012), pp. 94-110. La correspondiente replica, ya sin Donald Andrews, quien falleció en Octubre de 2010, ver WORMITH, Stephen, GENDREAU, Paul y BONTA, James, "Deferring to Clarity, Parsimony, and Evidence in Reply to Ward, Yates, and Willis", Criminal Justice and Behavior, vol. 39, $\mathrm{n}^{\circ} 1$ (2012), pp. 111-120.

${ }^{72}$ Como incluso lo reconocen Tony Ward y Shadd Maruna. Ver WARD/MARUNA, Rehabilitation, cit. nota $\mathrm{n}^{\mathrm{o}} 11$, pp. xi y 20 y ss.

${ }_{74}^{73}$ CULLEN, "The Twelve", cit. nota $\mathrm{n}^{\circ} 38, \mathrm{p} .16$.

${ }^{74}$ El "estreno" de estos principios puede verse en ANDREWS, Donald, BONTA, James y HOGE, Robert, "Classification for effective rehabilitation: Rediscovering psychology", Criminal Justice and Behavior, vol. 17, (1990) pp. 19-52, passim. Sobre la evolución y ampliación de estos principios, ver ANDREWS/BONTA, The Psychology, cit. nota $\mathrm{n}^{\circ}$ 54, pp. 45 y ss.

${ }^{75}$ ANDREWS/BONTA/HOGE, "Classification", cit. nota $\mathrm{n}^{\mathrm{o}} 74$, pp. 20 y ss. y más recientemente ANDREWS/BONTA, The Psychology, cit. nota $\mathrm{n}^{\circ} 54$, pp. xiii-xv y pp. 37 y ss.
} 
VELÁSQUEZ, Javier. "El origen del paradigma de riesgo".

caracterizada por un gran nivel de pesimismo frente a lo que la psicología pudiere decir al respecto.

Como ya hemos venido mencionando, lo central del modelo se encuentra en los principios de Riesgo, Necesidad y Responsividad (en adelante, "RNR"), que en palabras de sus propios autores significan:

“1. Principio de Riesgo: Destinar servicios de intervención intensiva a los infractores de ley con alto riesgo de reincidir, disminuir las intervenciones a aquellos que se evalúe como de bajo riesgo. 2. Principio de Necesidad: Enfocar el tratamiento a las necesidades criminógenas del individuo. 3. Principio de Responsividad: Proveer el tratamiento en un estilo y forma que responda a los estilos y habilidades de aprendizaje del infractor de ley."76

Que el modelo se haya centrado en estos tres principios tiene diversas consecuencias. Por ejemplo, la referencia al principio del riesgo lleva implícita una opción metodológica que en su tiempo era novedosa: el abandono de modelos clínicos de predicción y la incorporación de instrumentos actuariales que tuvieran una base teórica psicológica. ${ }^{77} \mathrm{En}$ este sentido, ya no sólo existen instrumentos generales para evaluar el riesgo de reincidencia, sino que estos instrumentos se han especializado según la naturaleza del tipo de reincidencia que se desea evaluar. Nos detendremos brevemente para tratar de explicar, a grandes rasgos, lo que hay detrás de este modelo.

\subsubsection{El principio del Riesgo.}

Andrews y Bonta sostienen que el principio del riesgo se compone de dos premisas: la primera es que el comportamiento delictivo puede predecirse. Luego, que la intervención que se realiza sobre determinado infractor de ley debe ser acorde con el nivel de riesgo que este presente en él. ${ }^{78}$

En relación con el primer aspecto de este principio, Andrews y Bonta construyen la predicción del comportamiento delictivo a través de la utilización de instrumentos actuariales de medición de riesgo de reincidencia. Estos instrumentos parten de la base de la existencia de factores de riesgo, conductas, comportamientos o situaciones específicas de la vida del evaluado que aumentan la probabilidad de que, en un futuro cercano, vaya a reincidir en la comisión de delitos. Por lo anterior, el resultado de la evolución no es binaria (riesgoso/no riesgoso), sino que probabilística (bajo riesgo, riesgo medio, alto riesgo).

El uso de estos instrumentos es una novedad, especialmente considerando como y cuanto han evolucionado los últimos 30 años. $^{79}$ En efecto, se ha pasado de sistemas de

\footnotetext{
${ }^{76}$ ANDREWS, Donald, y BONTA, James, "Rehabilitating criminal justice policy and practice", Psychology, Public Policy, and Law, vol. 16, no 1 (2010), p. 44.

${ }^{77}$ Sobre este punto ver ANDREWS/BONTA, The Psychology, cit. nota n ${ }^{\circ} 54$, pp. 309 y ss.

${ }^{78}$ ANDREWS/BONTA, The Psychology, cit. nota n ${ }^{\circ}$ 54, p. 47.

79 ANDREWS/BONTA, The Psychology, cit. nota n ${ }^{\circ}$ 54, pp. 311 y ss. A modo de ejemplo sobre la evolución de los instrumentos predictivos de agresores sexuales, ver HANSON, R. Karl, "Clinical, actuarial and dynamic risk assessment of sexual offenders: Why do thinks keep changing?", Journal of Sexual Aggression, vol. $16, \mathrm{n}^{\circ} 3$ (2010), pp. 296-310.
} 
Polít. crim. Vol. 9, No 17 (Julio 2014), Art. 3, pp. 58-117.

[http://www.politicacriminal.cl/Vol_09/n_17/Vol9N17A3.pdf]

predicciones basadas en el juicio subjetivo del psicólogo o psiquiatra, a instrumentos actuariales que objetivan o estandarizan la evaluación al establecer un parámetro común respecto de todos los evaluados: El sujeto en cuestión tiene o no tiene factores de riesgo. Evidentemente, estos factores de riesgo no han sido escogidos al azar, sino que se han logrado establecer luego, a través de investigaciones, se detectara tiene una relación causal con algunas conductas delictivas. ${ }^{80}$ Siendo la psicología una ciencia eminentemente de individuos y no de grupos, esto se ha traducido en la proliferación de instrumentos de riesgos actuariales que se adaptan a determinados tipos de delitos y sujetos. ${ }^{81}$

Dicho esto, cabe mencionar que este proceso por el cual se evalúa el riesgo de reincidencia de un determinado individuo, no sólo nos permite clasificar al individuo según su nivel de riesgo, sino que nos entrega información clave para individualizar qué factores en la vida del sujeto se encuentran asociadas a su carrera delictiva. ${ }^{82}$ Así, conociendo qué factores impactan en el sujeto, se puede construir una intervención especifica para dicho sujeto, orientada a reducir estos factores de riesgo, de manera de que, una vez que el individuo vuelva al medio libre, no incurra en conductas de riesgo que le lleven a cometer nuevos delitos.

El segundo aspecto del principio de riesgo, dice relación un hallazgo que podemos calificar como "peculiar". Resulta que contrario a lo que se puede creer, las investigaciones recientes han detectado que aquellos infractores de ley que, al ser evaluados, arrojan un nivel bajo de riesgo de reincidencia no se ven favorecidos por intervenciones de este tipo. De hecho, al contrario, la intervención de este tipo de cohorte, incluso puede llegar a ser perjudicial. ${ }^{83}$ Este hallazgo no sólo permite racionalizar los recursos respecto de aquellos sujetos que requieren de un mayor control, sino que también refuerza la antigua noción de que la sanción penal debiera adaptarse al sujeto, y no ser una reacción estandarizada.

\subsubsection{El principio de Necesidad.}

Este principio, estrechamente vinculado con el primero, y tiene que ver con lo que Andrews y Bonta denominan "necesidades criminógenas" (criminogenic needs). ${ }^{84}$ De acuerdo a estos

\footnotetext{
${ }^{80}$ Sobre los principales factores de riesgo ver ANDREWS/BONTA, The Psychology, cit. nota ${ }^{\circ} 54$, pp. 55 y ss.

81 ANDREWS/BONTA, The Psychology, cit. nota n 54, pp. 461 y ss. Ver también CONROY/MURRIE, Forensic Assessment, cit. nota $\mathrm{n}^{\circ}$ 44, pp. 135 y ss. y QUINSEY, Vernon L., HARRIS, Grant T., RICE, Marnie E. y CORMIER, Catherine A., Violent Offenders: Appraising and Managing Risk, Washington D.C.: American Psychological Association, 2006, pp. 83 y ss.

${ }^{82}$ ANDREWS/BONTA, The Psychology, cit. nota $\mathrm{n}^{\circ}$ 54, p. 310.

${ }^{83}$ ANDREWS/BONTA, The Psychology, cit. nota no 54 p. 48. Ver también LOWENKAMP, Christopher T., LATESSA, Edward J. y HOLSINGER, Alexander, "The Risk Principle in Action: What Have We Learned From 13,676 Offenders and 97 Correctional Programs?”, Crime \& Delinquency vol. 52 (2006), pp. 77 - 93. También ANDREWS, Donald y DOWDEN, Craig, "Risk Principle of Case Classification in Correctional Treatment: A Meta-Analytic Investigation", International Journal of Offender Therapy and Comparative Criminology vol. 50, (2006) pp. 88-100; Más recientemente y específicamente sobre el caso de los agresores sexuales ver, LOVINS, Brian, LOWENKAMP, Christopher T. y LATESSA, Edward J. “Applying the risk principle to sex offenders: Can treatment make some sex offenders worse?", The Prison Journal, vol. 89 (2009), pp. 344-357.

${ }^{84}$ ANDREWS/BONTA, The Psychology, cit. nota n ${ }^{\circ} 54$, pp. 48 y ss.
} 
VELÁSQUEZ, Javier. "El origen del paradigma de riesgo".

autores todas las personas, infractores como no infractores, poseen ciertas necesidades o carencias, por ejemplo, algunos infractores de ley con alto riesgo de reincidencia pueden necesitar encontrar un lugar donde vivir luego de haber cumplido su condena, o bien "pueden tener baja autoestima, jaquecas crónicas o cavidades en sus dientes" ${ }^{85}$ El modelo RNR nos plantea la necesidad de identificar cuáles de estas carencias son criminógenas y cuales no. En otras palabras, si el objetivo de la intervención es reducir la reincidencia de los infractores de ley, entonces, la intervención debe determinar cual de las carencias del sujeto evaluado tienen una relación directa con su historial delictivo, o bien incidan en situaciones de riesgo que puedan derivar en la comisión de nuevos delitos. ${ }^{86}$

Esta aproximación, introduce una nueva dinámica a la hora de construir programas de intervención: Por un lado reconfigura el papel de la intervención penal buscando la utilización eficiente de los recursos, y por ende, impactando en aquellas concepciones asistencialistas de la intervención rehabilitadora. No sólo busca la obtención de resultados, sino que además acota los resultados a los objetivos de reducción del riesgo de reincidencia y, por lo mismo, busca una nueva legitimidad para la rehabilitación. Por otra parte, también evita que las intervenciones se ocupen en ciertas carencias que, si bien son relevantes desde el punto de vista de asistencia social, al no tener relación con el riesgo de reincidencia, no incidan en resultados visibles, y revivan los viejos temores y críticas de la sociedad en contra de las intervenciones. ${ }^{87}$

\subsubsection{El principio de Responsividad.}

Este principio tiene dos aspectos, un de carácter "general" y otro aspecto más "especifico", el primero dice relación con que "el programa de intervención debe ser entregado en un estilo y modo que sea consistente con las habilidades y los estilos de aprendizaje del infractor" ${ }^{88}$ Por lo anterior para Andrews y Bonta las mejores herramientas provienen de las aproximaciones cognitivas-conductuales y de aprendizaje cognoscitivo social. ${ }^{89} \mathrm{En}$ términos sencillos este principio apunta a que la intervención no puede ser entregada de una forma idéntica para todos grupos de infractores. Así, evidentemente las capacidades cognitivas y la forma en que se interviene a un adulto dista mucho de la intervención que deba realizarse a un adolescente. Es más, cuando nos referimos a distintos tipos de infractores hablamos no sólo nos referimos al nivel de riesgo, sino la edad, el sexo, la etnia y las discapacidades socio-cognitivas de éstos. Asimismo la reducción conductas de riesgo de ciertos tipos de delitos va a requerir necesariamente intervenciones diferentes. ${ }^{90}$

\footnotetext{
${ }^{85}$ ANDREWS/BONTA, The Psychology, cit. nota ${ }^{\circ}$ 54, p. 49.

${ }^{86}$ ANDREWS/BONTA, The Psychology, cit. nota n ${ }^{\circ} 54$, p. 49.

${ }^{87}$ Sobre este punto ver ROBINSON, Gwen, McNEILL, Fergus y MARUNA, Shadd, "Punishment in Society: The Improbable Persistence of Probation and Other Community Sanctions and Measures", en: SIMON, Jonathan y SPARKS, Richard (eds.), The Sage Handbook of Punishment and Society, Londres: Sage, 2013, pp. 325.

${ }_{88}$ ANDREWS/BONTA, The Psychology, cit. nota $\mathrm{n}^{\circ}$ 54, pp. 49 y ss.

${ }^{89}$ ANDREWS/BONTA, The Psychology, cit. nota n ${ }^{\circ} 54$, p. 50.

${ }^{90}$ Se puede consultar ANDREWS/BONTA, The Psychology, cit. nota $\mathrm{n}^{\circ} 54$, pp. 461 y ss., otro tanto puede verse en CONROY/MURRIE, Forensic Assessment, cit. nota ${ }^{\circ}$ 44, pp. 83 y ss. También MACKENZIE, Doris Layton, What Works in corrections: Reducing the criminal activities of offenders and delinquents, Nueva York: Cambridge University Press, 2006, pp. 65-66 y sobre cohortes especificas ver capítulos octavo (agresores sexuales), noveno (infractores adolescentes) y décimo (violencia intrafamiliar). En el mismo
} 
Polít. crim. Vol. 9, No 17 (Julio 2014), Art. 3, pp. 58-117.

[http://www.politicacriminal.cl/Vol_09/n_17/Vol9N17A3.pdf]

En lo que respecta al aspecto "específico", siguiendo la línea del principio general, se ocupa de resaltar la importancia de identificar los estilos de personalidad y cognición del sujeto que recibe la intervención de manera de que este ase adecue de la mejor persona a éste. ${ }^{91}$ En otras palabras, esta suerte de adaptabilidad que sugiere el principio de responsividad no sólo opera a la hora de construir la intervención, sino que también este debe ser un elemento a considerar a la hora de entregar dicha intervención a una persona específica. De esta forma se rescata la individualidad de cada uno de los infractores de ley que reciben una intervención, y busca entregar un servicio que realmente los respete como personas.

\section{3 ¿El triunfo de la rehabilitación?}

El relato de Cullen, en definitiva, plantea que Andrews y Bonta, entre otros psicólogos canadienses y norte americanos, construyeron una teoría sobre la rehabilitación efectiva. ${ }^{92}$ Debemos concederle a Cullen que es una buena forma de caracterizar el trabajo realizado por estos investigadores, especialmente considerando que, como ya hemos dicho, esta "construcción" tiene en su origen diversos estudios empíricos que la respaldan ${ }^{93}$ y que el modelo de RNR ha influido en investigadores fuera de Canadá. Así, a mediados de los años 90, por ejemplo, comenzaron a replicarse investigaciones de este tipo en el Reino Unido, donde se desarrolló lo que se llamó "El movimiento de ¿Qué funciona?". ${ }^{44}$ Desde este punto de vista, durante los últimos 20 años se puede apreciar una fuerte "ofensiva" por parte de psicólogos de distintos países por legitimar la rehabilitación al interior de sus sistemas penales. $^{95}$

Pero, ¿había triunfado la rehabilitación? Por lo menos aquello parecía querer plantear Cullen cuando escribió su artículo "Las 12 personas que salvaron la rehabilitación: Cómo la ciencia de la criminología hizo la diferencia", manifestando un optimismo que fue rápidamente criticado por autores como Tony Ward y Shadd Maruna. Para ellos el problema no estaba en que Cullen no tuviese razón respecto al resurgimiento de la rehabilitación como alternativa, sino que, para ellos, difícilmente puede sostenerse que la historia ha terminado, como podría desprenderse de su optimista artículo. ${ }^{96}$

Y es que, cuando se analiza el relato de Cullen a la luz de las políticas criminales que se han desarrollado en los países anglosajones, por ejemplo en el Reino Unido, uno se percata de que la rehabilitación aun se encuentra en una situación delicada frente a otras estrategias desarrolladas en las últimas décadas. Ejemplo de esto es la frágil legitimidad de las sanciones alternativas a las penas privativas de libertad; ${ }^{97}$ las adaptaciones que estas

sentido QUINSEY/HARRIS/RICE/CORMIER, Violent Offenders, cit. nota $n^{\circ} 81$, p. 83 y ss. en concreto capitulo cinco (infractores con desordenes mentales), capitulo seis (pirómanos) y capitulo séptimo (agresores sexuales).

${ }^{91}$ ANDREWS/BONTA, The Psychology, cit. nota $\mathrm{n}^{\circ}$ 54, p 50.

${ }^{92}$ CULLEN/JONSON, "Rehabilitation", cit. nota $\mathrm{n}^{\circ} 38, \mathrm{p} .318$.

${ }_{93}$ CULLEN/JONSON, "Rehabilitation", cit. nota n 38 , pp. 322 y ss.

${ }^{94}$ RAYNOR/ROBINSON, Rehabilitation, Crime And Justice, cit. nota ${ }^{\circ}$ 48, pp. 112 y ss. Y también ver ROBINSON/CROW, Offender Rehabilitation, cit. nota $\mathrm{n}^{\circ} 48$, pp. 75 y ss.

${ }^{95}$ WARD/MARUNA, Rehabilitation, cit. nota ${ }^{\circ} 11$, p. 44.

${ }^{96}$ WARD/MARUNA, Rehabilitation, cit. nota no 11, p. 9.

${ }^{97}$ ROBINSON, "Punishment", cit. nota n ${ }^{\circ} 87$, pp. 321-341. 
VELÁSQUEZ, Javier. "El origen del paradigma de riesgo".

medidas han debido sufrir para mantener su credibilidad frente a las exigencias de mayor punición de las sociedades actuales han transformando radicalmente a instituciones como la libertad condicional o la libertad vigilada de lo que era en sus orígenes. ${ }^{98}$

¿Está o no en lo correcto Cullen? La respuesta no es sencilla, por un lado Cullen tiene razón en que hoy no se puede hablar de que la rehabilitación ha muerto, pero como bien plantean Gwen Robinson, Fergus McNeill y Shadd Maruna:

“...es más preciso hablar de la "evolución” de la rehabilitación que de su sobrevivencia o renacimiento, por cuanto estos dos últimos términos implican, de alguna forma, una imagen algo estática (e imprecisa). Este proceso evolutivo ha creado visiones y formas de rehabilitación en el contexto de las sanciones en comunidad que divergen de previas encarnaciones" 99

En otras palabras, el relato de Cullen ha tenido un objetivo bastante loable, que es permitir lo que él ha llamado "reafirmar la rehabilitación"100. Y es evidente que su trabajo ha permitido no sólo la sociabilización de los éxitos del modelo RNR fuera de la disciplina de la psicología, facilitando, por tanto, que estos sean adoptados y constituidos en políticas públicas. Es más, uno no puede dejar de observar que detrás de la obra de Cullen no sólo se trata de demostrar mediante evidencia científica que la rehabilitación funciona, sino que también existe un discurso político que pretende delinear una narrativa que fuerce al poder político a adoptar decisiones basadas en la evidencia y no en el mero populismo.

En efecto, de alguna manera el trabajo de Cullen parece entender que el nudo crítico del problema se puede resolver si tan sólo construyéramos nuestras políticas públicas basándonos en la evidencia científica. Por lo que, como expone David Garland, el conflicto se situaría en conflicto entre lo técnico (científico) y este poder político que toma medidas populistas sin considerar la evidencia. ${ }^{101} \mathrm{El}$ problema está en que esta explicación que se sugiere, resulta insuficiente para explicar la manera en que han evolucionado los sistemas penales de la modernidad tardía en los últimos 30 años.

Por un lado, como señalan Robinson, McNeill y Maruna, la pregunta sobre el triunfo de la rehabilitación pareciera ser inadecuada para captar el panorama actual de ésta al interior de los sistemas penales. La tecnologías de predicción y manejo del riesgo hoy en día conviven con otros métodos de control como es el monitoreo telemático o las leyes que permiten aplicar medidas post delictuales privativas de libertad. En este sentido la rehabilitación aparece como una herramienta más dentro de un amplio abanico de medidas y tecnologías disponibles al aparato punitivo para controlar a los individuos.

En suma, el problema del relato de Cullen es su parcialidad, al buscar "reafirmar la rehabilitación" nos entrega una historia que sólo nos introduce a parte del problema, y que largamente ignora las dinámicas internas de los sistemas penales. A nuestro entender lo más complejo es que simplifica la oposición entre técnico/político, y no se hace cargo respecto

\footnotetext{
${ }^{98}$ Sobre este punto ROBINSON, "Punishment", cit. nota $\mathrm{n}^{\circ} 87$, passim.

${ }^{99}$ ROBINSON, "Punishment", cit. nota $\mathrm{n}^{\circ} 87$, p. 330

${ }^{100}$ CULLEN/GILBERT, Reaffirming Rehabilitation, cit. nota ${ }^{\circ} 39$, passim.

${ }^{101}$ GARLAND, La Cultura del Control, cit. nota ${ }^{\circ} 40$, pp. 191 y ss.
} 
Polít. crim. Vol. 9, № 17 (Julio 2014), Art. 3, pp. 58-117.

[http://www.politicacriminal.cl/Vol_09/n_17/Vol9N17A3.pdf]

de las formas en que los instrumentos de riesgo y los modelos de intervención son efectivamente utilizados y adoptados por los sistemas penales. Una cosa es que la tecnología se transforme en política pública, otra muy distinta es como dicha política pública se mantiene fiel a la tecnología en la cual se inspira.

\section{La aproximación Gubernamental al riesgo.}

Como ya señalamos al comienzo de este artículo, en esta tercera parte vamos a complementar el relato sobre los orígenes del paradigma de riesgo en el sistema penal con los estudios que se han efectuado desde una aproximación foucultiana. Estos estudios nos permitirán ampliar el contexto o trasfondo en el cual se sitúa el relato de Cullen, al permitirnos dar una mirada a la forma en que el sistema penal ha lidiado durante las últimas décadas con la predicción de reincidencia.

Desde 1970 y hasta 1984, el año de su muerte, Michel Foucault dictó la cátedra de "Historia de los sistemas de pensamiento" (Histoire des systèmes de pensée) en el Collège de Francia. Colin Gordon plantea que el objeto de esta cátedra no estaba orientado a dictar clases lectivas de un determinado programa, sino a dar cuenta del resultado de las investigaciones que llevaba Foucault. ${ }^{102}$ La relevancia de estos cursos reside en que, durante su desarrollo, Foucault retomó y refinó investigaciones previas, continuando lo que sería uno de los ejes esenciales de su obra: el análisis del poder y el desarrollo de una analítica del gobierno. ${ }^{103}$ Es en estos cursos donde Foucault formularía por primera vez el concepto de "Gubernamentalidad".

El concepto de "Gubernamentalidad" aparece por primera vez en la clase dictada el primero de febrero de 1978 como parte del curso "Seguridad, Territorio y Población" 104 (Sécurite, territoire et population), dictado entre 1977 y 1978. Esta formulación inicial, como plantea Michel Senellart, se va deslizando "de manera gradual de un sentido preciso,

${ }^{102}$ GORDON, Colin, "Governmental rationality: An introduction”, en: BURCHELL, Graham, GORDON, Colin y MILLER, Peter (Eds.), The Foucault Effect: Studies in Governamentality, Chicago: The University of Chicago Press, 1991, p. 1. En estricto rigor esta afirmación no es completamente cierta, ocurre que hasta por lo menos 1975 Foucault preparaba y estructuraba los cursos, sin embargo aquello que quitaba mucho tiempo en perjuicio de sus investigaciones. Es por ello que durante la primera clase del curso "Defender la sociedad" (Il faut défendre la société), el 7 de Enero de 1976, Foucault plantea un cambio en la estructura de los cursos, señalando que ya no ve las clases como "actividades de enseñanza, sino más bien como una especie de informes públicos de un trabajo que, por otra parte, me dejan hacer mas o menos como yo quiero". Ver FOUCAULT, Michel, Defender la sociedad: Curso en el Collège de France (1975-1976), trad. PONS, Horacio, Buenos Aires: Fondo de Cultura Económica, 1997/2000, pp. 15 y ss. Este cambio explica los motivos por los cuales, a partir de este año, los cursos se transforman en instancias impredecibles, donde los temas propuestos al inicio del curso, mutan en el transcurso del mismo, pudiendo apreciarse mejor la forma de discurrir del pensamiento de Foucault.

${ }^{103}$ BRÖCKLING, Ulrich, KRASSMANN, Sussanne y LEMKE, Thomas, "From Foucault's Lectures at the Collège de France to Studies of Governamentality: An Introduction", en: BRÖCKLING, Ulrich, KRASSMANN, Sussanne y LEMKE, Thomas (eds.), Governamentality: Current Issues and Future Challenges, Nueva York: Routledge, 2011, pp. 2 y ss.

${ }^{104}$ La transcripción del curso puede encontrarse en FOUCAULT, Seguridad, Territorio, Población, cit. nota $\mathrm{n}^{\circ}$ 27. Por otro lado el registro de audio de esas clases puede encontrarse disponible en el Archivo de Audio de la Universidad de Berkley al cual puede accederse en: http://www.lib.berkeley.edu/MRC/foucault/stp.html [Visitado 07.XI.2013]. 
VELÁSQUEZ, Javier. "El origen del paradigma de riesgo".

históricamente determinado, a una significación más general y abstracta". ${ }^{105}$ En efecto, siendo la cátedra una especie de foro en el que Foucault podía dar cuenta de la actualidad de sus investigaciones e inquietudes intelectuales, el término sería utilizado y ampliado durante el transcurso de los siguientes años. ${ }^{106}$ Así, el término se convertiría en una de las ideas centrales de los análisis de Foucault hasta su muerte. ${ }^{107}$

Así Jacques Donzelot en su artículo "La miseria de la cultura política" rescata la novedad del enfoque de trabajo de Foucault frente a otros "nuevos" estudios sobre el "poder". ${ }^{108}$ En este sentido, critica que estos discursos políticos se aproximen al análisis del poder haciendo de este "un chivo expiatorio a través de una definición restrictiva y una imagen totalmente negativa: la del funcionamiento y expansión de una instancia exterior a la sociedad, el estado, que paralizaría y destruiría la socialidad (socialité)". ${ }^{109}$ Frente a dichas aproximaciones contrapone el método de Foucault, puesto que se acerca al estudio del poder, considerándolo "como un fenómeno especifico, irreductible a un determinado sujeto (el Estado), como materialidad productiva, inteligible como cualquier otra tecnología". ${ }^{110}$

En efecto, se puede plantear que el concepto de "Gubernamentalidad" es una consecuencia de la conceptualización que Foucault hace del poder. Así en 1979, durante el curso de las "Tanner Lectures" que Foucault dictó en la Universidad de Standford, comentó

"El poder no es una sustancia. Tampoco es una propiedad misteriosa cuyo origen haya que ahondar. El poder es simplemente un particular tipo de relaciones entre individuos. (...)La principal característica del poder es que algunos hombres pueden, en mayor o menor medida, determinar la conducta de otros hombres."111

He dicho consecuencia, pues el mismo Foucault definió, ese mismo año, la "Gubernamentalidad" como "una grilla de análisis" para el estudio de las relaciones de poder que tienen por objeto conducir la conducta de los hombres. ${ }^{112}$ En este sentido, cuando Foucault se enfrenta a las relaciones de poder detrás del "gobierno de los otros" "no busca analizar las diferentes instituciones o mecanismos a través de los cuales los Estados se equipan asimismo para asegurar su sobrevivencia", ${ }^{113}$ sino que traslada el foco a las racionalidades o mentalidades gubernamentales. Vale decir, hacia "un sistema de

105 SENELLART, Michel, "Situación de los cursos", PONS, Horacio (trad.) en: FOUCAULT, Michel, Seguridad, Territorio, Población, cit. nota n ${ }^{\circ} 27$, p. 447.

${ }^{106}$ SENELLART, "Situación de los cursos", cit. nota n ${ }^{\circ} 105$, pp. 447 y ss.

${ }^{107}$ De hecho, los dos últimos cursos que dictó, entre los años 1982 hasta 1984 se denominaron "El gobierno de si y de los otros" (Le Gouvernement de soi et des autres).

${ }^{108}$ DONZELOT, "Misère de la culture politique", cit. nota n ${ }^{\circ} 28$, passim.

${ }^{109}$ DONZELOT, "Misère de la culture politique", cit. nota n ${ }^{\circ} 28$, p. 575.

${ }^{110}$ DONZELOT, "Misère de la culture politique" cit. nota $n^{\circ} 28, p .575$. Sobre el concepto de poder en Foucault ver una clara explicación del mismo en FOUCAULT, Michel, "La vérité et les formes juridiques", trad.: PRADO, J.W., en: FOUCAULT, Michel, Dits et écrits I. 1954-1975, Paris: Quarto Gallimard, 1994/2001, pp. 1510-1511. Existe una versión en español de este texto, ver: FOUCAULT, Michel, La verdad y las formas jurídicas, trad.: LYNCH, Enrique, Barcelona: Gedisa, 1978/2010, pp. 178-180. Cabe plantear la observación que tanto el texto francés como el español son traducciones del texto original en portugués, por lo que pueden existir diferencias.

${ }^{111}$ FOUCAULT, "Omnes et Singulatim", cit. nota no 27, p. 253.

${ }^{112}$ FOUCAULT, Nacimiento de la Biopolítica, cit. nota $\mathrm{n}^{\circ}$ 27, p. 218.

${ }^{113}$ FOUCAULT, "Omnes et Singulatim", cit. nota no 27, p. 242. 
Polít. crim. Vol. 9, № 17 (Julio 2014), Art. 3, pp. 58-117.

[http://www.politicacriminal.cl/Vol_09/n_17/Vol9N17A3.pdf]

pensamiento sobre la naturaleza del ejercicio del gobierno (¿Quién puede gobernar? ¿Qué es gobernar? ¿Qué o quienes son gobernados?". ${ }^{114}$ En este sentido, Pat O'Malley nos explica que:

"Las mentalidades gubernamentales son gubernamentales precisamente en el sentido de que se dirigen a modelar la conducta de aquellas cosas, eventos y sujetos que pretenden gobernar. Son en este sentido intensamente prácticas. Imaginan al mundo como gobernable: Los problemas son construidos de maneras que los hacen sujeto a soluciones practicables. De acuerdo con esto, estas mentalidades o "racionalidades de gobierno" (conjunto más o menos coherente de problemáticas, objetivos, categorías, subjetividades, etc.) están siempre vinculadas a tecnologías para hacer cosas, respuestas a la pregunta "¿Qué hacer?",115

Si bien Foucault no abordó el estudio de las tecnologías de riesgo, como ya hemos mencionado supra, ${ }^{116}$ varios de sus discípulos y colegas abordaron el estudio de estas tecnologías a través del análisis gubernamental. Desde esta aproximación nos centraremos en el análisis del fenómeno de la predicción de riesgo al interior del sistema penal.

\subsection{La predicción de reincidencia en el sistema penal.}

Como plantea O’Malley, lo central de esta línea de análisis es la comprensión del riesgo "como una tecnología de gobierno". ${ }^{117}$ En esta misma línea, Lupton señala que, para esta lectura, el riesgo "puede ser entendido como una estrategia gubernamental de poder regulatorio por el cual la población y los individuos son monitoreados y administrados". 118

Sin embargo: ¿En qué consiste el riesgo? ¿Qué es el riesgo? Decir que los instrumentos de riesgo son una tecnología de gobierno que nos permite controlar a los sujetos nada nos dice de las particularidades de este fenómeno. En otras palabras, tenemos una tecnología, tenemos el desarrollo de instrumentos predictivos $\mathrm{y}$, por su puesto, una serie de consecuencias sociales derivadas de que un sujeto sea calificado como "riesgoso", pero no obstante ello, el concepto de riesgo parece algo difuso, vago, intangible. Probablemente una de las mejores definiciones nos ha sido proporcionada por François Ewald, quien dice:

"Nada es un riesgo en si mismo; no existen los riesgos en la realidad. Pero, por otro lado, cualquier cosa puede ser un riesgo; todo depende de cómo uno analice el peligro, cómo considere un evento. Como Kant podría haberlo explicado, la categoría de riesgo es una categoría del entendimiento; no puede entregarse a la sensibilidad o a la intuición."

\footnotetext{
${ }^{114}$ GORDON, “Governmental rationality”, cit. nota $\mathrm{n}^{\mathrm{o}} 102, \mathrm{p} .3$.

115 O’MALLEY, Riesgo, Neoliberalismo y Justicia Penal, cit. nota n ${ }^{\text {o }} 33$, p. 30.

${ }^{116}$ Ver cit. notas $n^{\circ} 28$ a 32, sobre este punto ver O`MALLEY, Riesgo, Neoliberalismo y Justicia Penal, cit. nota $\mathrm{n}^{\mathbf{0}} 33$, pp. 31 y ss.

${ }^{117}$ O’MALLEY, "Riesgo", cit. nota no 33, p. 31.

${ }^{118}$ LUPTON, Risk, cit. nota ${ }^{\circ} 4$, pp. 116-117.

${ }^{119}$ EWALD, "Insurance and Risk", cit. nota n' 14, p. 199.
} 
VELÁSQUEZ, Javier. "El origen del paradigma de riesgo".

El riesgo es, bajo esta lectura, un constructo social. Surge donde el conocimiento busque generarlo, se manifiesta en los espacios que se pretende controlar, pero en la medida que no sea "invocado" este no existe, no tiene cuerpo, mucho menos alma. Con todo, la pregunta que debemos responder en segundo lugar es: Si el riesgo es un constructo social ¿Cuál es su origen? Y, lo más importante, ¿Cómo comienza a ser utilizado al interior de los sistemas penales? El relato que Cullen nos ha dado sobre el origen y el uso de los instrumentos nos responden parcialmente estas interrogantes. Sin embargo, el desarrollo de tecnologías de predicción como un método de clasificación y control de ciertas clases de infractores de ley pareciera tener un origen previo, más complejo e intrincado.

Por un lado, hay que considerar que el concepto moderno de "riesgo" debe su origen, por lo menos desde un aspecto técnico, al desarrollo del comercio marítimo durante el siglo XVII y la necesidad de regular jurídica-patrimonialmente las consecuencias de que la carga transportada fuese dañada, perdida, robada o destruida durante el viaje. Esta regulación daría pie al origen moderno de las compañías de seguros. El crecimiento de esta rama económica, especialmente en el mundo anglosajón, incidiría en el surgimiento de la necesidad de profesionalizar los estudios sobre la predicción de las variables estadísticas involucradas en el cálculo del riesgo. ${ }^{120}$ Así surge lo que se ha denominado como "ciencia actuarial". Dentro de este contexto, el concepto de "riesgo" se podía definir como "la posible ocurrencia futura de un hecho negativo el cual es objetivamente mesurable en términos de probabilidad." 121

Dicho esto, es relevante destacar que el uso de tecnologías de riesgo al interior del sistema no se inicia en los años $70 .{ }^{122}$ Como ya habíamos relatado supra, por lo menos desde los años 30 ya habían existido instrumentos de riesgo aplicados al sistema penal, como fue el caso del trabajo de Burguess ${ }^{123}$ asimismo, parte del trabajo del matrimonio Glueck también se orientó a este objetivo. ${ }^{124}$ Este punto es fundamental: si la tecnología predictiva de riesgo ya se encontraba disponible desde los años 30 ¿Por qué no fue utilizada en aquel entonces? Tenemos dos posibles respuestas: o el sistema penal sólo comenzó a predecir la conducta de los infractores de ley desde los años 70, o bien resulta que hasta esa época el sistema penal utilizaba otra tecnología para predecir el comportamiento. A nuestro entender la respuesta más acertada es que el paradigma de riesgo vino a reemplazar a la peligrosidad. Por tanto, el quid del asunto no es el surgimiento de una nueva práctica gubernamental, sino el reemplazo de una serie de mecanismos, tecnologías y prácticas predictivas, por otras.

\footnotetext{
${ }^{120}$ DOUGLAS, Mary, "Risk as a Forensic Resource: From "chance" to "danger", Daedalus, vol. 119, no 4 (1990), pp. 2 y ss. También detalladamente ver WOOD JR., Oliver G, "Evolution of the concept of Risk", The Journal of Risk and Insurance, vol. 31, n 1 (1964), pp. 83 y ss.; Además DEFERT, Daniel, "Popular Life and Insurance Technology" en: BURCHELL, Graham, GORDON, Colin y MILLER, Peter (Eds.), The Foucault Effect: Studies in Governamentality, Chicago: The University of Chicago Press, 1991, pp. 217 y ss.

${ }^{121} \mathrm{La}$ evolución del concepto en este sentido en WOOD JR., "Evolution", cit. nota n ${ }^{\circ} 120$, pp. 90 y ss.

${ }^{122}$ O'MALLEY, Pat, "Risk societies and the government of crime", en: BROWN, Mark y PRATT, John (Eds.) Dangerous offenders: Punishment and social order, Nueva York: Routledge, 2000, pp. 17- 34, passim. Ver también O’MALLEY, Riesgo, Neoliberalismo y Justicia Penal, cit. nota nº 33, pp. 167 y ss.

${ }^{123}$ Ver cit. nota $\mathrm{n}^{\circ} 37$.

${ }^{124}$ O’MALLEY, Crime and Risk, cit. nota n ${ }^{\circ}$ 4, p. 46.
} 
Polít. crim. Vol. 9, No 17 (Julio 2014), Art. 3, pp. 58-117.

[http://www.politicacriminal.cl/Vol_09/n_17/Vol9N17A3.pdf]

Surge entonces la pregunta respecto a los orígenes de las prácticas predictivas en el sistema penal. Se revela la necesidad de buscar el quiebre, el contexto que lleva a reemplazar una tecnología establecida por otra. Asimismo, este cambio, a nivel de tecnologías, plantea preguntas entorno a la permanencia y ruptura con las mentalidades gubernamentales existentes. En otras palabras: ¿Qué cambia? ¿Qué permanece igual?, ¿Qué realidades surgen producto del cambio?

\subsubsection{Genealogía de la predicción de peligrosidad.}

La progresiva introducción de los instrumentos de riesgo a partir de los años 70, como hemos relatado, no implicó la creación de prácticas de control gubernamental nuevas. El ejercicio de predecir la reincidencia de un individuo y, en función de aquello, tomar medidas basadas únicamente en dicho diagnostico, precede a la creación, introducción y perfeccionamiento de instrumentos de riesgo en los sistemas penales modernos. En rigor, las prácticas predictivas al interior de los sistemas penales se pueden rastrear a una serie de cambios en la conceptualización de la función del derecho penal a fines del siglo XIX. Son estos cambios los que consolidaron tecnologías predictivas psiquiátricas basadas en el concepto de peligrosidad.

Existe cierto consenso ${ }^{125}$ en torno a que el origen de la peligrosidad, por lo menos al interior del debate jurídico penal, surge a fines del siglo XIX y tuvo lugar dentro de lo que se conoció como "La Unión Internacional de Derecho Penal", ${ }^{126}$ específicamente de la mano del jurista belga Adolphe Prins, quien convirtió la noción de "El estado peligroso" en uno de los elementos centrales de su teoría de la defensa social. ${ }^{27}$ No obstante ello,

${ }^{125}$ Así, por ejemplo, en diversas oportunidades Luis Jiménez de Asua: JIMÉNEZ DE ASÚA, Luis, El estado peligroso del delincuente y sus consecuencias ante el derecho penal, Madrid: Editorial Reus, 1920, pp. 8 y ss.; Cuestión que reiteraría a lo largo de diversas conferencias dictadas durante los años 50, las que se encuentran recogidas en JIMÉNEZ DE ASÚA, Luis, El Criminalista: segunda serie, tomo I, Buenos Aires: Victor P. De Zavalía editor, 1955, pp. 283-284 y JIMÉNEZ DE ASÚA, Luis, El Criminalista: segunda serie, tomo II, Buenos Aires: Victor P. De Zavalía editor, 1958, pp. 106, 138-139, 254. También Foucault se refirió a este tema en FOUCALT, Michel, "L' évolution de la notion d' "Individu dangereux" dans la psychiatrie légale", Déviance et société, vol. 5 no 4 (1981), pp. 420 y ss. Entre otros se puede agregar a MIR PUIG, Santiago, Introducción a las bases del Derecho Penal, segunda edición, Buenos Aires: Editorial B de F, 1976/2002, pp. 163 y ss.; y GARCÍA-PABLOS DE MOLINA, Antonio, Tratado de Criminología: $4^{a}$ edición actualizada, corregida y aumentada, Valencia: Tirant lo Blanch, 2009, p. 423. Asimismo ver DANET, Jean, "La dangerosité, une notion criminologique, séculaire et mutante", Champ pénal, vol. 5 (2008), passim, en http://champpenal.revues.org/6013 [visitado el 01/06/2013].

${ }^{126}$ La Unión fue fundada en 1888 manteniéndose activa hasta 1915, para luego desaparecer lentamente. Se puede considerar como la antecesora espiritual de la actual "Asociación Internacional de Derecho Penal". En profundidad ver BERDUGO GOMEZ DE LA TORRE, Ignacio, La Evolución del Derecho Penal Contemporáneo y la Unión Internacional de Derecho Penal, Salamanca: Universidad Pontificia, 1982, pp. 11 y ss.

${ }_{127}$ PRINS, Adolphe, La défense sociale et Les Transformations du Droit Pénal, Paris: Misch et Thron editores, 1910. Sobre el estado peligroso ver pp. 70 y ss., sobre la teoría de la defensa social, ver pp. 36 y ss. Existen dos traducciones al español, ver PRINS, Adolphe, La defensa social y las transformaciones del derecho penal, trad. CASTEJON y MARTÍNEZ DE ARIZALA, Federico, Madrid, Hijos de Reus, editores, 1912. La otra, más reciente: PRINS, Adolphe, La defensa social y las transformaciones del derecho penal, trad.: CODINO, Rodrigo, Buenos Aires: Ediar, 2010. Sobre la obra de Prins, ver CORNIL, Paul, "Adolphe Prins et la défense sociale", Revue Internationale de Droit Pénal, vol. 22, n 2 y 3 (1951), pp. 177-189, passim; TULKENS, Françoise, "Un chapitre de l'histoire des réformateurs. Adolphe Prins et la défense 
VELÁSQUEZ, Javier. "El origen del paradigma de riesgo".

estrictamente hablando, lo que Prins hace es darle una estructura conceptual a una noción, o conjunto de ideas si se prefiere, que ya se encontraba presente en los debates políticocriminales y criminológicos del siglo XIX. En este sentido, parte de las ideas elaboradas por Prins ya se encontraban presente, a su vez, en el concepto de la "temibilitá" de Raffaele Garofalo. ${ }^{128}$

Para Foucault, el desarrollo de la noción de peligrosidad al interior de los sistemas penales se encuentra estrechamente vinculado con la influencia que la psiquiatría comenzó a ejercer en dicho campo a comienzos del siglo XIX, específicamente entre los años 1800 y $1835 .{ }^{129}$ Foucault nos dice que el derecho penal moderno, el que surge a fines del siglo XVIII y comienzos del siglo XIX bajo la influencia de Becaria y Bentham, no modificó ni estableció nuevos mecanismos para regular el diagnóstico de la imputabilidad, por lo que gran parte del inicio de la relación entre la psiquiatría y el derecho surge producto de las dificultades prácticas y no de una teorización que pretendiera establecer nuevos mecanismos en que se relacionarían ambas disciplinas. ${ }^{130}$

En concreto, Foucault nos plantea que las dificultades para la determinación de la imputabilidad no provinieron de aquellos casos en los cuales se contaba con evidencia patente de la existencia de deficiencias cognitivas en el sujeto, sino por el contrario, cuando individuos sin rastro aparente de enfermedad mental alguna, se volvían autores de hechos completamente inexplicables, particularmente horribles. Así, por ejemplo, relata el caso Sélestat: En 1817, durante un invierno muy crudo, una campesina, aprovechando que su marido había ido al pueblo, da muerte a su hija, luego y antes de deshacerse del cuerpo, le corta un muslo y prepara una sopa de coles con él. ${ }^{131}$ La ausencia absoluta de un historial de violencia o de comportamientos que permitieran a los jueces inmediatamente

sociale", en: TULKENS, Françoise, Généalogie de la défense sociale en Belgique (1880-1914) Travaux du séminaire qui s' est tenu à L' Université Catholique de Louvain sous la direction de Michel Foucault, Bruselas: Story-Scientia, 1988, pp. 17-48, passim.

${ }^{128}$ Expuesta por primera vez en su libro "Di un criterio positivo della penalità de 1880. Este concepto contenía, en lo sustancial, varias de las ideas que convergerían en la idea de la peligrosidad, ver GAROFALO, Raffaele, Di un criterio positivo della penalità, Napoles: Doctor Leonardo Villardi, editor, 1880, p. 53.

${ }^{129}$ FOUCAULT, "L' evolution", cit. nota $n^{\circ} 125$, p. 404. En lo relativo a este texto cabe hacer un par de prevenciones: El origen de este artículo se encuentra en una charla que dictó Canadá en un simposio de Derecho y Psiquiatría. En 1978 apareció una traducción al inglés en: FOUCAULT, Michel, "About the concept of the "dangerous individual" in 19th-century legal psychiatry", trad. BAUDOT, Alain y COUCHMAN, Jane, International Journal of Law and Psychiatry, Vol. 1 (1978) pp. 1-18. Sin embargo, dicha traducción difiere en cuanto a la estructura, orden de ciertos párrafos e incluso en parte del contenido con la versión francesa publicada en 1981. Por otro lado, la versión que fue recogida en el libro recopilatorio de textos de Foucault "Dits et écrits", si bien sitúa como fecha de origen del texto el año 1978, el texto publicado es una reimpresión de la versión francesa de 1981, y, por tanto, difiere de la versión en ingles ya mencionada. En este contexto, en este trabajo optamos por citar la versión en francés y no la traducción en ingles. La versión recopilada puede encontrarse en FOUCAULT, Michel, "L' évolution de la notion d' "Individu dangereux" Dans la psychiatrie légale", en: FOUCAULT, Michel, Dits et écrits II. 1976-1988, Paris: Quarto Gallimard, 1994/2001, pp. 443-464.

${ }^{130}$ FOUCAULT, "L' evolution", cit. nota ${ }^{\circ} 125$, pp. 411-412. Sobre este punto ver RENNEVILLE, Marc, Crime et Folie: Deux sicles d' enquêtes médicales et judiciaires, Paris: Fayard, 2003, pp. 45 y ss.

${ }^{131}$ FOUCAULT, “L' evolution”, cit. nota n ${ }^{\circ} 125$, pp. 404 y ss. 
Polít. crim. Vol. 9, No 17 (Julio 2014), Art. 3, pp. 58-117.

[http://www.politicacriminal.cl/Vol_09/n_17/Vol9N17A3.pdf]

considerarla inimputable llevó a la necesidad de discutir sobre la existencia o no de alguna patología mental en ella. ${ }^{132}$

Esta relación entre el sistema penal y la psiquiatría se irá estrechando al punto que, en Francia, durante la Monarquía de Julio, se publicará la "Ley no 7443 sobre los "alienados" del 30 de Junio de 1838”. Esta ley no sólo establecerá y regulará la instituciones publicas y privadas para tratar a los "alienados" sino que también dará origen a mecanismos administrativos destinados a permitir el internamiento "ordenado por la autoridad pública" cuando el estado de la enfermedad mental, diagnosticada o no, "comprometa el orden publico o la seguridad de las personas". ${ }^{133}$ Particularmente relevante es su artículo 19, que planteaba que en casos de "peligro inminente", el que podía ser acreditado por un medico (psiquiatra) o por "la notoriedad publica" de la conducta del sujeto, facultaba a la policía tomar "todas las medidas provisorias necesarias". La norma no sólo abrió la puerta para que los psiquiatras se convirtieran en verdaderos funcionarios de la higiene pública, sino que consolidó la relación de dicha disciplina al interior de los dispositivos de control, en especial, se les otorgó la legitimidad para determinar quien o quienes eran inimputables. ${ }^{134}$

Como se podrá apreciar, estas breves consideraciones sobre los inicios de institucionalización del poder-saber psiquiátrico para que no sólo pudieren identificar a los sujetos inimputables, sino que además ejercieran una suerte de protección de la sociedad frente a los individuos "anormales" aun se encuentra lejos de una conceptualización patológica de la criminalidad. Esta ley se mueve aun en la excepcionalidad de la locura y, en principio, no choca con el derecho penal clásico que castiga por el delito cometido y no por las tendencias internas del individuo. La pregunta entonces que debemos formularnos es ¿Cuándo surge la noción de imputable peligroso? La respuesta, curiosamente, es que la noción de imputable peligroso comienza a desarrollarse con la aparición de una noción fuera de los ámbitos del derecho y de la psiquiatría, sino con la irrupción de la idea de "Clases Peligrosas".

\subsubsection{De las "Clases Peligrosas" a los "Individuos Peligrosos".}

Los orígenes de la noción de "Clase Peligrosa" podemos rastrearla a este mismo periodo de la historia francesa: La Monarquía de Julio (1830-1848). Aun cuando no nos ha sido posible determinar quien o como se acuñó el término, si se puede afirmar que su utilización cobró bastante relevancia hacia fines de la década de 1830. En efecto, para 1838 el uso del

\footnotetext{
${ }^{132}$ FOUCAULT, Michel, Los Anormales, trad.: PONS, Horacio, Buenos Aires: Fondo de Cultura Económica, 1999/2000, pp. 109-110 y 131-132. Otro ejemplo de las discusiones sobre imputabilidad, en este periodo que Foucault puede verse en la obra editada por Foucault en 1976 sobre el caso de Pierre Rivière. Existe una versión incompleta del texto original editado por Foucault traducido al español, este texto incluye todos los informes del caso, pero prescinde de los artículos que fueron publicados por Foucault y sus discípulos comentando el caso. FOUCAULT, Michel (ed.), Yo, Pierre Rivière, habiendo degollado a mi madre, a mi hermana y a mi hermano.... Un caso de parricidio del siglo XIX presentado por Michel Foucault, VINYOLI, Joan, (trad.), Barcelona: Tusquets editores, 1976/2009.

133 Art. 18, sección II, Ley $\mathrm{n}^{\circ}$ 7443. El texto íntegro de la ley puede encontrarse en http://elearning.trree.org/pluginfile.php/34816/mod folder/content/0/09_Loi_francaise esquirol.pdf [Visitado 18.03.2014].

${ }^{134}$ En detalle, ver FOUCAULT, Los Anormales, cit. nota n ${ }^{\circ} 132$ pp. 132 y ss.
} 
VELÁSQUEZ, Javier. "El origen del paradigma de riesgo".

término llevó al "Instituto de Francia" a convocar un concurso, cuyo ganador sería quien, mediante el método positivo, pudiera describir a aquella parte de la población que "forma una clase peligrosa por sus vicios, su ignorancia y su miseria". ${ }^{135}$ El ganador de este concurso fue un antiguo policía llamado Honoré Fregier, cuya obra se publicó en 1840, y quien a la sazón, respondió a la pregunta formulada por el concurso de la siguiente manera:

"Las clases pobres y viciosas siempre han sido y serán uno de las fuentes más productivas de todo tipo de malhechores: A ellos son quienes, nosotros, designamos muy particularmente con el titulo de clases peligrosas; aun cuando el vicio no se encuentre acompañado de perversidad, al aliarse con la pobreza del mismo individuo, el es una justa fuente de miedo para la sociedad, el es peligroso. El peligro social aumenta y se vuelve acuciante, cuando la condición del pobre se deteriora por el vicio, lo que empeora con el ocio. Desde el momento que el pobre, librado a las malas pasiones, deja de trabajar, él se convierte en un enemigo de la sociedad, ya que hace caso omiso de la ley suprema, que es el trabajo."136

Johanes Scheu planea que el concepto de "Clase Peligrosa" emerge en una borrosa intersección entre dos campos socio-epistemológicos, esto es, entre el concepto psiquiátrico-patológico vinculado al "loco peligroso" y el miedo de la burguesía a aquella masa anónima y violenta conformada por la clase trabajadora ${ }^{137}$ En efecto, el trasfondo político-social francés fue sumamente inestable durante gran parte del siglo XIX a lo que sumó el surgimiento de la cuestión social y las consecuencias de la revolución industrial. Así se generó un terreno fértil para una percepción de crisis, y en particular, permitió el surgimiento de un terreno fértil para una conceptualización patológica del fenómeno delictual. ${ }^{138}$

En este sentido, como plantea Foucault, lo relevante está en comprender que la evolución de lo que se entiende por enfermedad mental fue ampliándose lentamente. Así cobró fuerza, al interior de la psiquiatría francesa, la teoría de la "degeneración", ${ }^{139}$ como una forma de

${ }^{135}$ Ver FRÉGIER, Honoré-Antoine, Des Classes Dangereuses de la Population Dans Les Grandes Villes et Des Moyens de les Rendre Meilleures, tomo uno, Paris: Librería de la Academia Real de Medicina, 1840, p. v. Sobre este punto ver también ZAFFARONI, Eugenio Raul, "Las "Clases Peligrosas": El fracaso de un discurso policial pre-positivista", Revista Seqüência, n 51 (2005), p. 144.

${ }^{136}$ FRÉGIER, Des Classes, cit. nota ${ }^{\circ} 135$, p. 7.

${ }^{137}$ SCHEU, Johannes, "Dangerous classes: tracing back an epistemological fear", Distinktion: Scandinavian Journal of Social Theory, vol. 12, nº 2 (2011), p. 117.

${ }^{138}$ Si bien Foucault no entra en este análisis particular, alude a el en FOUCAULT, "L'evolution", cit. nota no 125, pp. 414-416. Ver también la clase del 7 de Marzo de 1973 de su cursos de la Sociedad Punitiva, FOUCAULT, Michel, La Société Punitive: Cours au Collège de France: 1972-1973, Paris: Gallimard, 2013, pp. 175 y ss.

${ }^{139}$ FOUCAULT, "L'evolution", cit. nota no 125, p. 414. Ver especialmente DEBUYST, Christian, "La notion de Dégénérescence. Sa progressive mise en place", en: DEBUYST, Christian, DIGNEFFE, Françoise y PIRES, Alvaro, Histoire des savoirs sur le crime et la peine: Des savoirs diffus à la notion de criminelle, Bruselas: Ediciones Larcier, 2008, pp. 289-314; DEBUYST, Christian, "La psychiatrie Française: Auteur de la notion de Dégénérescence" en: DEBUYST, Christian, DIGNEFFE, Françoise y PIRES, Alvaro, Histoire des savoirs sur le crime et la peine: La rationalité pénale et la naissance de la criminologie, Bruselas: Ediciones Larcier, 2008, pp. 454-472; PICK, Daniel, Faces of degeneration: A European Disorder, c. 1848-c. 1918, Cambridge: Cambridge University Press, pp. 37-59; y también NYE, Robert, Crime, Madness \& Politics in modern France: The medical concept of national decline, Nueva Jersey: Princeton University Press, 1984, pp. 119 y ss. 
Polít. crim. Vol. 9, No 17 (Julio 2014), Art. 3, pp. 58-117.

[http://www.politicacriminal.cl/Vol_09/n_17/Vol9N17A3.pdf]

explicar no sólo la locura sino el decaimiento de la nación, e incluso como una manera de comprender la existencia un supuesto embrutecimiento generalizado y violento por parte de la clase obrera. ${ }^{140}$ La labor higienicista de los psiquiatras, los lleva a tratar de abordar y explicar todos los problemas sociales desde el prisma de su disciplina. Más pronto que tarde, la cuestión social, comienza a ser vista como un consecuencia de un "algo" patológico, e incluso, las diferencias entre "clase social" pasan a ser vistas como diferencias raciales. ${ }^{141}$

Así, la percepción social burguesa de aquello que le amenaza se transforma en el objeto real de preocupación, y por tanto, lo que se vuelve necesario estudiar y comprender. En otras palabras, el miedo a la clase obrera, miedo que no sólo contiene el temor al delito, sino que también a la insurrección, a la in-civilización y a la barbarie. La solución de los psiquiatras es buscar una explicación a la violencia, no a través de la comprensión del fenómeno desde una perspectiva socio-política, sino que por el contrario, se precisa la negación de todo carácter político como causa del conflicto, y el abordamiento del problema se realiza desde el ámbito de la anormalidad. ${ }^{142}$ Por tanto, en la "clase trabajadora" se encuentra el origen de todos los males, no sólo se le imputan todos los delitos que la clase burguesa padece, sino que también se la responsabiliza de su propia miseria. ${ }^{143}$

Otro aspecto relevante es que, si bien hemos dicho que la noción de clase peligrosa se puede rastrear en Francia, en mayor o menor medida, el trabajo de Fregier llevó a otros autores a investigar la existencia de las clases peligrosas fuera de Francia. Así surgirían investigaciones sociales análogas, por ejemplo en el Reino Unido los trabajos de Mary Carpenter o Henry Mayhew, ${ }^{144}$ o Friedrich Christian Benedikt Avé- Lallement en Alemania con su "Gaunertum", todos identificando una sub-clase de sujetos "peligrosos" pertenecientes a las clases trabajadoras de sus respectivas realidades sociales. ${ }^{145}$

\footnotetext{
${ }^{140}$ Sobre este punto PICK, Faces of degeneration, cit. nota ${ }^{\circ}$ 139, p. 52, y NYE, Crime, Madness \& Politics, cit. nota $\mathrm{n}^{\circ} 139$, p. 62.

${ }_{141}$ LAGRANGE, Hugues, La civilité a l'épreuve: Crime et sentiment d'insécurité, Paris: Presses Universitaires de France, 1995, p. 129, especialmente pp. 122-133. También ver CHEVALIER, Louis, Laboring Classes \& Dangerous Classes: In Paris During the First Half of the Nineteenth Century, trad.: JELLINEK, Frank, Nueva York: Howard Ferting, 1958/1973, pp. 359 y ss. Tambien LIDSKY, Paul, Les écrivains contre la Commune: Postfacé inédite, Paris: Editions La Découverte, 2010, pp. 23 y ss.

${ }^{142}$ Un ejemplo podemos encontrarlo en la obra de Paul Lidsky, quien analiza las reacciones de los literatos franceses hacia la comuna de Paris. Ver particularmente LIDSKY, Les écrivains, cit. nota ${ }^{\circ} 141$, pp. 45 y ss. Otro tanto puede apreciarse en la obra de Morel, ver PICK, Faces of degeneration, cit. nota no 139, pp. 52 y ss.

${ }^{143}$ LAGRANGE, La civilité, cit. nota $\mathrm{n}^{\circ}$ 141, pp. $95-97$ y 99 y ss. También GARLAND, Punishment and Welfare, cit. nota $\mathrm{n}^{\circ} 40$, pp. 40 y ss.

${ }^{144}$ Mary Carpenter publicaría en 1851 su libro "Reformatory Schools: For the Children of the Perishing and Dangerous Classes and for Juvenile Offenders". Mayhew en cambio haría lo suyo en 1861 con "The London Underworld in the Victorian Period". Ver WETZELL, Richard, Inventing the Criminal: A history of German criminology, 1880-1945, Chapel Hill: The University of North Carolina Press, 2000, p. 26.

${ }^{145}$ WETZELL, Inventing the Criminal, cit. nota $\mathrm{n}^{\circ} 144$, p. 26. También se puede consultar DIGNEFFE, Françoise, "Problèmes sociaux et représentations du crime et du criminel: De Howard (1777) à Engels (1845)" en: DEBUYST, Christian, DIGNEFFE, Françoise y PIRES, Alvaro, Histoire des savoirs sur le crime et la peine: Des savoirs diffus à la notion de criminelle, Bruselas: Ediciones Larcier, 2008, pp. 145-228, particularmente ver pp. 172 y ss.
} 
VELÁSQUEZ, Javier. "El origen del paradigma de riesgo".

Finalmente, cabe plantear que el desplazamiento de la noción de "Clase Peligrosa" a "Individuo Peligroso", fue una de las consecuencias de la ampliación del concepto de enfermedad mental de la psiquiatría. En concreto, la necesidad de diseccionar a la masa anónima y estudiar lo específicamente patológico de los sujetos pertenecientes a dicha clase. En este sentido, la psiquiatría pasa a evaluar a los sujetos de forma individual, por lo que el estudio pronto pasa a buscar la característica que vuelve a determinado sujeto peligroso. A lo anterior se sumó el surgimiento, de los estudios antropológicos, específicamente dedicados al estudio del hombre criminal. Así, en este contexto, con la aparición de la obra de Lombroso, y su correspondiente debate, se consolidó la idea de la existencia de un "homo delincuente". ${ }^{146}$

\subsubsection{El delincuente incorregible.}

A partir de 1870 se comienza a vivir un particular periodo de tranquilidad política en los países Europeos. Por un lado Italia y Alemania consolidan sus procesos de unificación y comienzan a organizar sus aparatos gubernamentales para hacerse cargo de la nueva realidad política que enfrentan. Por otro lado, países como Bélgica y Holanda llevan un par de décadas con regímenes de gobierno estables y para que hablar del "Imperio Británico" que se encuentra inmerso en la gloriosa "época victoriana". El caso Frances, es particular, precisamente por que la estabilidad política sólo llega con posterioridad a la gran crisis que provocó la derrota a manos de los prusianos y que desembocaría en la Comuna de Paris. Con todo, la tercera republica significaría el mayor periodo de estabilidad política desde la revolución de 1789, estabilidad que se extendería hasta 1940.

En este sentido, lo relevante es que estos estados modernos van a comenzar a rearticularse de manera interna, a hacerse cargo de los problemas derivados de las revoluciones industriales, a convertirse, al fin y al cabo, en estados nacionales. Uno de los objetivos fundamentales de esta rearticulación es la mantención del orden interno y, por tanto, el control de la delincuencia y los posibles brotes protestas sociales se volverán un tema central. ${ }^{147}$ A lo anterior se debe considerar el auge del modelo positivista, lo que sumado a la relativa paz entre los distintos estados, permitirá que el debate de la criminalidad florezca en foros internacionales que irán cobrando cada vez más relevancia e influencia ${ }^{148}$. Más allá de las particulares y especificas formas en que los debates se acojan al interior de los diversos sistemas penales, es posible encontrar influencias reciprocas en las formas y reacciones que diversos países adoptan para enfrentar el mismo fenómeno.

\footnotetext{
${ }^{146}$ LOMBROSO, Cesare, L'uomo delinquente : studiato in rapporto alla antropologia, alla medicina legale ed alle discipline carcerarie, Milan: Ulrico Hoepli editor, 1876. Sobre la obra de Lombroso ver WOLFGANG, Marvin E., "Pioneers in Criminology: Cesare Lombroso (1835-1909), The Journal of Criminal Law, Criminology, and Police Science, vol. 52, nº 4 (1961), pp. 361-391. Más recientemente GIBSON, Mary S., "Cesare Lombroso and Italian criminology: theory and politics", en: BECKER, Peter y WETZELL, Richard (Eds.), Criminals and their Scientists: The History of Criminology in International Perspective, Nueva York: Cambridge University Press, 2006, pp. 137-158.

${ }^{147}$ En sentido similar GIDDENS, Consecuencias de la modernidad, cit. nota ${ }^{\circ} 6$ pp. 60 y ss.

${ }^{148}$ Como ocurre con la "Unión Internacional de Derecho Penal" de Von Liszt, ver GARLAND, Punishment and Welfare, cit. nota $\mathrm{n}^{\circ}$ 40, p. 173. BERDUGO GOMEZ DE LA TORRE, La Evolución del Derecho Penal, cit. nota $\mathrm{n}^{\circ} 126$, pp. 11 y ss.
} 
Polít. crim. Vol. 9, No 17 (Julio 2014), Art. 3, pp. 58-117.

[http://www.politicacriminal.cl/Vol_09/n_17/Vol9N17A3.pdf]

A partir de esta época el conocimiento científico, se había abocado a tratar de aportar una explicación "científica" al fenómeno de la "Clase Peligrosa". El método era básicamente tratar de encontrar en el delincuente una las razones o motivos de su "peligrosidad". En otras palabras, se buscaba dar legitimidad a la percepción de peligrosidad en base a teorías que permitieran confirmar la maldad de estos sujetos. A partir de 1870, a la psiquiatría se le suma la antropología, y con ello, la búsqueda de una explicación para la "anormalidad" cobraría renovada fuerza.

Así, el trabajo de Lombroso fue sumamente importante para dar una legitimidad a la anormalidad del delincuente. Una de las ideas centrales de su obra fue atribuir la gran mayoría de los delitos a la existencia de un "hombre delincuente", cuya anormalidad, demostrada por su conducta salvaje y violenta, se explicaba por un motivo antropológico: El atavismo. ${ }^{149}$

En este sentido lo relevante es dejar claro que los "científicos", comenzaron a desarrollar discursos para legitimar la percepción social de una diferencia, casi racial, entre el burgués "normal" y el delincuente "anormal". ${ }^{150}$ Percepción que, por lo demás, esconde una identificación entre delincuente y el sujeto que pertenece a la clase obrera ${ }^{151}$ y que por lo mismo era sintomática de otros conflictos sociales que en estricto rigor no tenían relación con la delincuencia, pero que era necesario controlar mediante los mecanismos disciplinarios del aparato penal.

Con todo, el punto de quiebre para las practicas gubernamentales de esta época, viene con la crisis de la prisión derivada de la reincidencia. En este sentido, como expone David Garland, la crisis de la prisión se explica particularmente por la confluencia de estos factores, anteriormente mencionados, que revelan el fracaso de las prácticas gubernamentales para disciplinar a los "delincuentes". La sola sospecha de la existencia de sujetos indisciplinables hacía tambalear los cimientos de la institución penal, y sembrar el miedo. En este contexto, Garland sitúa la crisis a partir de $1890,{ }^{152}$ donde la reincidencia se transforma en el nudo crítico de todo el sistema penal, llegando a ser calificados los reincidentes como la "gangrena criminal". 153

\footnotetext{
${ }^{149}$ En otras palabras, Lombroso clamaba haber descubierto que estos sujetos eran anormales por una razón biológica, en términos simples, eran sujetos involucionados, y por lo mismo, sus comportamiento violento era el que nuestros antepasados habían dejado atrás con la evolución y la civilización. Sobre el Atavismo en su quinta edición ver LOMBROSO, Cesare, L'uomo delinquente, cit. nota ${ }^{\circ} 146$, p. 373.

${ }^{150}$ FOUCAULT, Michel, "Vigilar y castigar: nacimiento de la prisión", Trad. GARZÓN DEL CAMINO, Aurelio, Buenos Aires: Siglo Veintiuno Editores Argentina, 1975/2008, p. 116.

151 LAGRANGE, La civilité, cit. nota $\mathrm{n}^{\circ}$ 141, p. 136, pp. 122 y ss. Confusión que sólo parece ir "despejándose" hacía comienzos del siglo XX como postula Dominique Kalifa, ver KALIFA, Dominique, Crime et culture au XIX ${ }^{a}$ siècle, Paris: Editions Perrin, 2005, p. 115 y ss. También en este sentido BERT, Jean-François, "Évolution (récente) et critique (politique) du concept de dangerosité dans la criminologie: la mise en perspective foucaldienne" en: MBANZOULOU, Paul, BAZEX, Hélène, RAZAC, Olivier y ALVAREZ Joséfina, Les nouvelles figures de la dangerosité, Paris: L' Hartmattan, 2008, p. 160.

${ }^{152}$ GARLAND, Punishment and Welfare, cit. nota $\mathrm{n}^{\circ} 40$, pp. 59 y ss. Para comprender la crítica en su contexto ver FOUCAULT, "Vigilar y castigar", cit. nota $\mathrm{n}^{\circ} 150$, pp. 315 y ss.

${ }^{153}$ CHÂLES-COURTINE, Sylvie, "De la bosse "du crime" aux expertises médico-judiciaires: une analyse socio-historique de la construction sociale de la dangerosité" en: MBANZOULOU, Paul, BAZEX, Hélène,
} 
VELÁSQUEZ, Javier. "El origen del paradigma de riesgo".

La reincidencia, entonces, pasa a ser el barómetro fundamental de la necesidad de "defensa" de la sociedad en contra de los infractores de ley. Así, por ejemplo, Franz von Liszt, escribiría en su "Programa de Marburgo" que "los reincidentes constituyen la mayoría de los delincuentes, y los irrecuperables, la mayoría de los reincidentes". ${ }^{154} \mathrm{El}$ mismo fenómeno se repetía en Bélgica, según relataba Adolphe Prins, en su libro Ciencia Penal y Derecho positivo de 1899, donde sostuvo que entre el 75 y $80 \%$ de la población reclusa eran delincuentes habituales, respecto de los cuales a la fecha, el legislador no había sabido abordar con la suficiente intensidad. ${ }^{155}$ Por su parte Enrico Ferri, en su libro Sociologia Criminae de 1900, llegaría afirmar que la tasa de reincidencia en Europa se encontraba entre el 50 y $60 \% .{ }^{156}$ No obstante lo anterior, en lo que respecta al Reino Unido, el debate presentó un matiz diferente, dado que se había constatado un descenso de la criminalidad, pero precisamente por dicho descenso la atención pública se dirigió en contra de los delincuentes habituales, lo que daría pie, como veremos a una reforma sustancial de régimen penitenciario ingles. ${ }^{157}$

El problema, sin embargo, no se encontraba precisamente en la ausencia de mecanismos para agravar la sanción de los reincidentes, el derecho penal "clásico" siempre ha contó con normas que agravaban la reincidencia. ${ }^{158}$ La gran diferencia estaba dada por lo que Marc Ancel denominó como la "brusca aparición del hombre individual", 159 en otras palabras, por la nueva conceptualización del delincuente como:

“...enemigo de todos, y que todos tienen interés en perseguir, cae fuera del pacto, se descalifica como ciudadano y surge como portador de un fragmento salvaje de naturaleza; aparece como el malvado, el monstruo, el loco quizá, el enfermo y pronto el "anormal", 60

La peligrosidad, entonces, reside en la indisciplina, en la incorregibilidad. Es peligroso porque no puede ser normalizado, y no puede normalizarse por que es parte de su naturaleza ser anormal. Por lo anterior, no es de extrañar que, pese a los constantes debates en la esfera criminológica, casi todas las explicaciones elaboradas en esta época sobre el comportamiento delictual, en mayor o menor, concibieran al delincuente como un sujeto anormal. ${ }^{161} \mathrm{Y}$, finalmente, soslayando la explicación para al fenómeno delictual, a nivel

RAZAC, Olivier y ALVAREZ Joséfina, Les nouvelles figures de la dangerosité, Paris: L’ Hartmattan, 2008, p. 30 .

${ }^{154}$ VON LISZT, Franz, La idea de fin en el Derecho Penal, trad.: AIMONE, Enrique, Valparaíso: Edeval, 1984 , pp. 116 y ss.

${ }^{155}$ PRINS, Adolphe, Science pénale et Droit positif, Bruselas: Bruylant-Christoph \& Cia. editores, 1899, p. 306.

${ }^{156}$ FERRI, Enrico, Sociologia Criminale, cuarta edición, Turin: Fratelli Boca Editori, 1900, pp. 204 y ss.

${ }^{157}$ RADZINOWICZ, Leon y HOOD, Roger, "Incapacitating the Habitual Criminal: The English Experience", Michigan Law Review, vol. 78, $\mathrm{n}^{\circ} 8$ (1980), pp. 1305-1389.

${ }^{158}$ FOUCAULT, "Vigilar y castigar", cit. nota $\mathrm{n}^{\circ} 150$, p. 116.

159 ANCEL, Marc, La nueva defensa social (un movimiento de política criminal humanista), trad. FERNANDEZ, Francisco y GARCIA, Delia, Buenos Aires: La Ley, 1961, p. 50.

${ }^{160}$ FOUCAULT, "Vigilar y castigar", cit. nota no 150 , p. 116. En términos similares LAGRANGE, La civilité, cit. nota $\mathrm{n}^{\circ} 141$, pp. 95-96.

${ }^{161}$ Ver HACKING, Ian, The taming of chance, Cambridge: Cambridge University Press, 1990, pp. 175-176. 
Polít. crim. Vol. 9, No 17 (Julio 2014), Art. 3, pp. 58-117.

[http://www.politicacriminal.cl/Vol_09/n_17/Vol9N17A3.pdf]

práctico, el resultado era el mismo: "El es peligroso". ${ }^{162}$ Pero ¿A quien iba dirigido este temor? ¿Quién es el delincuente incorregible para los criminólogos del siglo XIX? La respuesta es, por cierto, trágica, puesto que el reincidente no es otro que el delincuente "habitual", el pequeño delincuente contra la propiedad, sea que fuere carterista o un timador de poca monta. ${ }^{163}$

Es así, finalmente, es como llegamos, por un lado, al trabajo de Franz Von Liszt, Gerard Van Hamel y Adolphe Prins, y su Unión Internacional de Derecho Penal. Fue este foro internacional el que tuvo la particularidad de buscar una forma jurídica para lidiar con los delincuentes peligrosos. ${ }^{164}$ Para 1939, el fruto de este debate significó que casi todos los países Europeos habían adoptado medidas de seguridad post delictuales o penas indeterminadas para lidiar con los individuos peligrosos. ${ }^{165}$

En suma el origen del debate penal y que termina creando las leyes basadas en la peligrosidad, aparentemente, es la búsqueda de mecanismos de control bio-político para defender a la sociedad del "enemigo" interno. La búsqueda de estrategias de inocuización en función del fracaso de las tecnologías vigentes de disciplina. Es necesario acoger el saber psiquiátrico o criminológico para diagnosticar, identificar y separar a estos sujetos anormales del resto de la sociedad tanto como sea posible.

Dijimos que esta explicación es aparente, puesto que, como explica el sociólogo JeanFrançois Bert:

"Detrás de la "peligrosidad" y la excesiva dramatización de la criminalidad, se encuentra una realidad política muy diferente que, para Foucault, fue capaz de aprovechar estratégicamente la "peligrosidad" para reforzar la intolerancia social, por ejemplo al tratar de hacer que los pobres o criminales fuesen totalmente responsables de su situación, pero especialmente, al aumentar el potencial represivo."

Lo anterior revela que la existencia de la peligrosidad tiene dos aristas: Por un lado tenemos esta estrategia gubernamental de control de un grupo, considerado anormal, y que

\footnotetext{
${ }^{162}$ De particular interés es la tesis de Laurent Mucchielli, sobre el falso antagonismo entre la escuela positiva Italiana y la escuela francesa de Lyon. Ver MUCCHIELLI, Laurent, "Hérédite et milieu social: le fauxantagonisme franco-italien", en: MUCCHIELLI, Laurent (ed.), Histoire de la Criminologie Française, Paris: Editions L' Harmattan, pp. 189-214, passim. En términos simples, para este trabajo, lo relevante se encuentra en que, más allá de las diferencias metodologías y teóricas, en ambas escuelas se podría encontrar un discurso que construía la criminalidad sobre la base de una anormalidad, la que podía deberse al atavismo o bien a la teoría de la degeneración. Un interesante aspecto de este debate puede encontrarse en RENNEVILLE, Marc "La réception de Lombroso en France (1880-1900)" en: MUCCHIELLI, Laurent (ed.), Histoire de la Criminologie Française, Paris: Editions L' Harmattan, pp.107-135, ver particularmente pp. 124 y ss.

163 VON LISZT, La idea de fin, cit. nota $\mathrm{n}^{\circ}$ 154, pp. 120-121. Ver también PRATT, Governing the Dangerous, cit. nota $\mathrm{n}^{\circ} 32$, p. 23. En este mismo sentido en RADZINOWICZ/HOOD, "Incapacitating the Habitual Criminal", cit. nota $\mathrm{n}^{\circ} 157$, pp. 1353 y ss.

${ }^{164}$ Sobre este punto, latamente JIMENEZ DE ASUA, El estado peligroso, cit. nota ${ }^{\circ} 125$, pp. 54 y ss. también ver BERDUGO, BERDUGO GOMEZ DE LA TORRE, La Evolución del Derecho Penal,, cit. nota $\mathrm{n}^{\circ} 126$, pp. 49 y ss.

${ }^{165}$ RADZINOWICZ, Leon, “The Persistent Offender”, Cambridge Law Journal, vol. 7 (1939), pp. 68-79, p. 71 y RADZINOWICZ/HOOD, "Incapacitating the Habitual Criminal”, cit. nota no 157, p. 1381.

${ }^{166}$ BERT, "Évolution et critique", cit. nota no 151, p. 160.
} 
VELÁSQUEZ, Javier. "El origen del paradigma de riesgo".

precisamente bajo este discurso es excluido, relegado y, en definitiva, aislado. Pero por otra parte tenemos el desarrollo de un discurso hacia la sociedad, el que viene a reforzar los sentimientos de inseguridad, y mediante ello, la flexibilización de las garantías y el aumento de los dispositivos de control bio-político. Y es que el discurso que da origen a los controles gubernamentales de peligrosidad más que ser un discurso destinado a dar seguridad a la población, viene a reforzar el miedo de esta hacia la delincuencia. La transformación del delincuente en un monstruo, abre espacios para que el Estado pueda obtener nuevos espacios donde ejercer control y reforzar aquellos donde ya ha logrado consolidar dichos controles.

\subsection{La Peligrosidad y la crisis del control.}

A estas alturas, el análisis genealógico que hemos desplegado más que permitirnos tener claridad sobre el concepto de peligrosidad, nos ha abierto la puerta a un constructo oscuro y sumamente ambiguo. Si efectivamente, como hemos venido sosteniendo, la peligrosidad no tiene un correlato científico y esta sujeta a la percepción social, en concreto al miedo ¿Cuáles son los ámbitos que circunscriben o permiten determinar que cierto sujeto eso no peligroso?

Quizás una de las definiciones más claras, y por lo mismo, que nos permiten dibujar los contornos problemáticos de la "peligrosidad" fue la aportada por Robert Castel en 1981:

"La peligrosidad es una noción bastante misteriosa, y profundamente paradojal, puesto que ella implica tanto la afirmación de la presencia de una cualidad inmanente a un sujeto ("El es peligroso"), y, al mismo tiempo, la de una simple probabilidad, un dato aleatorio, puesto que la prueba del peligro puede solo ocurrir después que éste se ha concretado. (...) Por ejemplo, al decir que un sujeto es un "monomaniaco" o un "perverso instintivo", ya esta suponiendo la existencia de un riesgo, pero un riesgo que, paradojalmente, se supone que reside en "él" sujeto, aun cuando este no se haya manifestado en la realidad. Dada la imprevisibilidad de la manifestación patológica: Todos los locos, aun cuando parezcan calmados, son portadores de una amenaza, cuya realización permanece aleatoria." $" 167$

Podrá replicarse que esta definición propuesta por Castel, no permite precisar quien es peligroso, que es demasiado plástica y ambigua, y, en definitiva, carece de certeza. Pues, precisamente aquello es lo que ha caracterizado a las prácticas predictivos basados en la peligrosidad. Entonces ¿Cómo es posible que la peligrosidad haya persistido tanto tiempo?

El criminólogo belga Christian Debuyst, plantea que el surgimiento y la persistencia de la noción de la peligrosidad no se explica tanto por una preocupación intelectual incesante, sino que encuentra su origen en una "voluntad política" que busca claramente la gestión de

${ }^{167}$ CASTEL, "De la dangerosité au risque", cit. nota n ${ }^{\circ}$ 29, p. 120. Mantuvo la misma definición en la revisión de su artículo, ver CASTEL, "From dangerousness to risk", cit. nota n ${ }^{\circ} 29$, p. 283. En sentido crítico similar DEBUYST, Christian, "La notion de dangerosité, maladie infantile de la criminologie", Criminologie, vol. 17, n 2 (1984), p. 7-24, passim. Asimismo, ROSE, Nikolas, "At Riks of Madness", en: BAKER, Tom y SIMON, Jonathan (eds.), Embracing Risk: The changing culture of insurance and responsibility, Chicago: The University of Chicago Press, 2002, p. 210. Otro tanto en FOUCAULT, Michel, “Attention: danger", en: FOUCAULT, Michel, Dits et écrits II. 1976-1988, Paris: Quarto Gallimard, 1994/2001, pp. 507-508. 
Polít. crim. Vol. 9, No 17 (Julio 2014), Art. 3, pp. 58-117.

[http://www.politicacriminal.cl/Vol_09/n_17/Vol9N17A3.pdf]

una población determinada, tanto por las dificultades que dicho grupo representa, como también como una forma de controlar, por dicho medio, al grupo social. ${ }^{168}$

En resumidas cuentas la noción de la peligrosidad surge de un temor social que la psiquiatría y, posteriormente, la naciente criminología buscaron explicar imputándoselo a ciertos grupos sociales. Sin embargo, no siendo la peligrosidad un diagnostico, sino uno de los síntomas posibles de la patología criminal, ninguna de las explicaciones entregadas por este "saber", logró sostenerse por mucho tiempo. Lo cierto es que, si los conocimientos psiquiátrico y criminológico lograron legitimar la noción de peligrosidad por tanto tiempo, no fue precisamente por la coherencia de sus explicaciones a largo plazo, sino por la percepción social de que efectivamente existían, o tenían que existir sujetos peligrosos.

Por otra parte, la judicialización de la peligrosidad petrificó la noción en normas jurídicas de distinta índole, y abrió un nuevo horizonte al concepto. En efecto, a partir de fines del siglo XX no sólo psiquiatras discutían sobre como debía entenderse el concepto de peligrosidad, sino que los juristas trataban de hacer encajar dicha noción, que supuestamente venía a dar cuenta al interior del derecho penal de una "realidad" que había sido efectivamente validada o legitimada por la ciencia. ${ }^{169}$

Ya no sólo, entonces, existía una dimensión patológica de la peligrosidad, sino una jurídica que debía lidiar con el hecho de que gran parte de los sistemas penales se basaban en una responsabilidad personal, y presumían el libre albedrío. Pero, pese a la evidente incongruencia de la incorporación de normas basadas en la peligrosidad, la llamada "voluntad política" supo ver, sobre todo, en este concepto un ámbito instrumental o utilitarista. La ambigüedad de la noción misma de "sujeto peligroso", la oscuridad del saber psiquiátrico y la evidencia patente de la existencia de reincidentes crónicos o sujetos con historial de violencia, permitió, por lo menos ante la opinión pública, salvar, por varias décadas, las inconsistencias del término..

Ahora bien, la misma plasticidad que hemos mencionado, llevó a que la percepción pública sobre la peligrosidad mutara a partir de los años 30, y especialmente a partir de los años 50 . Si bien, aun percibían la existencia de sujetos peligrosos, bajo esta nueva sensibilidad (producto de los cambios sociales derivados de las dos guerras), dichos "los peligrosos" distaban muchos de ser los delincuentes contra la propiedad que tanto atormentaban a los burgueses de fines de siglo XIX. Se produce un desplazamiento hacía las poblaciones de delincuentes que atentaban contra las personas, especialmente, se comenzó a constituir el monstruo más deleznable de todos: El agresor sexual. ${ }^{170}$ Este desplazamiento hacia una

\footnotetext{
${ }^{168}$ DEBUYST, “La notion de dangerosité”, cit. nota $\mathrm{n}^{\circ} 167$, p. 10

${ }^{169}$ JIMENEZ DE ASUA, El estado peligroso, cit. nota ${ }^{\circ} 125$, pp. 54 y ss. Para ver la evolución de esta discusión ver la conferencia organizada por la Sociedad Internacional de Criminología en 1953, donde la controversia estaba más viva que nunca. PINATEL, Jean (ed.), Deuxième tours International de Criminologie: Paris 14- Septembre - 23 Octobre 1953: Le problème de L' 'Etat Dangereux, Paris: Ministère de Justice, 1954.

${ }^{170}$ PRATT/DICKSON, "Dangerous, inadequate, cit. nota $\mathrm{n}^{\circ}$ 32, pp. 375 y ss. Ver también FREEDMAN, Estelle, "Uncontrolled Desires: The Response to the Sexual Psychopath, 1920-1960", The Journal of American History, vol. 74, n 1 (1987), p. 94 y EWING, Charles Patrick, Justice Perverted: Sex Offense Law, Psychology and Public Policy, Nueva York: Oxford, 2011, pp. 6 y ss. y pp. 73 y ss.
} 
VELÁSQUEZ, Javier. "El origen del paradigma de riesgo".

población que nadie se atrevía a defender, hizo que los análisis críticos de la peligrosidad centraran su atención, ya no en la existencia misma de sujetos peligrosos, sino en la capacidad real de jueces y peritos para poder predecir que alguien era o no peligroso. ${ }^{171}$

\subsubsection{La crisis de la peligrosidad en el sistema anglosajón.}

Llegado a este punto empalmamos con el inicio del relato que Cullen hace del paradigma de riesgo. En efecto, para los años 70 la crisis no sólo se trataba de la finalidad de la pena sino la totalidad del modelo de justicia penal. Es posible sostener que la crisis, por lo menos en parte, fue debido a un análisis crítico de la forma en que el sistema penal estaba instrumentalizando al saber psiquiátrico y psicológico. Si se prefiere, que una parte del problema fue un replanteamiento de lo verdaderamente "científico" de las medidas adoptadas por el sistema penal.

En el caso de Estados Unidos, a partir de los años 30 se había producido una estrecha relación entre la psiquiatría y el poder judicial, la que fue especialmente provechosa para la primera. De pronto la psiquiatría comenzó a gozar del prestigio social derivado de la confianza que en ella depositaba el estado para mantener el orden y la salud mental de sus ciudadanos, a cambio el Estado pudo ampliar sus mecanismos de control bio-político. ${ }^{172}$

En el particular ambiente judicial norteamericano, terminó ocurriendo lo mismo que Foucault denunciaba en su libro Vigilar y Castigar, ${ }^{173}$ que esta relación entre el poder-saber psiquiátrico y el poder judicial implicaba que, en diversas ocasiones, las decisiones sobre normalidad o anormalidad del sujeto quedaban al arbitrio del psiquiatra. Por otra parte, la confianza en que la noción de la peligrosidad podía predecirse llevo a una ampliación de los ámbitos de la valoración de la misma, llegando al extremo de que los jueces, para adoptar casi cualquier decisión judicial sobre el sujeto, debían realizar algún tipo de predicción. $^{174}$

De hecho, a partir de los años 70 no fueron pocos los psiquiatras quienes criticaron ${ }^{175}$ que el sistema judicial estaba delegando en ellos facultades judiciales, puesto que su decisión

171 Desde el lado psiquiátrico podemos ver SHAH, Saleem, "Dangerousness and Mental Illness: Some Conceptual, Prediction, and Policy Dilemmas", en: FREDERIK, Calvin (ed.) Dangerous Behavior: A problem in law and mental health, Washington, DC: US Dept of Health, Education, and Welfare (1978) pp. 158-191. Ver también MONAHAN, John, y SHAH, Saleem A., "Dangerousness and Commitment of the Mentally Disordered in the United States”, Schizophrenia Bulletin, vol. 15, no 4 (1989) pp. 541-553, passim; Análisis del trabajo de Shah, ver LIDZ, Charles y MULVEY, Edward, "Dangerousness: From legal definition to theoretical research.", Law and Human Behavior, vol. 19, $\mathrm{n}^{\circ} 1$ (1995), pp. 41-48, passim. Desde la trinchera jurídica podemos encontrar: VON HIRSCH, Andrew, "Prediction of Criminal Conduct and Preventive Confinement of Convicted Persons", Buffalo Law Review, vol. 21, no 3 (1972), pp. 717-758 y DERSHOWITZ, Alan M., "The Law of Dangerousness: Some Fictions about Predictions", Journal of Legal Education, vol. 23 (1970) pp. 24 - 47, MORRIS, Norval y MILLER, Marc, "Predictions of Dangerousness", Crime and Justice, vol. 6 (1985) pp- 1-50 y ZIMRING, Franklin, y HAWKINS, Gordon, "Dangerousness and Criminal Justice", Michigan Law Review, vol. 85, n 3, (1986) pp. 481-509.

${ }^{172}$ FREEDMAN, "Uncontrolled Desires", cit. nota no 170, passim, ver especialmente pp. 85, 90 y 99.

${ }^{173}$ FOUCAULT, "Vigilar y castigar", cit. nota $\mathrm{n}^{\mathrm{o}} 150$, p. 31.

${ }^{174}$ SHAH, "Dangerousness and Mental Illness", cit. nota n ${ }^{\circ} 171$, pp. 155-156.

${ }^{175}$ MONAHAN, John, "The Future of Violence Risk Management”, en: TONRY, Michael (ed.), The Future of Imprisonment, Nueva York: Oxford University Press, 2004, pp. 239. También SHAH, Saleem, “Some 
Polít. crim. Vol. 9, No 17 (Julio 2014), Art. 3, pp. 58-117.

[http://www.politicacriminal.cl/Vol_09/n_17/Vol9N17A3.pdf]

final sobre la anormalidad, o peligrosidad, de tal o cual sujeto podía llegar, en algunos casos, a condenar a muerte a un infractor de ley. En efecto, en algunos estados de Norteamérica, como el caso de Texas, uno de los requisitos a satisfacer para condenar a la pena de muerte a un sujeto era precisamente que éste fuese considerado como un peligro. ${ }^{176}$ Lo anterior provocó una reacción por parte de la Asociación Americana de Psiquiatría (en adelante "APA"), que comenzó a evaluar la labor de sus miembros en casos donde se les llamara a pronunciarse sobre la peligrosidad de una persona como requisito para imponer la pena de muerte. ${ }^{177}$ Las intervenciones de la APA se realizaron a través de la figura del "Amicus Curiae". ${ }^{178}$ A través de dichos informes, se preocuparon de informar a la Corte Suprema Estadounidense que el estado de la ciencia respecto de las predicciones de peligrosidad presentaba serias falencias metodológicas.

En 1983, en el caso Barefoot v. Estelle, 463 U.S. 880, la Corte Suprema se hizo cargo de zanjar el problema. Thomas Barefoot, condenado por el homicidio de un policía, fue condenado a muerte por un "jurado de sus iguales", luego que dos psiquiatras, los doctores John Holbrook y James Grigson, testificaran que "Barefoot continuaría siendo un peligro" "179. La defensa de Barefoot logró que la Corte Suprema de Estados Unidos de Norteamérica, a través de un writ of certiorari, ${ }^{180}$ revisara el caso. El principal argumento del requirente decía relación con la verdadera capacidad de los psiquiatras individualmente, y como grupo, para predecir el peligro de reincidencia. ${ }^{181}$

Ante esta discusión, la APA envió a la Corte Suprema un informe lapidario respecto de sus propias capacidades: en primer lugar señalaban que los psiquiatras no se les debiera permitir declarar en predicciones de peligrosidad futura a largo tiempo, dado que el conocimiento médico simplemente no había avanzado al punto de que estas predicciones pudiesen ser hechas con cierto nivel de razonabilidad. Incluso plantearon que las

interactions of law and mental health in the handling of social deviance.", Catholic University Law Review, vol. 23 (1974), pp. 674-719; LIDZ/MULVEY, "Dangerousness", cit. nota $\mathrm{n}^{\mathrm{o}}$ 171, p. 41, SHAH, "Dangerousness and Mental Illness", cit. nota $\mathrm{n}^{\circ}$ 171, passim, y MONAHAN/SHAH, "Dangerousness and Commitment", cit. nota $\mathrm{n}^{\circ} 171$, passim. Ver también MONAHAN, John y GEIS, Gilbert, "Controlling "Dangerous" People", en: NEWMAN, G.R. (ed.), Crime and Justice in America:1776-1976, Philadelphia: American Academy of Political and Social Science, 1976, pp. 142-151, y MONAHAN, John, "Empirical Analyses of Civil Commitment: Critique and Context”, Law \& Society Review, vol. 11, no 4 (1977), pp. 619628.

${ }^{176}$ Así el Código de Procedimiento Penal de Texas vigente en los años 80, ver RICHARDS, Edward "The Jurisprudence Of Prevention: The Right Of Societal Self-Defence Against Dangerous Persons", Hastings Constitutional Law Quarterly, vol. 16 (1989), en: http://biotech.law.lsu.edu/cphl/articles/hastings/hastingsContents.htm, [visitado el 01/06/2013].

177 APA, Brief Amicus Curiae - "Thomas A. Barefoot, Petitioner v. W. J. Estelle, Jr., Director, Texas Department of Corrections, Respondent”. American Psychiatric Association. En: http://www.psych.org/File\%20Library/Learn/Archives/amicus_1982_barefoot.pdf [ultima visita 04.04.2014].

${ }^{178}$ La figura del "Amicus Curiae" consiste en que terceros ajenos a un proceso se ofrecen para entregar información, la cual no ha sido solicitada por ninguna de las partes, y tiene por objeto ayudar al Tribunal a resolver mejor sobre un determinado punto. Queda a la valoración del Tribunal si acepta o no la información ofrecida.

179 APA, "Barefoot", cit. nota no 177, pp. 3 y ss.

${ }^{180}$ El Certoriari es un remedio procesal que vendría a ser una especie de equivalente al recurso de casación en nuestro sistema procesal.

${ }^{181}$ BAREFOOT v. ESTELLE, 463 U. S. 880 (1983) p. 463 U. S. 896. 
VELÁSQUEZ, Javier. "El origen del paradigma de riesgo".

investigaciones realizadas sobre esta materia indicaban que las predicciones de peligrosidad futura eran erradas por lo menos en 2 de cada 3 casos. ${ }^{182}$ Por otro lado critico expresamente el hecho de que en la práctica la decisión sobre si un sujeto era o no peligroso, y por tanto indirectamente si una persona era condenada a muerte o no, estaba recayendo en la opinión de un psiquiatra, debido a que, pese a la existencia de un jurado que debía manifestar su convicción, era evidente que cuando se presentaba a un perito, el argumento de autoridad determinaba al jurado a fallar de cierta forma, aún cuando el testimonio no tuviere fundamento científico alguno. ${ }^{183}$

Pese a todos los argumentos expuestos por el requeriente e incluso por la APA, la respuesta de la Corte fue rechazar estos argumentos basados en que sería como pedirles que "desinventaran la rueda". Por un lado, se mostraron incrédulos respecto de la incapacidad de los psiquiatras para pronunciarse sobre predicciones de comportamiento futuro, y además plantearon que en definitiva si lo que el perito declara en juicio no tiene asidero científico, debe ser el jurado quien decida el valor que le puede dar a dicho testimonio, especialmente considerando que la defensa puede contra-examinar al perito y además incorporar un perito propio que acoja su teoría del caso. ${ }^{184}$

Esta postura, que el jurista norteamericano Thomas Regnier llamó "la regla del laissez faire respecto de la admisibilidad del testimonio experto" ${ }^{\text {"185 }}$, dejaba claro que, la Corte, prefería soslayar el hecho de que un jurado no letrado carecía de la capacidad para poder evaluar por sí mismos si el testimonio de un perito era o no científicamente válido. De hecho, la lógica de presentar el testimonio de un perito es permitir que el jurado pueda acceder a una visión técnico-científica respecto de los puntos oscuros de un caso. En este sentido, era ridículo que se pretendiese además valorar la declaración pericial, como un testimonio más del caso. Sin ir más lejos, James Grigson, uno de los psiquiatras que declaró por parte del Estado de Texas en este caso, se convirtió en el paradigma de lo que la APA trataba de combatir: un perito que sin tener mayores antecedentes científicos más que su "ojo clínico" se prestaba para diagnosticar a cuanto individuo el Estado le solicitaba que evaluara.

Este momento nos parece fundamental para la historia de la peligrosidad y los paradigmas de riesgo en el sistema anglosajón. Este fallo, dictado casi una década después del famoso "Nada Funciona" de Martinson, ante la misma crítica que se le formuló a los programas de rehabilitación, esto es, la falta de validez científica y eficacia de los mismos, termina blindando las practicas predictivas, fundadas en que se han vuelto parte del ejercicio rutinario de la labor judicial, son engranajes de la maquina,

Siguiendo con la lectura foucaultiana de estos procesos, es interesante notar que el actuar de la APA representa una forma de independizar su conocimiento científico de la instrumentalización que el poder judicial estaba llevando a cabo. Más allá de que para los años 80 la psiquiatría podía considerarse una disciplina medica consolidada, lo cierto es que

\footnotetext{
${ }^{182}$ APA, "Barefoot", cit. nota $\mathrm{n}^{\circ}$ 177, pp. 6, énfasis son nuestros.

${ }^{183}$ APA, "Barefoot", cit. nota n ${ }^{\circ} 177$, pp. 6.

${ }^{184}$ BAREFOOT v. ESTELLE, cit. nota ${ }^{\circ} 181$, pp. 463 U. S. 896-890.

${ }^{185}$ REGNIER, Thomas, "Barefoot in Quicksand: The Future of Dangerousness Predictions in Death Penalty Sentencing in the World of Daubert and Kumho", Akron Law Review, vol. 37, n 3 (2004), p. 493.
} 
Polít. crim. Vol. 9, No 17 (Julio 2014), Art. 3, pp. 58-117.

[http://www.politicacriminal.cl/Vol_09/n_17/Vol9N17A3.pdf]

la "rebelión" de este saber-poder resulta notable dentro de lo que había sido una relación de subordinación que llevaba casi doscientos años.

Por otra parte, la negativa de la Corte Suprema Norteamericana finalmente lleva a reflejar que las practicas predictivas, que para esa época quedaban, muchas veces, en manos de jueces, no eran otra cosa que la institucionalización de una forma de control y ejercicio del poder que se había estado escondiendo durante todos estos años detrás de la legitimidad que le proveía este saber psiquiátrico. Pero que a la vez, parecía ser una noción de tanto "sentido común", de tanta "lógica", que ya nadie se cuestionaba la realidad de aquello que era la "peligrosidad”. Entonces ¿Cómo se explica su existencia?

En este sentido, la peligrosidad jugaba un papel en varias esferas: Por un lado permitía, dada su plasticidad, la creación de un "enemigo interno" que, debido a su carácter conflictivo, era necesario controlar. A través de la designación de "sujeto peligroso" se daba una cierta legitimidad a la flexibilización de las garantías y, por tanto, la utilización de mecanismos de control que normalmente le hubieren estado vedados. Pero, por otro lado, también la peligrosidad permitía ejercer un control disciplinario a través del miedo, lo que permitía delinear el grupo de conductas o comportamientos considerados anormales. De esta manera, se buscaba disciplinar a la población, sea mediante la evitación de las conductas por miedo a ser catalogados como anormales o a la consecuencia que podría tener aparejadas la realización de las mismas. ${ }^{186}$

Pero, la "rebelión" de la psiquiatría cambiaría las reglas del juego. En este sentido de forma paralela al trabajo de los psicólogos que buscaban legitimar su disciplina al encontrar evidencias de que el trabajo psicológico en el área correccional reducía la reincidencia, los psiquiatras se abocaron al desarrollo de instrumentos de riesgo como una manera de objetivar y restringir los juicios de peligrosidad. Así, por motivos diferentes, tanto la psiquiatría como la psicología confluyeron hacia la necesidad de desarrollar instrumentos predictivos de riesgo que fuesen objetivos. En cierta forma, uno pudiera plantear que el advenimiento de los instrumentos de riesgo, es consecuencia, por lo menos en parte, de un juego de poderes sobre la predicción del comportamiento humano al interior del aparato estatal. Esta situación, tiene una consecuencia bastante marcada: la tensión entre el uso "correcto" o "adecuado" de las tecnologías de predictivas de riesgo versus el uso "político" o "populista" del mismo.

\section{Riesgo y Peligrosidad: Hacía nuevas y viejas formas de control.}

A nuestro parecer, la problemática de la introducción del paradigma de riesgo en cualquier sistema penal debe tener en consideración que se encuentran operando dos ámbitos que ejercen influencia entre sí pero que son necesariamente excluyentes. Si se prefiere, siguiendo las ideas desarrolladas, se puede ver una pugna entre lo que las disciplinas de la salud mental, como la psicología y la psiquiatría, entienden que debe ser el modelo de riesgo, y por otro lado el uso que finalmente le da el Estado a dicho conocimiento. Simplificando al extremo, podemos graficar un ámbito técnico y un ámbito político.

\footnotetext{
${ }^{186}$ Sobre la utilización del miedo al delito como una forma de control ver SIMON, Governing Through Crime, cit. nota $\mathrm{n}^{\mathrm{O}} 62$, pp. 259 y ss.
} 
VELÁSQUEZ, Javier. "El origen del paradigma de riesgo".

Hemos dicho que se encuentran en pugna porque si bien, en apariencia, ambas se refieren a una sola tecnología gubernamental, ambas obedecen a estrategias de control bio-político diferentes. La psiquiatría y la psicología buscan entregar un modelo "objetivo" orientado a rescatar una forma de comprender el tratamiento de la rehabilitación, pero este ámbito técnico se ve inmerso en un escenario más grande: Las estrategias y formas disciplinarias que el Estado ha adoptado como mecanismos de control y gobierno de la población.

Si la crisis de la peligrosidad implicó la caída de una serie de estrategias de control instauradas en el sistema penal, el advenimiento de las tecnologías de riesgo, más que un reemplazo ha significado que el Estado se ha adaptado al nuevo saber-poder, y ha comenzado a reconstruir las viejas estrategias de control alrededor de esta tecnología. La tensión entre la existencia de una tecnología de control gubernamental, como son los instrumentos de riesgo, y la forma que el aparato estatal decida implementar dicha tecnología, es el corazón de la problemática del riesgo al interior del sistema penal. Nos detendremos, brevemente, en los problemas que cada uno de estos aspectos debe enfrentar.

\subsection{El ámbito "técnico" del paradigma de riesgo.}

Cuando consideramos a los instrumentos de riesgo dentro de su aspecto netamente técnico, como ha hecho el relato de Cullen, nos topamos con varios problemas y desafíos que deben resolverse, cuando se trata de la implementación de este modelo a una realidad dada. Por un lado el modelo de riesgo implica dos actividades separadas: El acto predictivo del riesgo y el manejo del riesgo.

El acto predictivo, dentro de este modelo, se orienta solamente a tomar conocimiento de cual es el nivel de riesgo de un sujeto, y, en caso de que el riesgo sea alto o medio, específicamente saber que áreas este riesgo es intervenible. Por lo anterior estos instrumentos permiten entregar información útil para el ámbito de decisiones orientadas a determinar el tipo de pena más adecuada para que determinado individuo pueda rehabilitarse. Entendiendo la rehabilitación, en dos ámbitos, como un proceso por el cual el sujeto reduce el riesgo de reincidencia, pero por otro, en el cual el Estado se preocupa de entregar apoyo al infractor para que logre reintegrarse a la sociedad.

En este sentido, dicha finalidad los vincula con la segunda etapa del modelo, una intervención que sea capaz de adecuarse a las necesidades criminógenas del infractor de ley. Ya decidida si la pena será privativa de libertad o bien una sanción que pueda cumplirse al interior de la comunidad, lo interesante es que el tratamiento mismo, permiten modificar el cumplimiento de la misma condena y, finalmente, que el control ejercido, en la forma que corresponda, permita la reintegración del sujeto, y el fin del ciclo de la reincidencia.

Pero para que este proceso pueda desarrollarse de manera eficaz, ha de tomarse en consideración que tanto los instrumentos de riesgo, como el tratamiento han de adecuarse a las características particulares de la población a la cual se va a aplicar. No es suficiente adaptar instrumentos extranjeros, sino que se deben desarrollar instrumentos de acuerdo a las específicas necesidades criminógenas de la población penitenciaria, en este caso, chilena. Asimismo, el otro desafío es que el tratamiento logre mantener la consistencia 
Polít. crim. Vol. 9, No 17 (Julio 2014), Art. 3, pp. 58-117.

[http://www.politicacriminal.cl/Vol_09/n_17/Vol9N17A3.pdf]

teórica-practica suficiente para cumplir los objetivos, en otras palabras, que el tratamiento que se le entrega sea integro y consistente con el modelo.

De lo expuesto se desprende que los desafíos fundamentales de la incorporación del modelo dicen relación con la existencia de capacidad técnica por parte de gendarmería, o la unidad responsable de la misma, como también de capacitación, equipo y políticas públicas que sepan apoyar el modelo impuesto.

Por otra parte, uno de los problemas derivados del modelo de riesgo es la introducción del lenguaje empresarial "manageralista" al interior de un modelo penitenciario y correccional. Este lenguaje que introduce criterios de medición de resultados, de eficiencia, de metas, puede jugar en contra de la comprensión que los operadores puedan tener del modelo que se quiere implementar, mirándolo de forma negativa por temor a que vaya a deshumanizar el tratamiento. Y por otra parte, puede llevar a creer que el problema de la rehabilitación, o la gestión de infractores de ley es un área que puede ser manejada con lógicas empresariales. $^{187}$

En síntesis la incorporación del modelo llama por una reconceptualización de la gestión correccional en nuestro país, y no solo de ésta, sino también sobre las políticas criminales que abordan la problemática penal. Esta reconceptualización pasa por requerir siempre que las decisiones que se tomen sean "basadas en la evidencia", tengan sustento científico que las valide. Puesto que, no basta la incorporación de una tecnología si finalmente su uso o no va a realizarse bajo las condiciones mínimas para obtener resultados o bien se termine desnaturalizando los objetivos de la misma al incorporar finalidades populistas.

\subsection{El uso político del riesgo.}

En 1970, el sociólogo Norbert Elias, en su texto “¿Qué es la sociología?”, señalaba:

“...el peligro reside no en los progresos de las ciencias de la naturaleza y la técnica, sino, en el aprovechamiento de los resultados de la investigación y los inventos tecnológicos por los hombres bajo la presión de una inter-dedependecia que los entrelaza y de las luchas ligadas a ella por el reparto de las posibilidades más variadas de poder. ${ }^{188}$

De alguna manera la reflexión de Elias resume un poco lo que hemos venido delineando en torno a la relación que se gesta entre la tecnología y el uso instrumental que el Estado le da a la misma. Es posible, incluso, señalar que el uso político del paradigma de riesgo es un

\footnotetext{
${ }^{187}$ Sin ir más lejos, los planes del Gobierno Británico para privatizar el servicio de "Probation" ha suscitado la oposición de los mismos oficiales correccionales, TRAVIS, Alan, "Probation officers strike in protest at privatisation plans", en: The Guardian, Martes 5 de Noviembre de 2013, http://www.theguardian.com/uknews/2013/nov/05/probation-officers-strike-protest-privatisation [ultima visita 06.12.2013]. Quienes por lo demás se han organizado para manifestar su rechazo a esta medida, puede verse más información en la pagina oficial de la NAPO (La asociación nacional de oficiales de Probation) http://www.napo.org.uk/about/probationunderthreat.cfm [ultima visita 06.12.2013].

${ }_{188}$ ELIAS, Norbert, Sociología Fundamental. MUÑOZ, Gustavo (Trad.), Barcelona: Editorial Gedisa, 1970/2008, p. 27.
} 
VELÁSQUEZ, Javier. "El origen del paradigma de riesgo".

problema que coincide con otros análisis críticos del mismo fenómeno, como el trabajo de Mary Douglas. ${ }^{189}$

El análisis critico a la utilización política del paradigma de riesgo por constituir una verdadera "nueva penología" no es nueva, ya a fines de los años 80 y durante los 90 los profesores Malcom Feeley y Jonathan Simon, ${ }^{190}$ desarrollaron esta línea critica, augurando que la incorporación de instrumentos actuariales al interior de la administración de justicia tendría como consecuencia la transformación del sistema penal en una mera justicia administrativa. No obstante no cumplirse la ominosa profecía, el panorama actual del sistema penal norteamericano, no deja por ello de ser menos sombrío. ${ }^{191}$

Lo que si ha ocurrido es que los Estados han adaptado las viejas prácticas y lógicas de la peligrosidad a la nueva tecnología de riesgo. Así, en vez de hablar de sujetos peligrosos se habla de infractores de ley de alto riesgo. El problema es que esta retórica sobrepasa los contornos del desarrollo de la tecnología predictiva, y desplaza la discusión desde la probabilidad de reincidencia hacia la dañosidad social de la conducta. En otras palabras, el alto "riesgo" de la tipología de la delincuencia esta dada por la gravedad del ilícito cometido por el infractor de ley, y por ende, la necesidad de control del grupo no esta fundada en estudios que los sindiquen como grupos altamente reincidentes, sino simplemente en fundamentos de seguridad pública o defensa social.

Pero, por si lo anterior pareciera discutible, el problema es que cuando se presenta este discurso, que evidentemente es un resabio de las lógicas peligrosistas que psiquiatras y psicólogos pretendían reemplazar, como ciencia. Muchas de las medidas de seguridad post delictuales privativas de libertad, por ejemplo, se fundan en una supuesta alto nivel de reincidencia que no esta científicamente acreditado. En otras palabras, se fundan medidas de seguridad en peligrosidad que se viste de riesgo. Miedo que se viste de cientificidad.

El paradigma de estos cambios ha sido el grupo de los agresores sexuales. Por un lado, investigaciones relativamente recientes, plantean que la incidencia de este tipo de delitos en los países europeos no sobrepasa el $2 \%{ }^{192}$ de la totalidad de delitos que se comenten. No obstante, la ocurrencia de uno de estos delitos no sólo trae aparejado una mayor reacción por parte de la sociedad, sino que también mayor cobertura mediática, y por tanto, la percepción de que su prevalencia es tanta o mayor que la de otros delitos.

Lo cierto es que a partir de los años 90 los delitos sexuales, y en concreto, el tema de los agresores sexuales se ha vuelto un tema recurrente en diferentes legislaciones, ${ }^{193}$ la

\footnotetext{
${ }^{189}$ Ver particularmente DOUGLAS, Risk and Blame, cit. nota $\mathrm{n}^{\mathbf{0}} 24$, pp. 38 y ss.

${ }^{190}$ Ver nota ${ }^{\circ} 31$.

191 Sobre este punto ver particularmente SIMON, "Punishment and the Political Technologies", cit. nota $\mathrm{n}^{\circ}$ 31, pp. 78 y ss. y FEELEY, "Origins of Actuarial Justice”, cit. nota n 31, pp. 229 y ss.

192 REDONDO, Santiago, "Delincuencia Sexual: Mitos y Realidades”, en: REDONDO, Santiago (Coord.), Delincuencia Sexual y Sociedad, Barcelona: Editorial Ariel, 2002, p. 38. El problema de la afirmación de Redondo es que no señala, ni tampoco cita, que estudios serían los que le permiten fundar dicha aseveración.

${ }^{193}$ A modo de ejemplo puede verse el número especial de la revista "Déviance et Société" de 2010, en el cual Van de Kerchove precisamente da cuenta de este fenómeno a nivel comparado, ver VAN DE KERCHOVE, Michel, "Introduction", en: ROBERT, Christian-Nils y VAN DE KERCHOVE, Michel (eds.), Risque,
} 
Polít. crim. Vol. 9, No 17 (Julio 2014), Art. 3, pp. 58-117.

[http://www.politicacriminal.cl/Vol_09/n_17/Vol9N17A3.pdf]

reacción generalizada ha sido la construcción mediática, y en parte apoyada por los sistemas penales, de la existencia de verdaderos depredadores sexuales. La idea se basa en despojar a quienes cometen este tipo de delitos de cualquier rasgo de humanidad, se les transforma en monstruos que no sólo se definen por el delito que han cometido, sino que también por el hecho de que probablemente en libertad continuaran reincidiendo.

Este punto es crucial, la percepción de que los agresores sexuales, en su gran mayoría, reincidirán, una vez que salgan de prisión, se ha convertido en un leitmotiv político criminal, ${ }^{194}$ que ha permitido la generación de medidas de seguridad post delictuales que van desde custodias de seguridad hasta prohibiciones para vivir cerca de determinados lugares. Sin embargo esto contrasta con la evidencia científica que nos informa que los agresores sexuales tienen una tasa de reincidencia de no más del 10-15\%. ${ }^{195}$

Aun cuando uno pudiere tratar de legitimar como una medida político criminal valida el endurecimiento de las penas y el aumento de los controles post-penitenciarios respectos de esta población de infractores de ley, lo cierto es que el debate, finalmente, se esta presentando nuevamente bajo las vestimentas de la existencia de una supuesta evidencia científica. Da igual si esta evidencia es cierta o mera especulación, lo cierto es que la percepción de los políticos es que estos "monstruos", estos sujetos "incorregibles" son una realidad. En efecto, ¿Quién va a prestar su capital político para defender a la población más detestable de infractores de ley? En otras palabras, el problema reside en que es el aparataje político el que retoma los discursos peligrosistas que tanto se habían tratado de evitar.

Esta tendencia de la política, como hemos planteado, ha sido una tendencia generalizada en diferentes países de realidades político criminales radicalmente diferentes, desde Estados Unidos hasta Alemania, pasando por Francia o España. ${ }^{196} \mathrm{Y}$, lo cierto, es que estos desarrollos tienen dos consecuencias desafortunadas para los sistemas penales.

Por un lado, enmascaran los discursos de exclusión sociales bajo el tipo de delito cometido, pasando por alto que en muchos casos determinados tipos de delitos son cometidos por una particular clase social o grupo de individuos socialmente excluidos. La consecuencia directa es, finalmente, la nueva validación de la deshumanización de ciertos infractores de ley, no sólo se les convierte progresivamente en parias, sino que las medidas de vigilancia y control post penitenciarias les impiden, o por lo menos dificultan, cualquier intento de

dangerosité et sécurité: Renaissance et mutations de la défense sociale, Ginebra: Editions Médicine et Hygiene, 2010, pp. 479-482, pp. 479 y ss. SILVA SÁNCHEZ, Jesús-María, "El retorno de la inocuización: El caso de las reacciones jurídicos penales frente a los delincuentes sexuales violentos en derecho comparado", en: REDONDO, Santiago (Coord.), Delincuencia Sexual y Sociedad, Barcelona: Editorial Ariel, 2002, pp. 143-159. El caso estadounidense puede verse en EWING, Justice Perverted, cit. nota $\mathrm{n}^{\circ} 170$, passim..

${ }^{194}$ El ejemplo paradigmático ha sido el uso de este discurso del miedo para legitimar medidas de seguridad post delictuales ver EWING, Justice Perverted, cit. nota ${ }^{\circ} 170$, pp. 78 y ss.

${ }^{195}$ Por ejemplo HARRIS, Andrew J.R.; HANSON, Karl, "Sex Offender Recidivism: A Simple Question" Ottawa: Public Safety Canada (2004), pp. 1-29.

${ }^{196}$ Sobre este punto ver dos obras colectivas que han abordado la peligrosidad de forma comparada, tenemos un primer texto Belga de 2010, ROBERT, Christian-Nils y VAN DE KERCHOVE, Michel (eds.), Risque, dangerosité et sécurité: Renaissance et mutations de la défense sociale, Ginebra: Editions Médicine et Hygiene, 2010. Luego tenemos un texto francés de 2011, de GIUDICELLI-DELAGE, Genevieve y LAZERGES, Christine (eds.), La dangerosité saisie par le droit penal, Paris: PUF, 2011. 
VELÁSQUEZ, Javier. "El origen del paradigma de riesgo".

reinserción social. Quizás el caso más paradigmático es el "ghetto" de agresores sexuales en Estados Unidos. Barrios donde solo viven agresores sexuales que, en libertad y aun después de haber cumplido su pena privativa de libertad, como consecuencia de las prohibiciones de vivir cerca de colegios o parques, y tanbien, producto de la obligación de que sus datos personales y detalles de sus condenas sean públicos, no logran encontrar hogar en ningún lado. ${ }^{197}$

La gravedad de los delitos cometidos impide o generan una disrupción ante cualquier sentimiento de solidaridad frente a estas graves formas de controles, que, a falta de otro nombre, podemos denominar como post-disciplinarios. En efecto, ya no se busca disciplina sino simplemente el control de estos sujetos mediante prácticas inocuizantes que, cada vez más, van construyendo un panóptico en libertad. Una sociedad que es a la vez una cárcel.

Esto nos lleva al segundo aspecto problematico de este tipo de legislación, las consecuencias que tiene para la sociedad. En efecto, debemos de pensar la persistencia de la lógica peligrosista, encubierta debajo de la cientificidad del paradigma de riesgo, no se detiene en la flexibilización de garantías que implica la legitimación de las medidas de seguridad post delictuales, sino que la articulación de los grupo de alto riesgo en torno al miedo que provocan, posibilita la emergencia de discursos de otros discursos de exclusión.

Sobre este punto, a partir del 11 de Septiembre de 2001, a nadie le ha de sorprender como el tratamiento de los "terroristas" ha tomado un derrotero similar al de los agresores sexuales. Lo cierto es que la flexibilización de las garantías en contra de los agresores sexuales, producto de su "peligro" para la sociedad, ha permito la construcción paulatina de discursos análogos para los autores de otro tipo de delitos.

En suma, podemos sostener que la peligrosidad ha logrado subsistir al modelo de riesgo, específicamente mediante estrategias gubernamentales que han sabido construir una nueva retórica peligrosista en los contornos que rodean la incorporación de la nueva tecnología del riesgo. En efecto, aun cuando la practica penitenciaria sea coherente y aplique los instrumentos de riesgo y sus respectivas intervenciones para reducirlo, lo cierto es que la definición de que grupos de infractores de ley resultan más "peligrosos" sigue decidiéndose políticamente.

Este ultimo punto es crucial, los operadores del sistema no sólo reciben las normas desde un legislativo que político criminalmente introduce nuevas formas de control postdisciplinario, sino que también es un aparato político que busca, a su vez, la obediencia de los operadores del sistema al tratar de que estos respondan a las críticas de una sociedad cada vez más movilizada por el miedo al delito.

En suma, el problema no es la tecnología, sino su uso. La distorsión que provoca el hecho de tomar una tecnología que fue construida para rehabilitar a los infractores de ley, que

\footnotetext{
${ }^{197}$ A modo de ejemplo se puede citar el siguiente reporte de prensa del año 2010, ALEKSANDER, Irina, "Sex-Offender City: Florida's sex criminals are crowding into a handful of neighborhoods", The Atlantic, Lunes $1^{\circ}$ de Marzo de 2010, http://www.theatlantic.com/magazine/archive/2010/03/sex-offender-city/307907/ [ultima visita 06.12.2013].
} 
Polít. crim. Vol. 9, No 17 (Julio 2014), Art. 3, pp. 58-117.

[http://www.politicacriminal.cl/Vol_09/n_17/Vol9N17A3.pdf]

busca facilitar su reinserción, es utilizada como una forma de control, y en algunos casos, de destrucción social del sujeto. El desafío que queda, por tanto, desde el análisis gubernamental es tratar de distinguir entre aquello que deriva de la aplicación de las tecnologías de riesgo frente a la toma de decisiones basadas en estrategias políticas de control.

\section{Conclusión}

Hemos querido, a lo largo de este trabajo, dar cuenta de las complejidades del paradigma de riesgo, de sus orígenes y de su surgimiento, en los sistemas penales modernos. La tarea no es fácil por cuanto, como hemos mencionado, el análisis del paradigma de riesgo es en sí mismo un terreno complejo, el que puede ser abordado de diversas perspectivas. Por otro lado, el particular análisis del sistema penal también resulta un terreno esquivo, porque existen, a su vez, varias teorías explicativas del mismo.

En este sentido, al tratar de dejar en evidencia estas dificultades, y en suma, al haber optado por dos aproximaciones, no hemos querido cerrar la puerta a otras explicaciones, sino por el contrario, plantear dos posibilidades explicativas tan validas como otras que hemos únicamente mencionado.

Lo fundamental, en definitiva, es la necesidad de tomar consciencia de que la complejidad del fenómeno debe ser considerado a la hora de un análisis y un debate crítico, por cuanto no es lo mismo hablar de los problemas del paradigma de riesgo en cuanto tecnología que en cuanto fenómeno sociológico.

Desde este cariz el desafío al cual nos enfrentamos es saber reconducir las críticas a los planos epistemológicos que corresponden: Lo técnico a lo técnico, lo sociológico a lo sociológico. Y si bien, este planteamiento resulta ser mucho más complejo de lo que puede parecer en su enunciación, lo que no hay que perder en consideración es que la aplicación del paradigma de riesgo tiene consecuencias importantes en el destino de personas.

Si bien, desde una perspectiva Foucaultiana, la mentada "humanidad" de los instrumentos de riesgo puede cuestionarse, lo que esta detrás de esta tecnología es la posibilidad cierta de generar un debate y una nueva realidad en la forma en que nuestro país trata a los infractores de ley. Aprovechando que el discurso técnico del riesgo pone en el centro del mismo a los infractores de ley, no en cuanto condenados o ex convictos, sino en cuanto personas, el desafío es tratar de mantener dicho foco y combatir los discursos de exclusión.

Quizás el paradigma de riesgo no sea completamente optimo, lo cierto es que es un paso fuera del abismo. No se trata de una panacea, no se trata de una tecnología que en si misma resuelva todos los problemas de un sistema penal que se ha caracterizado por excluir y controlar a los infractores, pero ciertamente nos permite sentar las bases para construir una resistencia. Un reenfoque del sistema penal en función de las consecuencias, mayoritariamente negativas, que tienen hoy en día la imposición de las penas. 
VELÁSQUEZ, Javier. "El origen del paradigma de riesgo".

No hablaré, por tanto, de una oportunidad de humanización del sistema penal, pero si podemos hablar de una oportunidad para reposicionar los derechos de los condenados y la oportunidad de estos para reinsertarse en la sociedad. 
Polít. crim. Vol. 9, No 17 (Julio 2014), Art. 3, pp. 58-117.

[http://www.politicacriminal.cl/Vol_09/n_17/Vol9N17A3.pdf]

\section{BIBLIOGRAFÍA}

1. ALEKSANDER, Irina, "Sex-Offender City: Florida's sex criminals are crowding into a handful of neighborhoods", The Atlantic, Lunes $1^{\circ}$ de Marzo de 2010, http://www.theatlantic.com/magazine/archive/2010/03/sex-offender-city/307907/ [ultima visita 06.12.2013].

2. ANCEL, Marc, "La nueva defensa social (un movimiento de política criminal humanista)", trad. FERNANDEZ DE MOREDA, Francisco Blasco y GARCIA DAIREAUX, Delia, Buenos Aires: La Ley, 1961.

3. ANDREWS, Donald, BONTA, James y HOGE, Robert, "Classification for effective rehabilitation: Rediscovering psychology", Criminal Justice and Behavior, vol. 17 (1990), pp. 19-52.

4. ANDREWS, Donald, ZINGER, Ivan, HOGE, Robert, BONTA, James, GENDREAU, Paul y CULLEN, Francis, "Does Correctional Treatment Work? A clinically relevant and psychologically informed Meta-Analysis", Criminology, vol. 28, n 3 (1990), pp. 369-404

5 . "A Human Science approach or more punishment and pessimism: A rejoinder to Lab and Whitehead", Criminology, vol. 28, nº 3 (1990), pp. $419-429$.

6. ANDREWS, Donald y DOWDEN, Craig, "Risk Principle of Case Classification in Correctional Treatment: A Meta-Analytic Investigation", International Journal of Offender Therapy and Comparative Criminology, vol. 50 (2006), pp. 88-100.

7. ANDREWS, Donald; BONTA, James, The Psychology of Criminal Conduct, $5^{\mathrm{a}}$ edición, Nueva Jersey: Anderson Publishing, 2010.

8. "Rehabilitating criminal justice policy and practice", Psychology, Public Policy, and Law, vol. 16, nº1 (2010), pp. 39-55.

9. ANDREWS, Donald, BONTA, James y WORMITH, Stephen, "The Risk-NeedResponsivity (RNR) Model: Does Adding the Good Lives Model?", Criminal Justice and Behavior, vol. 38, $\mathrm{n}^{\mathrm{o}} 7$ (2011) pp.735-755.

10. APA, Brief Amicus Curiae - "Thomas A. Barefoot, Petitioner v. W. J. Estelle, Jr., Director, Texas Department of Corrections, Respondent". American Psychiatric Association. En: http://www.psych.org/File\%20Library/Learn/Archives/amicus_1982_barefoot.pdf

[ultima visita 04.04.2014].

11. BECK, Ulrich, La Sociedad del Riesgo: Hacia una nueva modernidad, Trad. NAVARRO, Jorge, JIMENEZ, Daniel y BORRAS, María Rosa, Buenos Aires: Editorial Paidos, 1986/1998.

12. BERDUGO GOMEZ DE LA TORRE, Ignacio, La Evolución del Derecho Penal Contemporáneo y la Unión Internacional de Derecho Penal, Salamanca: Universidad Pontificia, 1982.

13. BERT, Jean-François, "Évolution (récente) et critique (politique) du concept de dangerosité dans la criminologie: la mise en perspective foucauldiene" en: MBANZOULOU, Paul, BAZEX, Hélène, RAZAC, Olivier y ALVAREZ Joséfina, Les nouvelles figures de la dangerosité, Paris: L' Hartmattan, 2008.

14. BOTTOMS, Anthony E. y McWILLIAMS, William, "A Non-Treatment Paradigm for Probation Practice”, British Journal of Social Work, vol. 9, n 2 (1979) pp. 159-202. 
VELÁSQUEZ, Javier. "El origen del paradigma de riesgo".

15. BRÖCKLING, Ulrich, KRASSMANN, Sussanne y LEMKE, Thomas, "From Foucault's Lectures at the Collège de France to Studies of Governamentality: An Introduction", en: BRÖCKLING, Ulrich, KRASSMANN, Sussanne y LEMKE, Thomas (Eds.), Governamentality: Current Issues and Future Challenges, Nueva York: Routledge, 2011, pp. 1-33.

16. BRUCE, Andrew A., BURGESS, Ernest W. y HARNO, Albert J., "The Probation and parole system", en: WIGMORE, John (Ed.), Illinois Crime Survey, Chicago: Illinois Association for Criminal Justice, 1929, pp. 422 - 574.

17. BURGESS, Ernest W, "Is Prediction Feasible in Social Work? An Inquiry Based upon a Sociological Study of Parole Records", Social Forces, vol. 7, no 4,(1929), pp. 533545.

18. , "Protecting the Public by Parole and by Parole Prediction", The Journal of Criminal Law \& Criminology, vol. 27, $\mathrm{n}^{\circ} 4$ (1936), pp. 491-502.

19. CAPLOW, Theodore y SIMON Jonathan, "Understanding Prison Policy and Population Trends", en: TONRY, Michael y PETERSILIA, Joan (Eds.), Crime and Justice Vol. 26: Prisons, Chicago: The University of Chicago Press, 1999, pp. 63-120.

20. CASTEL, Robert, "De la dangerosité au risque", Actes de la recherche en sciences sociales, Vol. 47-48 (1983) pp. 119-127.

21. _—_From dangerousness to risk", en: BURCHELL, Graham, GORDON, Colin y MILLER, Peter (Eds.), The Foucault Effect: Studies in Governamentality, Chicago: The University of Chicago Press, 1991, pp. 281-298.

22. CHÂLES-COURTINE, Sylvie, "De la bosse "du crime" aux expertises médicojudiciaires: une analyse socio-historique de la construction sociale de la dangerosite" en: MBANZOULOU, Paul, BAZEX, Hélène, RAZAC, Olivier y ALVAREZ Joséfina, Les nouvelles figures de la dangerosité, Paris: L' Hartmattan, 2008.

23. CHEVALIER, Louis, Laboring Classes \& Dangerous Classes: In Paris During the First Half of the Nineteenth Century, JELLINEK, Frank (trad.), Nueva York: Howard Ferting, 1958/1973.

24. CONROY, Mary Alice y MURRIE, Daniel C., Forensic Assessment of Violence Risk, Nueva Jersey: John Wiley \& Sons, 2007.

25. CORNIL, Paul, "Adolphe Prins et la défense sociale", Revue Internationale de Droit Pénal, vol. 22, nº 2 y 3 (1951), pp. 177-189.

26. CULLEN, Francis T., "From nothing works to what works: Changing professional ideology in the 21st century", The Prison Journal, vol. 81, nº 3 (2001), pp. 313-338.

27. __ "Assessing the penal harm movement", Journal of research in crime and delinquency, vol. 32, $\mathrm{n}^{\circ} 3$ (1995), pp. 338-358.

28. _ "The twelve people who saved rehabilitation: How the science of criminology made a difference", Criminology, vol. 48, no 1 (2004), pp.1-42.

29. __ "It's time to reaffirm rehabilitation", Criminology \& Public Policy, vol. 5, $\mathrm{n}^{\circ}$ 4 (2006) pp. 665-672.

30. _Make rehabilitation correction's guiding paradigm", Criminology \& Public Policy, Vol. 6, nº 4 (2007) pp. 717-727.

31. _ Francis T., "Taking rehabilitation seriously: Creativity, science, and the challenge of offender change", Punishment \& Society, vol. 14 (2012), pp. 94-113.

32. CULLEN, Francis T. y GILBERT, Karen, Reaffirming Rehabilitation, Cincinnati: Anderson Publishing, 1982. 
Polít. crim. Vol. 9, No 17 (Julio 2014), Art. 3, pp. 58-117. [http://www.politicacriminal.cl/Vol_09/n_17/Vol9N17A3.pdf]

33. CULLEN, Francis T. y GENDREAU, Paul, "Assessing Correctional Rehabilitation: Policy, Practice, and Prospects", en: HORNEY, J. (Ed.), NIJ Criminal Justice 2000: Changes in decision making and discretion in the criminal justice system, Washington, DC: U.S. Department of Justice, National Institute of Justice, 2000, pp. 109 -175.

34. CULLEN, Francis T., SMITH, Paula, LOWENKAMP, Christopher T. \& LATESSA, Edward J., "Nothing works revisited: deconstructing Farabee's rethinking rehabilitation", Victims and Offenders, vol. 4 (2009), pp. 101-123.

35. CULLEN, Francis T., JONSON, Cheryl L., NAGIN, Daniel S., "Prisons do not reduce recividism: The high cost of ignoring science", The Prison Journal, vol. 91, $\mathrm{n}^{\mathrm{o}} 3$ (2011), pp. 48-65.

36. CULLEN, Francis T. y JONSON, Cheryl L., "Rehabilitation and Treatment Programs", en: WILSON, James Q. y PETERSILIA, Joan (Eds.), Crime and Public Policy, Nueva York: Oxford University Press, 2011, pp. 293-367.

37. Correctional Theory: Context and Consequences, California: Sage, 2012.

38. DANET, Jean, "La dangerosité, une notion criminologique, séculaire et mutante", Champ Pénal/Penal Field vol. V (2008), passim, en: http://champpenal.revues.org/6013 [visitado el 01/06/2013]

39. DEBUYST, Christian, "La notion de dangerosité, maladie infantile de la criminologie", Criminologie, vol. 17, $\mathrm{n}^{\circ} 2$ (1984), pp. 7-24.

40 . , "La notion de Dégénérescence. Sa progressive mise en place", en: DEBUYST, Christian, DIGNEFFE, Françoise y PIRES, Alvaro, Histoire des savoirs sur le crime et la peine: Des savoirs diffus àla notion de criminel-né, Bruselas: Editions Larcier, 2008, pp. 289-314.

41. _L_ "La Psychiatrie Française: Autor de la notion de Dégénérescence", en: DEBUYST, Christian, DIGNEFFE, Françoise y PIRES, Alvaro, Histoire des savoirs sur le crime et la peine: La rationalité pénale et la naissance de la criminologie, Bruselas: Editions Larcier, 2008, pp. 454-472.

42. DEFERT, Daniel, "Popular Life and Insurance Technology" en: BURCHELL, Graham, GORDON, Colin y MILLER, Peter (Eds.), The Foucault Effect: Studies in Governamentality, Chicago: The University of Chicago Press, 1991, pp. 211-233.

43. DERSHOWITZ, Alan M., "The Law of Dangerousness: Some Fictions about Predictions", Journal of Legal Education, vol. 23 (1970) pp. 24-47.

44. Diccionario de la lengua española, "Responsivo", avance de la vigésima tercera edición, http://lema.rae.es/drae/srv/search?id=h1H4hImVMDb21lFqVBkz [visitado 18.03.2014].

45. DIGNEFFE, Françoise, "Problèmes sociaux et représentations du crime et du criminel: De Howard (1777) à Engels (1845)" en: DEBUYST, Christian, DIGNEFFE, Françoise y PIRES, Alvaro, Histoire des savoirs sur le crime et la peine: Des savoirs diffus àla notion de criminel-né, Bruselas: Editions Larcier, 2008, pp. 145-228.

46. DONZELOT, Jacques, "Misère de la culture politique", Critique, vol. 34 (1978), pp. $572-586$.

47. _ "Pleasure in work", en: BURCHELL, Graham, GORDON, Colin y MILLER, Peter (Eds.), The Foucault Effect: Studies in Governamentality, Chicago: The University of Chicago Press, 1991, pp. 251-280.

48. DOUGLAS, Mary y WILDAVSKY, Aaron, Risk and Culture: An essay on the selection of technological and environmental dangers, Londres: University of California Press, 1982. 
VELÁSQUEZ, Javier. "El origen del paradigma de riesgo".

49. DOUGLAS, Mary, Risk acceptability according to the social sciences, Nueva York: Russel Sage Foundation, 1985.

50. ,"Risk as a Forensic Resource: From "chance" to "danger", Daedalus, vol. 119, $\mathrm{n}^{\circ} 4$ (1990), pp. 1-16.

51. _ Risk and Blame: Essays in cultural theory, Londres: Routledge, 1992.

52. DOYLE, Aaron, "Trust, Citizenship and Exclusion in the Risk Society", en: Law Commission of Canada, Risk and Trust: Including or Excluding Citizens?, Halifax: Fernwood Publishing, 2007, pp. 7-22.

53. ELIAS, Norbert, Sociología Fundamental, MUÑOZ, Gustavo (Trad.), Barcelona: Editorial Gedisa, 1970/2008.

54. ERICSON, Richard y HAGGERTY, Kevin, Policing the risk society, Toronto: University of Toronto Press, 1998.

55. EWALD, François, "Responsabilité et dangerosité: Extrait de l'ouvrage de F. Ewald, L' Etat Providence, Paris, Grasset, 1986, p. 409-416", en: TULKENS, Françoise, Généalogie de la défense sociale en Belgique (1880-1914): Travaux du séminaire qui s' est tenu à L' Université Catholique de Louvain sous la direction de Michel Foucault, Bruselas: Editions Story-Scientia, 1988.

56. __ "Insurance and Risk", en: BURCHELL, Graham, GORDON, Colin y MILLER, Peter (Eds.), The Foucault Effect: Studies in Governamentality, Chicago: The University of Chicago Press, 1991, pp.197-210.

57. _ _ "The Return of Descartes's Malicious Demon: An Outline of a Philosophy of Precaution", Trad. UTZ, Stephen, en: BAKER, Tom y SIMON, Jonathan (Eds.), Embracing Risk: The changing culture of insurance and responsibility, Chicago: The University of Chicago Press, 2002, pp. 273-301.

58. EWING, Charles Patrick, Justice Perverted: Sex Offense Law, Psychology and Public Policy, Nueva York: Oxford, 2011.

59. FARABEE, David, Rethinking Rehabilitation: Why can't we reform our criminals?, Washington D.C.: American Enterprise Institute for Public Policy Research, 2005.

60. FEELEY, Malcolm, "Origins of Actuarial Justice", en: ARMSTRONG, Sarah y MCARA, Lesley (Eds.) Perspectives on punishment: The contours of control, Nueva York: The Oxford University Press, 2006, pp. 217-232.

61. FEELEY, Malcolm y SIMON, Jonathan, "The New Penology: Notes on the emerging strategy of corrections and its implications", Criminology, vol. 4 (1992) pp. 449-479.

62. __ "Actuarial Justice: the emerging new criminal law", NELKEN, David (ed.), The Futures of Criminology, Londres: Sage 1994, pp. 173-201.

63. FERRI, Enrico, Sociologia Criminale, cuarta edición, Turin: Fratelli Boca Editori, 1900.

64. FOUCAULT, Michel, "L'évolution de la notion d' "Individu dangereux" dans la psychiatrie légale", Déviance et société, vol. 5 n 4 (1981), pp. 403-422. También en FOUCAULT, Michel, Dits et écrits II. 1976-1988, Paris: Quarto Gallimard, 1994/2001, pp. 443-464.

65. __ "About the concept of the "dangerous individual" in 19th-century legal psychiatry", Trad. BAUDOT, Alain y COUCHMAN, Jane, International Journal of Law and Psychiatry, vol. 1 (1978), pp. 1-18.

66.

"La vérité et les formes juridiques", trad.: PRADO, J.W., en:

FOUCAULT, Michel, Dits et écrits I. 1954-1975, Paris: Quarto Gallimard, 1994/2001, pp. 1406-1514. 
Polít. crim. Vol. 9, No 17 (Julio 2014), Art. 3, pp. 58-117.

[http://www.politicacriminal.cl/Vol_09/n_17/Vol9N17A3.pdf]

67. , La verdad y las formas jurídicas, trad.: LYNCH, Enrique, Barcelona: Gedisa, 1978/2010.

68. "Attention: danger", en: FOUCAULT, Michel, Dits et écrits II. 19761988, Paris: Quarto Gallimard, 1994/2001, pp. 507-508.

69. , "Omnes et Singulatim: Towards a Criticism of 'Political Reason",, Biblioteca digital de "Tanner Lectures" de la Universidad de Utah: http://tannerlectures.utah.edu/_documents/a-to-z/f/foucault81.pdf $\quad$ [Visitado el 12.10.2013]. Versión en francés por DAUZAT, Pierre-Emmanuel (Trad.), en: FOUCAULT, Michel, Dits et écrits II. 1976-1988, Paris: Quarto Gallimard, 1994/2001, pp. 953-980.

70. _ Vigilar y castigar: nacimiento de la prisión, Trad. GARZÓN DEL CAMINO, Aurelio, Buenos Aires: Siglo Veintiuno Editores Argentina, 1975/2008.

71. __ (ed.), Yo, Pierre Rivière, habiendo degollado a mi madre, a mi hermana y a mi hermano...: Un caso de parricidio del siglo XIX presentado por Michel Foucault, Trad.: VINYOLI, Joan, Barcelona: Tusquets editores, 1976/2009.

72. __ La Société Punitive: Cours au Collège de France: 1972-1973, Paris: Gallimard, 2013.

73. __ El poder psiquiátrico: Curso en el Collège de France (1973-1974), Trad. PONS, Horacio, Buenos Aires: Fondo de Cultura Económica, 2003/2005.

74. _L Los Anormales: Curso en el Collège de France (1974-1975), Trad.: PONS, Horacio, Buenos Aires: Fondo de Cultura Económica, 1999/2000.

75. _ Defender la sociedad: Curso en el Collège de France (1975-1976), trad. PONS, Horacio, Buenos Aires: Fondo de Cultura Económica, 1997/2000.

76. __ Seguridad, Territorio, Población: Curso en el Collège de France (1977-1978), Trad. PONS, Horacio, Buenos Aires: Fondo de Cultura Económica, $2004 / 2006$.

77. _ Nacimiento de la Biopolítica: Curso en el Collège de France (19781979), Trad. PONS, Horacio, Buenos Aires: Fondo de Cultura Económica, 2004/2007.

78. FREEDMAN, Estelle, "Uncontrolled Desires: The Response to the Sexual Psycopath, 1920-1960", The Journal of American History, vol. 74, n 1(1987), pp. 83-106.

79. FRÉGIER, Honoré-Antoine, Des Classes Dangereuses de la Population Dans Les Grandes Villes et Des Moyens de les Rendre Meilleures, tomo uno, Paris: Librería de la Academia Real de Medicina, 1840.

80. GARCÍA-PABLOS DE MOLINA, Antonio, Tratado de Criminología: $4^{a}$ edición actualizada, corregida y aumentada, Valencia: Tirant lo Blanch, 2009.

81. GARLAND, David, Punishment and Welfare, Aldershot: Gower, 1986.

82. _ La Cultura del Control: Crimen y Orden Social en la Sociedad Contemporánea, Trad. SOZZO, Máximo, Barcelona: Gedisa, 2001.

83. __ "The Rise of Risk", en: ERICSON, Richard V. y DOYLE, Aaron, Risk and Morality, Toronto, University of Toronto Press, 2003, pp.48-86.

84. GAROFALO, Raffaele, Di un criterio positivo della penalità, Napoles: Doctor Leonardo Villardi, editor, 1880.

85. GENDREAU, Paul y ROSS, Robert, "Effective Correctional Treatment: Bibliotherapy for Cynics", Crime \& Delinquency, vol. 25, nº 4 (1979) pp. 463-489.

86. _ "Revivification of rehabilitation: Evidence from the 1980s", Justice Quarterly, vol. 4 (1987), pp. 349-407. 
VELÁSQUEZ, Javier. "El origen del paradigma de riesgo".

87. GIBSON, Mary, "Cesare Lombroso and Italian Criminology: Theory and politics", en: BECKER, Peter y WETZELL, Richard (eds.), Criminals and their scientists: The history of criminology in international perspective, Nueva York: Cambridge University Press, 2006, pp. 137-158.

88. GIDDENS, Anthony, Consecuencias de la modernidad, Trad. LIZÓN, Ana, Madrid: Alianza Editorial, 1990/1993.

89. __ "La sociedad del riesgo: El contexto de la política británica", Trad. ORENSANZ, Lucrecia, Estudios Demográficos y Urbanos, vol. 13, nº 3 (1998), pp. 517-528.

90. GIUDICELLI-DELAGE, Genevieve y LAZERGES, Christine (eds.), La dangerosité saisie par le droit penal, Paris: PUF, 2011.

91. GLASS, Gene, "Primary, Secondary, and Meta-Analysis of Research", Educational Researcher, vol. 5, nº10 (1976), pp. 3-8.

92. GORDON, Colin, "Governmental rationality: An introduction", en: BURCHELL, Graham, GORDON, Colin y MILLER, Peter (Eds.), The Foucault Effect: Studies in Governamentality, Chicago: The University of Chicago Press, 1991, pp. 1-51.

93. HACKING, Ian, "Risk and Dirt", en: ERICSON, Richard V. y DOYLE, Aaron, Risk and Morality, Toronto, University of Toronto Press, 2003, pp. 22-47.

94. __ The taming of chance, Cambridge: Cambridge University Press, 1990.

95. HANSON, R. Karl, "Clinical, actuarial and dynamic risk assessment of sexual offenders: Why do thinks keep changing?", Journal of Sexual Aggression, vol. 16, $\mathrm{n}^{\circ} 3$ (2010), pp. 296-310.

96. HARRIS, Andrew J.R.; HANSON, Karl, Sex offender Recidivism: A Simple Question, Ottawa: Public Safety Canada, 2004.

97. HART, Hornell, "Predicting Parole Success", Journal of Criminal Law and Criminology, Vol. 14, (1924), pp. 405-413.

98. HOLLIN, Clive R.; PALMER, Emma J., "Offending behaviour programmes: history and development", en: HOLLIN, Clive R.; PALMER, Emma J. (eds.), Offending Behaviour Programmes: Development, application and controversies, West Sussex: John Wiley \& Sons, 2006, pp. 1-32.

99. JIMÉNEZ DE ASÚA, Luis, El estado peligroso del delincuente y sus consecuencias ante el derecho penal, Madrid: Editorial Reus S.A, 1920. 100. El Criminalista: segunda serie, tomos I y II, Buenos Aires: Victor P. De Zavalía, editor, 1955/1958.

101. KALIFA, Dominique, Crime et culture au XIX ${ }^{a}$ siècle, Paris: Editions Perrin, 2005.

102. KEMSHALL, Hazel, Understanding risk in criminal justice, Maidenhead: Open University Press, 2003.

103. LAB, Steven y WHITEHEAD, John, "From "Nothing Works" to "The appropriate works": The latest stop on the search for the secular grail", Criminology, vol. $28, \mathrm{n}^{\circ} 3$ (1990), pp. 405-417

104. LAGRANGE, Hugues, La civilité a l'épreuve: Crime et sentiment d'insécurité, Paris: Presses Universitaires de France, 1995.

105. LARRAURI, Elena, "Control de delito y castigo en Estados Unidos", Jueces para la democracia, $\mathrm{N}^{\circ} 32$ (1998), pp. 85-88.

106. LATESSA, Edward J., CULLEN, Francis T. y GENDREAU, Paul, "Beyond correctional quackery - Professionalism and the possibility of effective treatment", Federal Probation, vol. 66, n 2 (2002) p. 15-22. 
Polít. crim. Vol. 9, No 17 (Julio 2014), Art. 3, pp. 58-117.

[http://www.politicacriminal.cl/Vol_09/n_17/Vol9N17A3.pdf]

107. LAWS, Richard y WARD, Tony, Desistance from sex offending: Alternatives to throwing away the keys, Nueva York: The Guilford Press, 2011.

108. LIANOS, Michalis, y DOUGLAS, Mary, "Dangerization and the end of deviance: the institutional environment", en: GARLAND, David y SPARKS, Richard (eds.) Criminology and social theory, Londres: Oxford University Press, 2000, pp.103-126.

109. LIDSKY, Paul, Les écrivains contre la Commune: Postfacé inédite, Paris: Editions La Découverte, 2010.

110. LIDZ, Charles; MULVEY, Edward, "Dangerousness: From legal definition to theoretical research", Law and Human Behavior, vol. 19, n¹ (1995), pp. 41-48.

111. LIPSEY, Mark, "What do we learn from 400 research Studies on the effectiveness of treatment with juvenile delinquents?", en: MCGUIRE, James (Ed.), What Works: Reducing Reoffending, West Sussex: John Wiley \& Sons, 1995, pp. 35 -62.

112. _ _Can Intervention Rehabilitate Serious Delinquents?", Annals of the American Academy of Political and Social Science, Vol. 564 (1999), pp. 142-166.

113. LIPSEY, Mark, CHAPMANN, Gabrielle y LANDENBERGER, Nana, "CognitiveBehavioral Programs for Offenders", Annals of the American Academy of Political and Social Science, Vol. 578 (2001), pp. 144-157.

114. LISTWAN, Shelley J., JONSON Cheryl L., Cullen, Francis. T. y LATESSA, Edward. J., "Cracks in the penal harm movement: Evidence from the field", Criminology \& Public Policy, vol. 7, n 3 (2008) pp. 423-465.

115. LOMBROSO, Cesare, L'uomo delinquente : studiato in rapporto alla antropologia, alla medicina legale ed alle discipline carcerarie, Milan: Ulrico Hoepli editor, 1876/ Quinta edición, Turin: Fratelli Boca Editor, 1896.

116. LÖSEL, Friedrich, "The efficacy of correctional treatment: A review and synthesis of Meta-evaluations", en: McGUIRE, James (Ed.), What Works: Reducing Reoffending, West Sussex: John Wiley \& Sons, 1995, pp. 79-111.

117. LOVINS, Brian, LOWENKAMP, Christopher T. y LATESSA, Edward J., "Applying the risk principle to sex offenders: Can treatment make some sex offenders worse?", The Prison Journal, vol. 89 (2009), pp. 344-357.

118. LOWENKAMP, Christopher T., LATESSA, Edward J. y HOLSINGER, Alexander, "The Risk Principle in Action: What Have We Learned From 13,676 Offenders and 97 Correctional Programs?", Crime \& Delinquency, vol. 52 (2006), pp. 77-93.

119. LUPTON, Deborah, Risk, segunda edición, Londres: Routledge, 2013.

120. MAIR, George y BURKE, Lol, Redemption, Rehabilitation and Risk Management: A history of Probation, Londres: Routledge, 2012.

121. MARUNA, Shadd, "Book Review: Rethinking rehabilitation: Why can't we reform our criminals?", Punishment \& Society, vol. 9, no 3 (2005), pp. 333-337.

122. MARTINSON, Robert, "What Works? - Questions and Answers About Prison Reform.", The Public Interest (1974), pp. 22-54.

123. _ "New Findings, New Views: A note caution regarding sentencing reform", Hofstra Law Review, vol. 7, no 2 (1979), pp. 243-258.

124. MATHIESEN, Thomas, "Selective Incapacitation Revisited", Law and Human Behaviour, vol. 22, no 4 (1998), pp. 455-469.

125. MIR PUIG, Santiago, "Introducción a las bases del Derecho Penal", segunda edición, Buenos Aires: Editorial B de F, 1976/2002. 
VELÁSQUEZ, Javier. "El origen del paradigma de riesgo".

126. MINISTERIO DE JUSTICIA, Nueva Ley $N^{\circ}$ 18.216. Análisis de las modificaciones introducidas por la ley 20.603. Material para capacitación, Santiago: Ministerio de Justicia, 2012.

127. MACKENZIE, Doris Layton, What Works in corrections: Reducing the criminal activities of offenders and delinquents, Nueva York: Cambridge University Press, 2006.

128. McGUIRE, James y PRIESTLEY, Philip, "Reviewing "What Works?": Past, Present and Future", en: McGUIRE, James (ed.), What Works: Reducing Reoffending, West Sussex: John Wiley \& Sons (1995) pp. 3-34.

129. McNEILL, Fergus, "A desistance paradigm for offender management", Criminology \& Criminal Justice, vol. 6, $\mathrm{n}^{\circ} 1$ (2006) pp. 39-62. Traducción al español por OLIVERO, Carmen, en: Documento de Trabajo $n^{\circ} 27$, Santiago: Defensoría Penal Pública, en: http://www.biblio.dpp.cl/biblio/DataBank/6190.pdf [visitado 12.03.2014].

130. McSHERRY, Bernardette, Managing Fear: The Law and ethics of preventive detention and risk assessment, Nueva York: Routledge, 2013.

131. MONAHAN, John, "Empirical Analyses of Civil Commitment: Critique and Context", Law \& Society Review, vol. 11, nº 4 (1977), pp. 619-628. "The Future of Violence Risk Management", en: TONRY, Michael (ed.), The Future of Imprisonment, Nueva York: Oxford University Press, (2004), pp. 237-263.

133. MONAHAN, John, y GEIS, Gilbert, "Controlling "Dangerous" People", en: NEWMAN, G.R. (ed.), Crime and Justice in America: 1776-1976, Philadelphia: American Academy of Political and Social Science, 1976, pp. 142-151.

134. MONAHAN, John, y SHAH, Saleem A., "Dangerousness and Commitment of the Mentally Disordered in the United States", Schizophrenia Bulletin, vol. 15, no 4 (1989) pp. 541-553.

135. MORRIS, Norval, The Future of imprisonment, Chicago: The University of Chicago Press, 1974.

136. MORRIS, Norval y MILLER, Marc, "Predictions of Dangerousness", Crime and Justice, vol. 6 (1985) pp. 1-50.

137. MUCCHIELLI, Laurent, "Hérédite et milieu social: le faux-antagonisme francoitalien", en: MUCCHIELLI, Laurent (ed.), Histoire de la Criminologie Française, Paris: Editions L'Harmattan, 1994, pp. 189-214.

138. NYE, Robert, Crime, Madness \& Politics in modern France: The medical concept of national decline, Nueva Jersey: Princeton University Press, 1984.

139. O'MALLEY, Pat, "Risk societies and the government of crime", en: BROWN, Mark y PRATT, John (eds.), Dangerous offenders: Punishment and social order, Nueva York: Routledge, 2000, pp. 17-34.

140. — Riesgo, Neoliberalismo y Justicia Penal, Trad. MONTERO, Augusto, Buenos Aires: Editorial Ad-hoc, 2006.

141. Crime and Risk, Londres: Sage, 2010.

142. PALMER, Ted, "Martinson Revisited", Journal of Research in Crime and Delinquency, vol. 12, $\mathrm{n}^{\circ} 2$ (1975) pp. 133-152.

143. PICK, Daniel, Faces of degeneration: A European Disorder, c.1848-c.1918, Cambridge: Cambridge University Press, 1989/1996.

144. PINATEL, Jean (ed.), Deuxième tours International de Criminologie: Paris 14Septembre - 23 Octobre 1953: Le problème de L'État Dangereux, Paris: Ministere de Justice, 1954. 
Polít. crim. Vol. 9, No 17 (Julio 2014), Art. 3, pp. 58-117.

[http://www.politicacriminal.cl/Vol_09/n_17/Vol9N17A3.pdf]

145. PRATT, John, "Dangerousness, Risk and Technologies of Power", Australian \& New Zealand Journal of Criminology, vol. 28, nº 3 (1995), pp. 3-31.

146. _ _ _Governing the Dangerous: An Historical Overview of Dangerous Offender Legislation”, Social \& Legal Studies, vol. 5 (1996), pp. 21-36.

147. _Criminology and History: Understanding the Present", Current Issues in Criminal Justice, vol. 60 (1996-1997), pp 60-76.

148. _ Governing the Dangerous: dangerousness, law and social change, Sidney: The Federation Press, 1997.

149. __ "Dangerousness and modern society", BROWN, Mark y PRATT, John (eds.), Dangerous Offenders: Punishment and Social Order, Londres: Routledge, (2000), pp. 35-48.

150. PRATT, John y DICKSON, Marny, "Dangerous, inadequate, invisible, out: Episodes in the criminological career of habitual criminals", Theoretical Criminology, vol. 1 (1997) pp. 363-384.

151. PRINS, Adolphe, La défense sociale et Les Transformations du Droit Pénal, Paris: Misch et Thron editores, 1910. Versión en español La defensa social y las transformaciones del derecho penal, Trad. CASTEJON y MARTÍNEZ DE ARIZALA, Federico, Madrid, Hijos de Reus, editores, (1912).

152. _ Science pénale et Droit positif, Bruselas: Bruylant-Christoph \& Cia, editores, 1899.

153. QUINSEY, Vernon, HARRIS, Grant, RICE, Marnie y CORMIER, Catherine, Violent Offenders: Appraising and Managing Risk, Washington D.C.: American Psychological Association, 2006.

154. RADZINOWICZ, Leon, "The Persistent Offender”, Cambridge Law Journal, vol. 7 (1939), pp. 68-79.

155. RADZINOWICZ, Leon y HOOD, Roger, "Incapacitating the Habitual Criminal: The English Experience”, Michigan Law Review, vol. 78, nº 8 (1980), pp. 1305-1389.

156. RAYNOR, Peter, "Community penalties: Probation, "What Works" and Offender Management", en: MAGUIRE, Mike, MORGAN, Rod y REINER, Robert (eds.), The Oxford Handbook of Criminology, Oxford: Oxford University Press (2007), pp. 10611099.

157. RAYNOR, Peter y ROBINSON, Gwen, Rehabilitation, Crime And Justice: Revised and updated edition", Hampshire: Palgrave Mcmillan, 2009.

158. REDONDO, Santiago, "Delincuencia Sexual: Mitos y Realidades", en: REDONDO, Santiago (coord.), Delincuencia Sexual y Sociedad, Barcelona: Editorial Ariel, 2002.

159. REGNIER, Thomas, "Barefoot in Quicksand: The Future of Dangerousness Predictions in Death Penalty Sentencing in the World of Daubert and Kumho", Akron Law Review, vol. 37, no 3 (2004), pp. 469-507.

160. RENNEVILLE, Marc, "La réception de Lombroso en France (1880-1900)" en: MUCCHIELLI, Laurent (ed.), Histoire de la Criminologie Française, Paris: Editions L'Harmattan, 1994, pp.107-135. 161. , Crime et Folie: Deux sicles d' enquêtes médicales et judiciaires,

Paris: Fayard, 2003.

162. RICHARDS, Edward, "The Jurisprudence Of Prevention: The Right Of Societal Self-Defense Against Dangerous Persons", Hastings Constitutional Law Quarterly, vol. 
VELÁSQUEZ, Javier. "El origen del paradigma de riesgo".

16 (1989), disponible en: http://biotech.law.lsu.edu/cphl/articles/hastings/hastingsContents.htm [visitado el 01/06/2013].

163. ROBERT, Christian-Nils y VAN DE KERCHOVE, Michel (eds.), Risque, dangerosité et sécurité: Renaissance et mutations de la défense sociale, Ginebra: Editions Médicine et Hygiene, 2010.

164. ROBINSON, James y SMITH, Gerald, "The effectiveness of correctional programs.", Crime And Delinquency, $\mathrm{n}^{\circ} 17$ (1971), pp. 67-80.

165. ROBINSON, Gwen y CROW, Ian, Offender Rehabilitation: Theory, Research and Practice, Londres: SAGE, 2009.

166. ROBINSON, Gwen, MCNEILL, Fergus y MARUNA, Shadd, "Punishment in Society: The Improbable Persistence of Probation and Other Community Sanctions and Measures", en: SIMON, Jonathan y SPARKS, Richard (eds.), The Sage Handbook of Punishment and Society, Londres: Sage. 2013.

167. ROSE, Nikolas, "At Risks of Madness", en: BAKER, Tom y SIMON, Jonathan (eds.), Embracing Risk: The changing culture of insurance and responsibility, Chicago: The University of Chicago Press, 2002, pp. 209-237.

168. SAAVEDRA, Oscar, "Justicia implanta nuevo modelo para pronosticar la reincidencia de presos" en: El Mercurio, Año CXIV, nº 40.927, Santiago: Jueves 8 de Agosto de 2013.

169. SCHEU, Johannes, "Dangerous classes: tracing back an epistemological fear", Distinktion: Scandinavian Journal of Social Theory, vol. 12, $\mathrm{n}^{\circ} 2$ (2011), pp. 115-134.

170. SCHUESSLER, Karl F., "Parole Prediction; Its History and Status", Journal of Criminal Law, Criminology and police science, vol. 45, $\mathrm{n}^{\circ} 4$ (1954), pp. 425-431.

171. SENELLART, Michel, "Situación de los cursos", PONS, Horacio (trad.) en: FOUCAULT, Michel, Seguridad, Territorio, Población: Curso en el Colège de France (1977-1978), Buenos Aires: Fondo de Cultura Económica de Argentina, 2004/2006, pp. 417-453.

172. SHAH, Saleem, "Some interactions of law and mental health in the handling of social deviance.", Catholic University Law Review, vol. 23 (1974) pp. 674-719.

173. _ "Dangerousness and Mental Illness: Some Conceptual, Prediction, and Policy Dilemmas", en: FREDERIK, Calvin (ed.) Dangerous Behavior: A problem in law and mental health, Washington, DC: US Dept of Health, Education, and Welfare, 1978, pp. 158-191.

174. SILVA SÁNCHEZ, Jesús-María, "El retorno de la inocuización: El caso de las reacciones jurídicos penales frente a los delincuentes sexuales violentos en derecho comparado", en: REDONDO, Santiago (coord.), Delincuencia Sexual y Sociedad, Barcelona: Editorial Ariel, 2002, pp. 143-159.

175. SIMON, Jonathan, "The Ideological Effects of Actuarial Practices", Law \& Society Review, vol. 22, n $^{\circ} 4$ (1988), pp. 771-800.

176. "Managing the Monstrous: Sex offenders and the new penology", Psychology, Public Policy, and Law, vol. 4, $\mathrm{n}^{\circ} 1$ (1998) 452-467.

$177 . \quad$ Governing Through Crime: How the war on crime transformed American Democracy and Created a Culture of Fear, Nueva York: Oxford University Press, 2007.

178. , "Punishment and the Political Technologies of the Body", en: SIMON, Jonathan y SPARKS, Richard (eds.), The Sage Handbook of Punishment and Society, Londres: Sage, 2013, pp. 60-89. 
Polít. crim. Vol. 9, No 17 (Julio 2014), Art. 3, pp. 58-117.

[http://www.politicacriminal.cl/Vol_09/n_17/Vol9N17A3.pdf]

179. SIMON, Jonathan y FEELEY, Malcolm, "The form and limits of the new penology", en: BLOOMBERG, Thomas y COHEN, Stanley (eds.), Punishment and social control: Enlarged second edition, New Jersey: Transaction Publishers, 2003, pp. 75-116.

180. SPARKS, Richard, "Degrees of estrangement: The cultural theory of risk and comparative penology", Theoretical Criminology, vol. 5, nº 2 (2001), pp. 159-176.

181. SZASZ, Thomas, "The Myth of Mental Illness", American Psychologist, vol. 15 (1960), pp. 113-118.

182. _ The Second Sin, Nueva York: Anchor Books, 1972.

183. TONRY, Michael, "Obsolescence and Immanence in Penal Theory and Policy", Columbia Law Review, vol. 105, no 4 (2005), pp. 1233 -1275.

184. TULKENS, Françoise, "Un chapitre de l'histoire des réformateurs. Adolphe Prins et la défense sociale", pp.17-48 en TULKENS, Françoise (ed.), Généalogie de la défense sociale en Belgique (1880-1914): Travaux du séminaire qui s' est tenu à L'Université Catholique de Louvain sous la direction de Michel Foucault, Bruselas: Editions StoryScientia, 1988.

185. VAN DE KERCHOVE, "Introduction", en: ROBERT, Christian-Nils y VAN DE KERCHOVE, Michel (eds.), Risque, dangerosité et sécurité: Renaissance et mutations de la défense sociale, Ginebra: Editions Médicine et Hygiene, pp. 479-482.

186. VON LISZT, Franz, La idea de fin en el Derecho Penal, trad. AIMONE, Enrique, Valparaíso: Edeval, 1984.

187. VON HIRSCH, Andrew, "Prediction of Criminal Conduct and Preventive Confinement of Convicted Persons", Buffalo Law Review, Vol. 21, no 3 (1972) pp. 717758.

188.

Wang, 1977.

189. , Doing Justice: The Choice of Punishments, Nueva York: Hill and of Sciences "Report on Criminal careers and "Career Criminals"", Criminal Justices Ethics, vol. 7 (1988), pp. 19-34.

190. VON HIRSCH, Andrew y GOTTFREDSON, Don M., "Selective Incapacitation: Some Queries About Research, Design, And Equity", New York University Review of Law and Social Change, vol. 12 (1983), pp. 11-51.

191. WACQUANT, Loïc, Castigar a los pobres: El gobierno neoliberal de la inseguridad social, trad.: POLO, Margarita, Barcelona: Gedisa, 2009.

192. WARD, Tony y MARUNA, Shadd, Rehabilitation, London: Routledge, 2007.

193. WARD, Tony, YATES, Pamela M. y WILLIS, Gwenda M., "The Good Lives Model and the Risk Need Responsivity Model: A Critical Response to Andrews, Bonta, and Wormith (2011)", Criminal Justice and Behavior, vol. 39, n 1 (2012) pp. 94-110.

194. WILSON, James Q., Thinking about Crime, Nueva York: Basic Books, 1975, pp. 198-209.

195. WILSON, James Q. y BOLAND, Barbara, "Incapacitation", en: GORHAM, William y GLAZER, Nathan (eds.), The Urban Predicament, Washington, DC: The Urban Institute, 1976, pp. 179-230.

196. WOLF, Fredric, Meta-Analysis: Quantitative Methods for Research Synthesis, California: Sage, 1986. 
VELÁSQUEZ, Javier. "El origen del paradigma de riesgo".

197. WOLFGANG, Marvin E., "Pioneers in Criminology: Cesare Lombroso (18351909), The Journal of Criminal Law, Criminology, and Police science, vol. 52, $\mathrm{n}^{\mathrm{o}} 4$ (1961), pp. 361-391.

198. WOOD JR., Oliver G., "Evolution of the concept of Risk", The Journal of Risk and Insurance, vol. 31, $\mathrm{n}^{\mathrm{o}} 1$ (1964), pp. 83-91.

199. WORMITH, Stephen, GENDREAU, Paul y BONTA, James, "Deferring to Clarity, Parsimony, and Evidence in Reply to Ward, Yates, and Willis", Criminal Justice and Behavior, vol. 39, $\mathrm{n}^{\circ} 1$ (2012) pp. 111-120.

200. ZAFFARONI, Eugenio Raul, "Las "Clases Peligrosas": El fracaso de un discurso policial prepositivista", Revista Sequiência, nº 51 (2005), pp. 141-168.

201. ZIMRING, Franklin, y HAWKINS, Gordon, "Dangerousness and Criminal Justice", Michigan Law Review, vol. 85, $\mathrm{n}^{\circ} 3$ (1986), pp. 481-509. 